\title{
Condições de saúde bucal dos idosos moradores no Município de São Paulo em 2006
}

\section{Doralice Severo da Cruz Teixeira}

Dissertação apresentada ao Programa de Pós-Graduação em Saúde Pública da Universidade de São Paulo para obtenção do título de Mestre em Saúde Pública.

Área de Concentração: Serviços de Saúde Pública

Orientador: Prof. Dr. Paulo Capel Narvai

São Paulo 
É expressamente proibida a comercialização deste documento tanto na sua forma impressa como eletrônica. Sua reprodução total ou parcial é permitida exclusivamente para fins acadêmicos e científicos, desde que na reprodução figure a identificação do autor 


\section{DEDICATÓRIA}

Dedico este trabalho com todo meu agradecimento, amor e carinho ao meu pai que me ensinou a ler e a gostar de ler.

E a minha mãe que nunca deixou de me incentivar e inúmeras vezes cuidou do meu pai sem poder contar com minha presença. 


\section{Agradecimentos}

Ao Professor Paulo Capel, por sua orientação repleta de generosidade e sabedoria e pela oportunidade que me foi concedida.

Ao Professor Roberto Castellanos, pela ajuda nos momentos difícies.

À Professora Maria Lúcia, pela oportunidade de participar do Projeto.

À Professora Sabina, Professor José Maria, Professor Jair, Professora Tânia e Professora Regina, pelas incansáveis explicações.

Ao Dr. José Carlos Alves, Dr. Vladen Vieira, Dra. Sueli Moreira e Dra. Julie Silvia Martins, pela ajuda na confecção das fichas e na calibração dos cirurgiões-dentistas.

À Dra. Maria da Candelária Soares, pelo apoio e pelas dicas valiosas. Aos meus colegas de trabalho, pelo carinho e generosidade.

Ao Fernão, pela seriedade e valiosa ajuda.

À Nazaré, Clarissa e Douglas, pelo suporte durante a duração do campo. À FAPESP, pelo apoio financeiro na compra do material usado para os exames bucais e pagamento aos cirurgiões-dentistas e anotadoras.

Aos idosos da Vila Cisper em especial ao Sr. Constanzo, pela paciência com os cirurgiões-dentistas.

À coordenadora da Unidade Básica de Saúde V.Cisper, Tereza, e a todas as Agentes Comunitárias de Saúde, pelo empenho na arregimentação dos idosos para a calibração. 
De forma especial, gostaria de agradecer aos cirurgiões-dentistas que realizaram os exames bucais nos idosos. Sem a amizade, disponibilidade e carinho que me demonstraram não teria sido possível realizar esta pesquisa.

\section{Adriana Tateno}

Eliene Maria de Souza

Helder Inocêncio Paulo de Souza

José Carlos Alves

José Roberto Bruno da Cunha

Luis Felipe de Andrade Santos

Luciana Keiko Matsumoto de Oliveira

Marco Ribeiro Silveira

Maria Cristina Martinez de Agostinho

Mary Schweitzer dos Anjos Gomes

Mônica Lopes Carmelo dos Anjos

Sandra Regina Lapa

Sandro Marcelo Ribeiro Garcia 
Teixeira DSC. Condições de saúde bucal dos idosos moradores no Município de São Paulo em 2006 [dissertação de mestrado]. São Paulo. Faculdade de Saúde Pública da USP; 2007.

\section{RESUMO}

Introdução - $\mathrm{O}$ envelhecimento da população tem implicações significativas para a organização da atenção odontológica. Objetivo - Este estudo teve por objetivo avaliar as condições de saúde bucal de idosos moradores na área urbana do município de São Paulo em 2006. Método - O Estudo SABE (Saúde Bem Estar e Envelhecimento) é um estudo multicêntrico envolvendo sete países da América Latina e Caribe cuja primeira fase teve início em 2000 e em 2006 transformou-se em um estudo longitudinal. Em 2006, foram examinadas 1.212 pessoas de 65 anos de idade e mais que representaram 515.040 idosos residentes na área urbana do município de São Paulo. Os exames foram realizados por 15 cirurgiões-dentistas calibrados segundo os critérios metodológicos recomendados pela Organização Mundial da Saúde. Resultados - A média do Índice CPOD (número de dentes cariados, perdidos e restaurados) nas mulheres foi de 29,87 e entre os homens de 27,42. A frequiência do CPOD variou de 7 a 32 nas mulheres e de 8 a 32 nos homens. Não houve idosos com todos os dentes presentes. A necessidade de tratamento mais prevalente foi de exodontia. Em relação à condição periodontal, nas mulheres, $90,84 \%$ dos sextantes superiores e $84,56 \%$ dos sextantes inferiores eram edêntulos e, nos homens, $82,11 \%$ e 74,96, respectivamente. Perda de inserção periodontal de 0 a $3 \mathrm{~mm}$ foi a alteração periodontal mais freqüente em ambos os sexos. A prevalência do edentulismo total foi de $69,40 \%$ nas mulheres e $30,60 \%$ nos homens; $74,48 \%$ das mulheres e $53,43 \%$ dos homens faziam uso de prótese total superior e $45,51 \%$ das mulheres e $33,77 \%$ dos homens faziam uso de prótese total inferior. Uso de prótese total superior e inferior teve prevalência de 44,40\% em mulheres e 32,90\% em homens. O uso de prótese parcial removível foi mais comum no arco dentário inferior em mulheres $(16,38 \%)$. Necessitavam de prótese total, mas não a usavam 5,70\% da população, sendo que a porcentagem foi maior na população masculina $(14,78 \%)$. A necessidade de prótese total teve maior prevalência seguida da necessidade de prótese parcial removível. Dentre os idosos que usam outros tipos de prótese a média de dentes presentes foi de 11,62 nas mulheres e 13,84 nos homens. No que diz respeito a presença de lesão em tecidos moles da cavidade bucal, $18,93 \%$ da mulheres e $15,95 \%$ dos homens, apresentaram algum tipo de lesão. Conclusão - As mulheres apresentaram índice CPOD maior que os homens. Com exceção do número de dentes cariados que foi maior entre a população masculina, os demais componentes tiveram maior prevalência entre a população feminina. Quanto à condição periodontal, a maior prevalência de sextantes nulos ocorreu entre as mulheres. Também o número de mulheres edêntulas foi maior que o número de homens nessa condição, assim como o uso de próteses foi mais prevalente entre elas. A presença de lesões nos tecidos moles da boca foi mais prevalente na população feminina. Pode-se concluir que as mulheres tiveram mais acesso aos serviços odontológicos e que os homens apresentaram grandes necessidades de tratamento acumuladas. Pela medida de mutilação apresentada pelas 
mulheres e pelas grandes necessidades acumuladas entre os homens, pode-se concluir que se deve buscar uma nova abordagem no cuidado em saúde bucal para o idoso.

Descritores: Saúde Bucal; Idoso; Levantamentos Epidemiológicos; Epidemiologia. Estudos populacionais em saúde pública; CPOD. 
Teixeira, DSC - Condições de saúde bucal dos idosos moradores no município de São Paulo em 2006./Oral heath conditions among the elderly population living in the City of São Paulo in 2006 [dissertation]. São Paulo (BR): Faculdade de Saúde Pública da Universidade de São Paulo; 2007.

\begin{abstract}
Introduction - The aging of the population has material effects on the dental assistance organization. Purpose - The purpose of this study was to evaluate the clinical conditions of dental health among the elderly population living in the city of São Paulo in 2006. Methodology - The SABE Study - Health, Welfare and Aging is a multicenter study made in seven countries of Latin America and Caribbean region. The first phase of this study began in 2000, having become a longitudinal study in 2006, year at which 1,212 people of 65 years old or more were examined, representing 515.040 elderly resident in the metropolitan area of São Paulo. 15 dental surgeons conducted the exams according to the methodological criteria established by the Wealth World Organization. Results - DMFT (number of lost or restored teeth or teeth with caries) rate average was 29.87 in the female population and 27.42 in the male population. The DMFT frequency had a variation from 7 to 32 in the female population and 8 to 32 in the male population. There were no elderly elements with all their permanent teeth. The more prevailing treatment was extraction. Among the female population $90.84 \%$ have no upper high sextant and $84.56 \%$ have no anterior sextant. Among the male population $82.11 \%$ and $74.96 \%$, respectively, have no sextants. Attachment losses from 0 to $3 \mathrm{~mm}$ were more frequent in both male and female population. The prevalence of total edentulism was $69.40 \%$ in the female population and $30.60 \%$ in the male population; $74.48 \%$ of women and $53.43 \%$ of men have total superior prostheses implanted and $45.51 \%$ of women and $33.77 \%$ of men have total inferior prostheses implanted. The use of total superior and inferior prosthesis prevailed among $44.40 \%$ in the female population and $32.90 \%$ in the male population; on the other hand, the removable partial prosthesis was more common in the inferior arcade of the female population (16.38\%). The average of population in the need but without a total prosthesis was $5.70 \%$, and the largest percentage was found among the male population (14.78\%). The necessity of total prosthesis was more prevailing, followed by removable partial prosthesis. Among the elderly population that has other prosthesis types implanted, the average of present teeth was 11.62 in the female population and 13.84 in the male population. As to the presence of injury in soft tissues in the oral cavity, $18.93 \%$ in the female population and $15.95 \%$ in the male population have any kind of injury. Conclusion - The female population had a higher DMFT ratio than the male population. Except the number of teeth with caries, which was higher among the male population, the other elements showed a higher prevalence among the female population. As to the periodontal condition, the higher prevalence of sextants inexistency was found, as well as the edentulous women, and the use o prosthesis. The presence of injury in the oral soft tissues was more prevailing among the female population. It is possible to conclude that the female population had more access to dental services and the male population has more accrued necessities. By the scope of the mutilation showed by women and
\end{abstract}


accrued necessities found among the male population it is possible to conclude that a new approach should be use to address dental treatment in the elderly population.

Descriptors: Oral Health; Elderly population; Health Surveys Epidemiology. Population Studies in Public Health; DMFT 


\section{SUMÁRIO}

\section{Página}

Parte I - Contexto e caracterização da pesquisa

1. Introdução 16

1.1. Envelhecimento Populacional 16

1.2. Saúde do Idoso 19

1.3. O Estudo SABE 22

1.3.1. Instrumento de coleta de dados 23

1.3.2. Amostra 26

$\begin{array}{ll}\text { 1.3.3. Procedimento de coleta de dados } & 27\end{array}$

1.4. Saúde Bucal do Idoso $\quad 29$

1.4.1. Saúde Bucal do Idoso Brasileiro 31

1.4.2. Saúde Bucal do Idoso no Projeto SABE 35

2. Objetivo Geral 36

2.1. Objetivos específicos 36

3. Material e Método 37

4. Resultados $\quad 39$

4.1. Cárie dentária $\quad 40$

4.2. Necessidade de tratamento 46

4.3. Condição Periodontal 49

4.3.1. Doença Periodontal 49

4.3.2. Perda de inserção periodontal

4.4. Uso de prótese dentária $\quad 59$

4.5. Necessidade de prótese dentária $\quad 64$

4.6. Lesão de tecidos moles da cavidade bucal $\quad 69$

$\begin{array}{ll}\text { Parte II - Minutas dos artigos } & 70\end{array}$

Artigo 1 - Condições dentárias dos idosos moradores no Município de São Paulo 71 em 2006

Artigo 2 - Uso e necessidade de prótese em idosos moradores no Município 93 
de São Paulo em 2006

$\begin{array}{ll}\text { Parte III - Referências e Anexos } & 115\end{array}$

5. Referências 116

Anexo A - Instrumento SABE (cópia em compact disc) 121

Anexo B - Aprovação do Comitê de Ética da Faculdade de Saúde Pública 123

da Universidade de São Paulo para o desenvolvimento da pesquisa

$\begin{array}{ll}\text { Anexo C - Caderno de Instruções } & 125\end{array}$

$\begin{array}{ll}\text { Anexo D - Ficha de exame } & 139\end{array}$ 


\section{Lista de Tabelas}

Tabela 1 - Número de idosos, média de idade, desvio padrão e percentual na

população segundo sexo. Município de São Paulo, 2006.

Tabela 2 - $\quad$ Número de mulheres, dentes hígidos, cariados, perdidos, restaurados e 40 CPOD em mulheres segundo faixa etária. Município de São Paulo, 2006.

Tabela 3 - Número de homens, dentes hígidos, cariados, perdidos, restaurados e

CPOD em mulheres segundo faixa etária. Município de São Paulo, 2006.

Tabela 4 - $\quad$ Média dos componentes e do índice CPOD em mulheres, segundo faixa etária. Município de São Paulo, 2006.

Tabela 5 - Média dos componentes e do índice CPOD em homens segundo faixa etária. Município de São Paulo, 2006.

Tabela 6 - Média dos componentes e do índice CPOD na população de idosos, segundo faixa etária. Município de São Paulo, 2006.

Tabela 7 - Tabela 7 - Composição percentual do índice CPOD em mulheres, segundo faixa etária. Município de São Paulo, 2006.

Tabela 8 - Composição percentual do índice CPOD em homens, segundo faixa etária. Município de São Paulo, 2006.

Tabela 9 - Média do índice CPOD, desvio padrão, limite inferior e limite superior segundo sexo e faixa etária. Município de São Paulo, 2006.

Tabela 10 - Distribuição percentual dos valores do índice CPOD, em mulheres, segundo faixa etária. Município de São Paulo, 2006.

Tabela 11 - Distribuição percentual dos valores do índice CPOD, em homens, segundo faixa etária. Município de São Paulo, 2006.

Tabela 12 - Número e porcentagem de dentes com e sem necessidade de tratamento em mulheres segundo faixa etária. Município de São Paulo, 2006.

Tabela 13 - Número e porcentagem de dentes com e sem necessidade de tratamento em homens segundo faixa etária. Município de São Paulo, 2006. 
Tabela 14 - Número e porcentagem de necessidade de tratamento em mulheres segundo o tipo de necessidade e faixa etária. Município de São Paulo, 2006.

Tabela 15 - Número e porcentagem de necessidade de tratamento em homens segundo o tipo de necessidade e faixa etária. Município de São Paulo, 2006.

Tabela 16 - Número e percentual de sextantes superiores em mulheres segundo condição do sextante e faixa etária. Município de São Paulo, 2006.

Tabela 17 - Número e percentual de sextantes superiores em homens segundo condição do sextante e faixa etária. Município de São Paulo, 2006.

Tabela 18 - Número e percentual de sextantes inferiores em mulheres segundo condição do sextante e faixa etária. Município de São Paulo, 2006.

Tabela 19 - Número e percentual de sextantes inferiores em homens segundo condição do sextante e faixa etária. Município de São Paulo, 2006.

Tabela 20 - Número e percentual de sextantes superiores em mulheres segundo condição do sextante e faixa etária. Município de São Paulo, 2006.

Tabela 21 - Número e percentual de sextantes superiores em homens segundo 55 condição do sextante e faixa etária. Município de São Paulo, 2006.

Tabela 22 - Número e percentual de sextantes inferiores em mulheres segundo condição do sextante e faixa etária. Município de São Paulo, 2006.

Tabela 23 - Número e percentual de sextantes inferiores em homens segundo condição do sextante e faixa etária. Município de São Paulo, 2006.

Tabela 24 - Número e porcentagem de mulheres segundo o uso de prótese dentária superior e faixa etária. Município de São Paulo, 2006.

Tabela 25 - Número e porcentagem de homens segundo o uso de prótese dentária superior e faixa etária. Município de São Paulo, 2006.

Tabela 26 - Número e porcentagem de mulheres segundo o uso de prótese dentária 61 inferior e faixa etária. Município de São Paulo, 2006.

Tabela 27 - Número e porcentagem de homens segundo o uso de prótese dentária inferior e faixa etária. Município de São Paulo, 2006. 
Tabela 28 - Número e porcentagem de mulheres que necessitam de prótese dentária superior segundo o tipo de prótese e faixa etária. Município de São Paulo, 2006.

Tabela 29 - Número e porcentagem de homens que necessitam de prótese dentária superior segundo o tipo de prótese e faixa etária. Município de São Paulo, 2006.

Tabela 30 - Número e porcentagem de mulheres que necessitam de prótese dentária inferior segundo o tipo de prótese e faixa etária. Município de São Paulo, 2006.

Tabela 31 - Número e porcentagem de homens que necessitam de prótese dentária inferior segundo o tipo de prótese e faixa etária. Município de São Paulo, 2006.

Tabela 32 Número e porcentagem de idosos que apresentaram algum tipo de lesão de tecidos moles da cavidade bucal segundo sexo e faixa etária. Município de São Paulo, 2006. 


\section{Siglas utilizadas}

CONEP - Conselho Nacional de Ética em Pesquisa

CPI - Índice Comunitário Periodontal

CPOD - Índice de dentes permanentes cariados, perdidos e obturados

IBGE - Instituto Brasileiro de Geografia e Estatística

JCE - Junção cemento esmalte

OMS - Organização Mundial da Saúde

OPAS - Organização Pan-Americana de Saúde

PIP - Índice de Perda de Inserção Periodontal

PNAD - Pesquisa Nacional por Amostra de Domicílios

SABE - Saúde Bem-Estar e Envelhecimento

SES-FSP - Secretaria de Estado da Saúde - Faculdade de Saúde Pública

UPA - Unidade primária de amostra

USA - Unidade secundária de amostra

USP-FSP - Universidade de São Paulo - Faculdade de Saúde Pública

UTA - Unidade Terciária de amostra

WHO - Organização Mundial da Saúde 


\section{PARTE I}

\section{CONTEXTO E CARACTERIZAÇÃO DA PESQUISA}




\section{1. - INTRODUÇÃO}

\section{1 - ENVELHECIMENTO POPULACIONAL}

No final do século XX deparou-se com a constatação do inexorável envelhecimento da população mundial que se traduziu pelo aumento da proporção de pessoas idosas em sua composição.

Segundo a Organização Mundial da Saúde são consideradas idosas pessoas com idade igual ou acima de 65 anos em países desenvolvidos e, nos países subdesenvolvidos, pessoas com idade igual ou acima de 60 anos.

Para CAMARANO (2006), a definição de pessoa idosa é difícil, pois não há idéia clara do que marca a transição entre o fỉm da idade adulta e o começo da última etapa. Embora se possam estabelecer marcos em processos biológicos como aparência física, aparecimento de doenças crônicas, perda de capacidades físicas e mentais, perda de papéis sociais ou nascimento de netos. Muitos desses processos caracterizam essa etapa, mas seu início é afetado pelas condições sociais, econômicas, regionais, culturais, de gênero, entre outras. No entanto, para finalidades operacionais, define-se como população idosa as pessoas de 60 anos e mais conforme estabelecido no Estatuto do Idoso e na Política Nacional do Idoso (BRASIL, 2003).

Envelhecer já não é privilegio de poucos. O envelhecimento populacional é um fenômeno que ocorre tanto em países desenvolvidos como em países subdesenvolvidos. Nos países subdesenvolvidos o envelhecimento populacional decorreu devido às conquistas tecnológicas do pós-guerra o que diminuiu a mortalidade. Além disso, a queda nas taxas de fecundidade e, mais recentemente, na mortalidade acima de 60 anos, proporcionou o aumento expressivo da proporção de idosos nesses países sem que tenham alcançado um bom nível de progresso social e econômico (KALACHE e col. 1998, CHAIMOWICZ, 1997).

Considerando-se o exemplo do Brasil, no início do século XX a expectativa de vida ao nascimento era de 33,7 anos, tendo atingido 43,2 anos em 1950. No decorrer da década imediatamente posterior, a expectativa de vida aumentou em quase 13 anos (55,9 em 1960). Na década seguinte a expectativa de vida ao nascimento 
passou a 57,1 e em 1980 atingiu 63,5 anos. Em 2004 observou-se uma diferença de quase oito anos em termos de esperança de vida ao nascer, segundo o sexo: 75,6 anos para as mulheres e 68,4 anos para os homens (MINISTÉRIO DA SAÚDE, 2005).

O aumento da expectativa de vida das populações de países desenvolvidos deveu-se à crescente melhora da qualidade de vida. Por outro lado, nos países subdesenvolvidos, este aumento deveu-se às conquistas tecnológicas da medicina moderna. $\mathrm{O}$ aumento na expectativa de vida conseqüente à redução da mortalidade verificada na maioria dos países subdesenvolvidos foi, portanto, um fenômeno que se pode chamar artificial, já que ocorreu em função da disponibilidade de tecnologias inexistentes até um passado muito próximo (KALACHE e col., 1987).

Em grande parte, o aumento do número de pessoas idosas em países menos desenvolvidos decorreu do alto número de nascimentos durante as primeiras décadas do século passado, associado a um progressivo decréscimo nas taxas de mortalidade. Da mesma forma, o envelhecimento da população de países europeus das últimas décadas deveu-se a taxas de natalidade relativamente altas no primeiro quarto do século associadas a taxas decrescentes de mortalidade em todos os grupos etários. Em seguida as taxas de natalidade decaíram, fazendo com que a proporção de adultos progressivamente aumentasse. O processo foi, portanto, dinâmico; para que houvesse o envelhecimento da população foi necessário o nascimento de muitas crianças, segundo que as mesmas sobrevivessem até idades avançadas e que, simultaneamente, o número de nascimentos diminuísse. Com isso a entrada de jovens na população decresceu e a proporção daqueles que sobreviveram até idades mais avançadas passou a crescer (KALACHE e col., 1987).

Tal é a rapidez com que se processam as mudanças que o Brasil deverá passar, entre 1960 e 2025 , da $16^{\text {a }}$ para a $6^{\text {a }}$ posição mundial em termos de número absoluto de indivíduos com 60 anos ou mais. Por estar intrinsecamente relacionada à modificação da incidência e prevalência de doenças na população, a velocidade com a qual este processo vem ocorrendo deverá determinar grandes dificuldades ao Estado para lidar com o novo perfil epidemiológico que aos poucos se sobrepõe, sem substituir completamente o perfil anteriormente predominante. 
Estas estatísticas reforçam a noção de que o envelhecimento populacional pode passar a representar mais um problema que uma conquista da sociedade, na medida em que os anos de vida ganhos não sejam vividos em condições de independência e saúde. Isto geralmente implica em custos elevados para o sistema de saúde.

Tal mudança demográfica surge como um grande desafio para a saúde pública, num momento em que o investimento na saúde da criança e do adolescente ainda representa uma importante prioridade, enquanto as necessidades de saúde dos adultos mais velhos e o desenvolvimento de infra-estruturas voltadas a uma sociedade em processo de envelhecimento, raramente recebem a atenção necessária (OPAS, 1988).

Daí a importância de se estudar as necessidades de saúde da população de idosos, para estimar quais seriam as prioridades e de que maneira abordálas para haver uma boa resolutividade e coerente destinação dos recursos provenientes dos investimentos do setor saúde para esse grupo populacional. 


\section{2 - SAÚDE DO IDOSO}

Em termos de saúde, o aumento do número de idosos em uma população se traduz por aumento na demanda por cuidados em saúde devido a doenças de longa duração. As doenças crônicas, comuns em pessoas com idade mais avançada, são cada vez mais prevalentes. $\mathrm{O}$ crescimento da população idosa leva inevitavelmente a um aumento dos recursos dispendidos na área de saúde. Na Inglaterra, a população acima de 65 anos, cerca de $17 \%$ da população total, utiliza $60 \%$ do orçamento do Departamento Nacional de Saúde e Cuidados Sociais. Há ainda os gastos com os idosos que vivem na comunidade que demandam além dos cuidados primários em saúde, auxílio para atividades domésticas e fornecimento de refeições, entre outras necessidades. A exemplo de outros países mais desenvolvidos, a Inglaterra dispende com os idosos cerca de três vezes mais que o dispêndio per capita com o resto da

população. É fundamental que se tenha uma política de saúde planejada de tal forma a usar os recursos disponíveis com máxima eficiência (KALACHE e col., 1987).

No Brasil, segundo o Censo de 2000 (IBGE, 2002), as pessoas com 60 anos ou mais de idade já representavam quase $10 \%$ da população do País, totalizando 14.536 .029 indivíduos.

De acordo com CHAIMOWICZ (1997), a população idosa brasileira, na maioria das vezes é portadora de mais de uma doença crônica, concorrendo com as necessidades em saúde da população mais jovem portadora de doenças infecto contagiosas ainda muito prevalentes.

RAMOS e col.(1993), em um inquérito domiciliar realizado na cidade de São Paulo relataram que $86 \%$ dos idosos entrevistados referiram ter pelo menos uma doença crônica.

VERAS (1994), em inquérito domiciliar no Rio de Janeiro, encontrou alta proporção de pessoas que relatavam "má visão" (42\%), "má audição" (17\%) e problemas dentários (63\%). Ainda neste grupo foi encontrada alta proporção de idosos cujos resultados de testes padronizados identificaram déficits cognitivos 
significativos $(30 \%)$ e depressão (35\%), embora o citado autor tenha considerado que modificações dos questionários e dos pontos de corte utilizados possam ter reduzido parcialmente as prevalências descritas.

LIMA-COSTA e col., (2003), ao descrever a situação de saúde da população idosa brasileira, utilizando os dados da PNAD 1998, relataram que $64 \%$ deles referiu pelo menos uma doença crônica, sendo que as mais prevalentes foram hipertensão $(43,90 \%)$ e artrite $(37,50 \%)$.

A Pesquisa Nacional por Amostra de Domicílios - PNAD é uma investigação populacional com representatividade nacional realizada no Brasil desde 1967 com frequiência anual. A PNAD é baseada em uma amostra probabilística obtida em três estágios de seleção: municípios, setor censitário e domicílio. São investigadas as características de todos os residentes no domicílio selecionado.

A PNAD de 2004, (IBGE, 2005) relata que o percentual de pessoas com 60 anos ou mais de idade era de 6,40\% em 1981, subiu para 8\% em 1993 e alcançou 9,80\% em 2004. A evolução do processo de envelhecimento da população também pode ser acompanhada por meio do indicador que relaciona o número de pessoas de 60 anos ou mais de idade para 100 crianças de menos de 5 anos de idade. Esse indicador estava em 48,3 em 1981, passou para 76,5 em 1993, atingiu 97,8 em 1999 e, alcançou 120,1 em 2004. Em 2002, o número de idosos de 60 anos ou mais de idade já havia suplantado o de crianças de menos de 5 anos de idade.

A cada ano, mais 650 mil idosos têm sido incorporados à população brasileira.

Quanto aos resultados de saúde para a população idosa no Brasil, a PNAD 2004 (IBGE, 2005) encontrou que as mulheres representavam 56,1\% do total de pessoas. A percepção de saúde foi declarada boa ou muito boa por $45,6 \%$ dos homens e $41,9 \%$ das mulheres. À medida que a idade avançava, maiores foram as chances de o idoso avaliar sua saúde como ruim ou muito ruim.

A doença crônica relatada com maior freqüência foi hipertensão, tanto para os homens $(36,6 \%$ e $40,4 \%)$ quanto para as mulheres $(49,7 \%$ e $55,3 \%)$. A artrite/reumatismo também foi bastante referida, porém bem menos que na 
PNAD 1998. O mesmo ocorreu com as doenças do coração, doença renal e depressão que apresentaram uma redução percentual para ambos os sexos em relação à PNAD de 1998. Além da hipertensão, houve um aumento nos relatos de câncer e diabetes. O câncer teve uma grande elevação proporcional em 2003. Doenças como artrite/reumatismo e depressão apresentaram uma distribuição diferencial por sexo e atingiram mais as mulheres que os homens. Quanto à freqüência ao cirurgião-dentista, $18,3 \%$ dos homens e 16,7\% das mulheres declararam ter ido ao dentista há menos de um ano. Este percentual experimentou um aumento em relação à PNAD de 1998 quando $14 \%$ dos homens e $12,5 \%$ das mulheres haviam ido ao dentista há menos de um ano. O número de idosos de ambos os sexos que nunca foram ao dentista diminuiu para todos os grupos etários em relação à PNAD de 1998. Quanto à perda da capacidade funcional, esteve diretamente relacionada com o aumento da idade; 93,3\% dos homens de 60 a 69 não tinham dificuldades para alimentar-se, tomar banho ou ir ao banheiro; já entre os idosos de 80 anos e mais essa porcentagem se reduz para 70,3\%. Entre as mulheres essa diferença é ainda mais acentuada com o avanço da idade: 91,1\% e 63,9\%, respectivamente. Para ambos os sexos, nota-se a perda de autonomia à medida que a idade avança, principalmente ao passar do grupo etário 75 anos ou mais para o grupo com mais de 80 anos.

No Estudo SABE (LEBRÃO e LAURENTI, 2005), houve alta prevalência de doenças crônicas entre a população idosa do Município de São Paulo, onde uma proporção elevada dos entrevistados declarou sofrer de três ou mais doenças, sendo que entre as mulheres houve maior prevalência (48\%) do que entre os homens (33\%). As principais doenças crônicas referidas foram: hipertensão arterial sistêmica $(53,3 \%)$, doenças ósteo-articulares $(31,7 \%)$, problemas cardíacos $(19,5 \%)$, diabetes $(17,9 \%)$, osteoporose $(14,2)$, doenças crônicas pulmonares $(12,2 \%)$, doenças circulatórias $(7,2 \%)$ e neoplasias $(3,3 \%)$. 


\section{3 - O ESTUDO SABE}

É provável que as características do envelhecimento populacional na América Latina, de velocidade sem precedentes e em condições sócio econômicas desfavoráveis, fará com que as coortes que alcançarão 60 anos no período de 2000-2020 demandem grandes necessidades por serviços de saúde (PALLONI e PELÁEZ, 2003).

O desenvolvimento social e econômico na América do Norte e Europa Setentrional e Ocidental já estava determinado quando as sociedades desses países começaram a envelhecer. O mesmo não ocorreu na América Latina onde se tem países de economias frágeis, com grandes desigualdades sociais, contraindo mais do que expandindo o acesso aos serviços e recursos de saúde. A maioria da população da região vive uma diminuição da renda real, um acesso mais pobre aos serviços de saúde e uma erosão de sua capacidade para reivindicar recursos públicos para aposentadoria e bemestar. Os grupos mais vulneráveis são as pessoas mais velhas e as crianças e é nesses grupos que o impacto dos efeitos deletérios será visto ((PALLONI e PELÁEZ, 2003)).

O estudo SABE - Saúde Bem Estar e Envelhecimento (LEBRÃO E LAURENTI, 2005), foi planejado, em parte, para tentar testar a conjectura acima mencionada e colocar, assim, luz na carga das demandas de saúde que provavelmente emergirão de uma população rapidamente idosa com ênfase nas necessidades de saúde da população com 75 anos e mais. O estudo também foi motivado pela necessidade percebida de antecipar o que se encontrará adiante, de modo que os países possam se planejar adequadamente para prevenir conseqüências mais negativas do processo do envelhecimento na região. Quatro dos países incluídos - Argentina, Barbados, Cuba e Uruguai - estão em estágios muito avançados do processo de envelhecimento enquanto os outros três, - Chile, México e Brasil - estão ligeiramente atrás dos precursores, mas, irão transpor, nessa ordem, uma escala inteira que vai de uma maior a uma menor velocidade de envelhecimento (PALLONI e PELÁEZ, 2003).

O estudo, organizado pela Organização Pan-Americana de Saúde (OPAS), entre os anos de 1997 e 2003, em sete grandes cidades da América 
Latina e do Caribe, Bridgetown (Barbados); Buenos Aires (Argentina); Havana (Cuba); México (México); Montevidéu (Uruguai); Santiago (Chile) e São Paulo (Brasil), caracterizou-se por ser multicêntrico, transversal, simultâneo, rigorosamente comparável e o primeiro dessa natureza na região da América Latina e Caribe (PAHO, 1999).

No Município de São Paulo, o trabalho de campo para a coleta de dados da primeira fase da pesquisa foi realizado de janeiro de 2000 a março de 2001.

Em 2006, a pesquisa teve continuidade no Município de São Paulo, transformando-se em um estudo longitudinal que buscou as pessoas entrevistadas em 2000, para aplicação de questionário para coleta de informações sobre as suas atuais condições de vida e saúde, com ênfase em fatores de risco para mortalidade, institucionalização, alterações da funcionalidade e fragilidade.

\subsection{1 - Instrumento de coleta de dados}

Os dados do Estudo SABE (LEBRÃO e LAURENTI, 2003) foram obtidos através de entrevista domiciliar, por meio de um questionário elaborado de maneira a fornecer informações comparáveis entre os vários países. Em particular, o objetivo foi incluir módulos e seções baseadas no inquérito AHEAD Assets and Health Dynamics Among the Oldest Old do The Health and Retirement Study da Universidade de Michigan (UNIVERSIDADE DE MICHIGAN), além de um conjunto de pesquisas realizadas pelo Centro de Estudos de População da citada universidade e seus colaboradores locais em vários países de Ásia.

Ao mesmo tempo em que se buscou fortalecer a comparabilidade, procurou-se fazer com que os módulos incluídos fossem congruentes com a realidade de cada cidade investigada. $\mathrm{O}$ instrumento final foi considerado apropriado para a identificação do que seja pertinente ao processo de envelhecimento das grandes zonas urbanas da região da América Latina e Caribe e das semelhanças que estas guardam com as de outros países. 
O questionário foi só um dos componentes do protocolo para reunir informações. O segundo componente consistiu em medidas antropométricas (peso, estatura, altura do joelho, circunferência do braço, circunferência da cintura e do quadril, prega tricipital, circunferência da panturrilha e circunferência do punho).

Este instrumento (Anexo A) foi submetido a dois prétestes até se chegar a sua forma final, composta por onze seções, a saber:

\section{Seção A - Dados pessoais}

Ano e país de nascimento, local de residência durante os primeiros quinze anos de vida, local de residência durante os últimos cinco anos de vida e razão para a mudança de residência se fosse o caso, história e estado civil, número de filhos, sobrevivência dos pais e, caso houvessem falecido, a idade em que faleceram, escolaridade.

\section{Seção B - Avaliação cognitiva}

Auto-avaliação da memória, avaliação da memória através do teste mini-mental modificado e validado no Chile para a realização do estudo. Para os que obtiveram escores inferiores a 12 pontos aplicou-se uma escala de desempenho funcional ao informante substituto a partir da questão "é capaz de...”.

\section{Seção C - Estado de saúde}

Auto-avaliação da saúde atual comparando com o ano anterior e da saúde na infância, doenças referidas considerando as mais prevalentes, hábitos, condições sensoriais, saúde reprodutiva, auto-avaliação da saúde bucal, ocorrência de quedas, escala de avaliação de depressão geriátrica e mini screening nutricional.

\section{Seção D - Estado funcional}

Avaliação do desempenho funcional e da ajuda recebida, quando necessário, nas atividades básicas e instrumentais da vida diária e identificação e caracterização dos principais cuidadores.

\section{Seção E - Medicamentos}


Medicamentos utilizados, incluindo indicação, tempo de uso, forma de utilização, obtenção e pagamento, gastos mensais com medicamentos e motivos referidos para a não utilização dos medicamentos prescritos.

\section{Seção F - Uso e acesso a serviços}

Serviços de saúde utilizados, públicos ou privados, nos últimos 12 meses e ocorrência de hospitalização, atendimento ambulatorial, exames nos últimos quatro meses, bem como tempo de espera para atendimento, terapêutica prescrita e gastos relacionados.

\section{Seção G - Rede de apoio familiar e social}

Número e características de pessoas que vivem com o idoso no mesmo domicílio (sexo, parentesco, estado marital, idade, escolaridade e condição de trabalho), assistência prestada ao idoso e fornecida por ele referente a cada membro citado, tempo gasto na ajuda ao idoso. As mesmas perguntas foram feitas em relação aos irmãos e filhos que não vivem no mesmo domicílio, bem como a outros familiares e que, de alguma forma, fornecem ou recebem ajuda do idoso, assistência recebida ou fornecida nos últimos 12 meses de alguma instituição ou organização, participação do idoso em algum serviço voluntário ou organização comunitária.

\section{Seção H - História laboral e fonte de renda}

Trabalho atual (tipo, renda, razões para continuar trabalhando); caso não trabalhasse mais, por que não o fazia, ocupação que teve durante o maior período de sua vida, horas trabalhadas, razões para mudança de atividade, aposentadoria, pensões, benefícios, outras fontes de renda, renda total pessoal e número de dependentes dessa renda, gastos pessoais (moradia, transporte, alimentação, vestimenta, saúde) e auto-avaliação de seu bem estar econômico.

\section{Seção J - Características de moradia}

Tipo e propriedade da moradia, condições de habitação (saneamento básico, luz, número de cômodos, bens presentes).

\section{Seção K - Antropometria}


Altura do joelho, circunferência do braço, da cintura e do quadril, prega triciptal, peso, circunferência da panturrilha, largura do punho e força da mão.

\section{Seção L - Flexibilidade e mobilidade}

Provas de equilíbrio, mobilidade e flexibilidade.

\subsection{2 - Amostra}

As amostras foram elaboradas pelo método clássico de amostras de etapas múltiplas por conglomerados, com estratificação das unidades primárias (ALBALA e col., 2005).

A distribuição da amostra por estrato geográfico ou socioeconômico foi determinada mediante probabilidade proporcional ao tamanho da população idosa. As Unidades Primárias de Amostra (UPA) foram divididas em unidades secundárias de amostra (USA), cada uma formada por um número menor de domicílios independentes. As USA foram integradas, por sua vez, por unidades terciárias de amostra (UTA), constituídas pelos domicílios selecionados em que se entrevistaram todas as pessoas de 60 anos e mais neles residentes que cumpriam os requisitos, incluindo os cônjuges, se estivessem presentes. Desta forma, o domicílio se constituiu no último estrato de agregação da amostra. As etapas do desenho permitiram ao investigador calcular as probabilidades de seleção de cada indivíduo alvo. Isso, junto com o conhecimento posterior das taxas de falta de resposta, forneceu informação suficiente para calcular os fatores de expansão, a fim de realizar inferências a respeito da população de referência a partir das amostras selecionadas. A taxa média de resposta foi de $80 \%$ (ALBALA e col., 2005).

A maior parte das entrevistas foi feita de forma direta.

Em alguns casos as respostas foram obtidas de um informante geralmente em conseqüência do estado cognitivo do idoso.

No Brasil, a população de estudo foi composta por pessoas de 60 anos e mais residentes na área urbana do município de São Paulo. A 
amostra de idosos foi obtida pelo critério de partilha proporcional distribuída segundo estratos definidos por sexo e grupo etário. A unidade primária de amostra foi o setor censitário já previamente ordenado segundo o número de chefes de família analfabetos. A amostra final foi alcançada através da somatória de uma amostra probabilística (sorteio de 1.500 idosos) e de uma amostra intencional (composição livre da amostra para os grupos ampliados). A necessidade de ampliação da amostra se deveu ao fato da baixa densidade na população de grupos etários de 75 anos e mais para permitir análises das condições de saúde que são raras precisamente porque ocorrem somente neste segmento de população. Ainda, para compensar o excesso de mortalidade em relação à população feminina, ajustaram-se as amostras do sexo masculino para número igual ao do sexo feminino (SILVA, 2003).

Para obtenção da amostra probabilística dos domicílios, foi utilizado o cadastro permanente de 72 setores censitários, disponível no Departamento de Epidemiologia da Faculdade de Saúde Pública da Universidade de São Paulo, oriundo do cadastro da PNAD 1995, sorteados sob o critério de probabilidade proporcional ao número de domicílios. Os domicílios a serem visitados foram sorteados sistematicamente. A complementação da amostra com pessoas de 75 anos e mais foi realizada pela localização de idosos moradores próximos aos setores sorteados até dentro dos limites dos distritos aos quais pertencia o setor sorteado (SILVA, 2003).

A atualização das listas de endereços introduziu alterações nas probabilidades de sorteio entre os setores censitários. Houve também necessidade de ajustar a distribuição da amostra segundo a distribuição da composição da população segundo sexo e faixa etária. Para compensar estas alterações foram calculados pesos para cada elemento amostral que variou de acordo com o setor censitário onde está localizado o domicílio, o sexo e a faixa etária a qual pertence o indivíduo sorteado (SILVA, 2003). 


\subsubsection{Procedimento de coleta de dados}

Após a seleção da amostra os idosos foram entrevistados em seus domicílios. A maior parte das entrevistas (88\%) foi feita de forma direta. Em algumas ocasiões, utilizou-se um proxi-respondente quando havia impossibilidade do idoso responder as questões devido a problemas físicos ou cognitivos.

A coleta de dados ocorreu em duas etapas. Na primeira foram preenchidas as seções de A a J e na segunda, que ocorreu de um a seis meses após a primeira, as seções L e K. Isso ocorreu, em parte, pela extensão do questionário e, por outro lado, as seções L e K exigiam maior disponibilidade do idoso para a realização de alguns testes, além de material específico.

Em 2006, no seguimento dos idosos entrevistados em 2000, durante o preenchimento das seções L e K, foram feitos os exames da cavidade bucal dos idosos.

O estudo foi submetido aos respectivos comitês de ética dos países envolvidos. No Brasil, o mesmo foi aprovado pelo Comitê de Ética da Faculdade de Saúde Pública da Universidade de São Paulo, a qual pertencem os principais investigadores do estudo e pelo CONEP - Conselho Nacional de Ética em Pesquisa. 


\section{4 - SAÚDE BUCAL DO IDOSO}

A conquista de uma maior esperança de vida para a população trouxe consigo inúmeras alterações fisiológicas e patológicas na saúde bucal dos idosos.

O envelhecimento da população tem implicações significativas para a organização da atenção em saúde bucal. Ainda que as prioridades dos programas de atenção nesta área continuem recaindo sobre os grupos de crianças e adolescentes, tanto no Brasil quanto em outros países, são crescentes as preocupações com a atenção à saúde bucal dos idosos.

Em 2003, a Organização Mundial da Saúde, através do WHO Global Oral Health Programme publicou um relatório sobre as condições de saúde bucal mundial com dados extraídos do Global Oral Data Bank. Este banco de dados é permanentemente atualizado com informações de vários países. O relatório mostrou que ao redor do mundo as pessoas idosas perderam um grande número de elementos dentários, muitas apresentaram doença periodontal e o risco de câncer de boca aumenta a partir dos 50 anos. Além disso, muitos eram portadores de mais de uma doença crônico-degenerativa o que os faziam consumidores, não raras vezes, de mais de um tipo de medicamento (WHO, 2003).

Para PETERSEN (2003), a saúde bucal é um componente importante para o envelhecimento saudável por ter uma participação significativa na saúde geral. A partir do banco de dados Global Oral Data Bank, o autor coletou dados de saúde bucal dos países para enfatizar a importância da promoção e recuperação da saúde bucal da população idosa.

A prevalência de cárie em adultos chegou a atingir $100 \%$ da população da maioria dos países. O edentulismo esteve associado com o baixo nível socioeconômico, baixos níveis educacionais e de renda. Alguns países desenvolvidos apresentaram uma tendência de declínio de perda dentária entre adultos, inclusive em idosos, mas as iniqüidades sociais, no que diz respeito à saúde bucal, ainda persistem mesmo em países que possuem programas avançados de saúde pública voltados para a saúde bucal. 
A cárie dentária e a doença periodontal foram as principais doenças que provocaram a perda dentária. $\mathrm{O}$ uso do tabaco também se constitui num fator de risco, particularmente entre idosos cujo consumo vinha de longos anos.

O uso de prótese parcial removível foi muito freqüente entre idosos habitantes de países desenvolvidos. Alguns países reportaram que 1/3 dos idosos usam próteses totais enquanto mais de três quartos usam algum tipo de prótese parcial removível.

Novamente a prevalência de próteses parciais removíveis mostrou uma considerável variação socioeconômica.

A estomatite foi a lesäo bucal mais comumente relatada entre os idosos. Sua prevalência variou entre 11 a $67 \%$ em usuários de prótese total e esteve fortemente relacionada à higiene, consumo de álcool e uso de tabaco ou ainda à alergia ao material com o qual a prótese foi confeccionada. A hiperplasia e a úlcera traumática foram também lesões associadas ao uso de prótese. Sua prevalência variou entre 4 a 26\%. Ambas as lesões foram mais frequentemente observadas entre usuários de prótese total do que entre usuários de prótese parcial removível.

A população idosa apresentou alta prevalência de cárie dentária em muitos países. A média de dentes cariados e obturados variou entre $22 \%$ a $35 \%$ em países desenvolvidos. Nos países em desenvolvimento as pesquisas foram escassas.

A média de dentes cariados e restaurados entre idosos nos países desenvolvidos foi de 2,2 e 5,3\% com um incremento de 1,31 faces cariadas por idoso a cada ano.

No mundo, a porcentagem de bolsas peridontais profundas variou entre $5 \%$ a $70 \%$ entre idosos. Baixos níveis educacionais, falta de acesso aos serviços odontológicos, poucos dentes presentes e uso do tabaco foram fatores que levaram à progressão da doença.

A prevalência da xerostomia foi de cerca de $30 \%$ na população acima de 65 anos de idade. A redução do fluxo salivar mostrou-se associada à idade e ao sexo sendo mais prevalente em mulheres. Certos medicamentos foram responsáveis pela xerostomia tais como: antidepressivos tricíclicos, antipsicóticos, atropina, beta 
bloqueadores e anti-histamínicos. A queixa de boca seca foi particularmente freqüente em pessoas tratadas de problemas de hipertensão, psiquiátricos ou urinários. $\mathrm{O}$ hábito de fumar também foi outro importante fator de risco para boca seca.

O câncer de boca, que aumenta progressivamente com a idade, foi mais comum em populações de países em desenvolvimento.

A prevalência de lesões pré-malignas como leucoplasia e líquen plano variou entre 1 a 4,80\% e 1,10 a 6,60\%, respectivamente. A leucoplasia foi mais freqüente entre os homens enquanto que o líquen plano foi mais freqüente em mulheres. O fumo foi o fator determinante mais importante para câncer de boca.

\subsection{1 - Saúde bucal do idoso brasileiro}

No Brasil, a Odontologia tem voltado sua atenção para a problemática da terceira idade. Há grande interesse em quantificar as condições de saúde bucal dos idosos.

Vários estudos têm sido realizados a fim de avaliar as condições dessa população. Apesar desse interesse, a maior parte das investigações sobre idosos refere-se a populações institucionalizadas (SILVA e FERNANDES, 2001; CARNEIRO, 2001; MENEGUIM e col., 2002). São ainda poucos os estudos epidemiológicos de base populacional voltados às condições de saúde bucal no Brasil (NARVAI e ANTUNES, 2003).

As principais alterações bucais encontradas nos indivíduos idosos são a cárie dentária, as doenças periodontais, a perda de grande número de dentes, o edentulismo e o câncer bucal ( NETTO, 1997; SILVA, 1999; PETERSEN, 2003).

A cárie dentária costuma se apresentar com maior freqüência em pessoas idosas com reduzido fluxo salivar (xerostomia), dieta cariogênica (muitas vezes associada à higienização precária em decorrência da dificuldade motora que costumam apresentar e a próteses totais mal adaptadas), além de alterações sistêmicas comuns nos idosos, que aumentam o risco de sua ocorrência (NETTO, 1997). 
No Levantamento Epidemiológico em Saúde Bucal: Estado de São Paulo, 1998 (SES-FSP, 1999), examinou-se 4.894 idosos (3.035 mulheres e 1.859 homens) de 65 a 74 anos, usuários de serviços de saúde e associados de grêmios variados.

O índice CPOD (número de dentes cariados, perdidos e obturados), encontrado foi de 28,52. Houve, em média, 0,67 dentes cariados e 1,27 dentes restaurados. O componente "dentes perdidos" correspondeu a 27,06.

Em 2005 foram publicados os resultados do mais abrangente levantamento epidemiológico realizado na área de saúde bucal no Brasil. O projeto SB Brasil 2003 - Condições de Saúde Bucal da População Brasileira (BRASIL, 2004), obteve dados para a população entre 65 e 74 anos. Foram examinados 5.349 idosos e o CPOD médio para o Brasil foi de 27,80 e para a região Sudeste 28,61 sendo que o componente perdido foi responsável por $93 \%$ do índice na composição do CPOD do país.

As doenças periodontais podem se manifestar desde a forma de uma gengivite até a forma de periodontite grave com conseqüente mobilidade e perda do elemento dentário. Apesar de comum nos idosos, a doença periodontal não é conseqüência da idade. O simples fato de deixar seqüelas eleva a quantidade de problemas encontrados nas idades mais avançadas (SILVA, 1999).

O levantamento epidemiológico de 1998, realizado no Estado de São Paulo (SES-FSP, 1999), relatou que quanto às condições periodontais, $6,7 \%$ dos idosos examinados tinham o periodonto sadio. Embora apenas 13,6\% tenham apresentado cálculo dental no momento do exame, isto se deveu ao fato de que a grande maioria dos idosos estava sem dentes.

O relatório do projeto SBBrasil 2003 (BRASIL, 2004), quanto às condições periodontais, encontrou, na faixa etária de 65 a 74 anos, 7,89\% das pessoas examinadas com periodonto normal e 31,31\% com sangramento gengival, cálculo dental ou bolsas periodontais. 
O edentulismo é um dos principais problemas que acomete a saúde bucal dos idosos. Os estudos realizados no Brasil relatam alta prevalência nessa população.

O levantamento epidemiológico de 1998 (SES-FSP, 1999) com relação ao uso de prótese dentária no arco superior, encontrou 7\% dos idosos examinados com necessidade de uma prótese fixa ou removível para substituir um elemento dentário; $22 \%$ com necessidade de uma prótese fixa ou removível para substituir mais de um elemento dentário; 30\% com necessidade de várias próteses dentárias ao mesmo tempo e $86 \%$ com necessidade de prótese total superior. No arco dentário inferior, $4 \%$ necessitavam de uma prótese fixa ou removível para substituir um elemento dentário; $21 \%$ necessitavam uma prótese fixa ou removível para substituir mais de um elemento dentário; $29 \%$ necessitavam de várias próteses dentárias ao mesmo tempo e $89 \%$ necessitavam de prótese dentária total inferior.

No relatório SBBrasil 2003 (BRASIL, 2004), quanto ao uso de prótese, 66,54\% dos idosos usavam algum tipo de prótese no arco superior e 42,57\% usavam algum tipo de prótese no arco inferior. No tocante à necessidade de prótese $30,96 \%$ das pessoas examinadas necessitavam de algum tipo de prótese superior e $54,52 \%$ de algum tipo de prótese inferior.

SILVA (1999) em estudo com idosos que freqüentavam um Centro de Saúde em Araraquara, SP, encontrou Índice CPOD de 26,66; a média de dentes cariados foi 1,10 , dentes restaurados 4,43 e perdidos 20,58, os edêntulos perfaziam $40,4 \%$ da amostra.

COLUSSI e col. (2004), em seu estudo sobre o perfil epidemiológico da cárie e do uso e necessidade de prótese na população idosa de Biguaçu, SC, encontrou uma prevalência de edentulismo de $48,4 \%$.

MESAS e col (2006) encontraram em idosos de uma comunidade de Londrina, PR, 43,1\% de edêntulos.

Os cânceres na boca correspondem a cerca de $4 \%$ dos óbitos por câncer nos homens e a $1 \%$ nas mulheres. É, em termos de saúde pública, o principal problema de saúde bucal dos idosos. O câncer de lábio é mais freqüente em pessoas 
brancas e registra maior ocorrência no lábio inferior em relação ao superior. Os coeficientes de incidência e mortalidade variam bastante segundo o sexo, atingindo mais fortemente os homens (INCA 2006).

BERCHT (1992) analisou dados do Instituto Nacional de Câncer, para o período de 1975 a 1980 e concluiu que, não obstante o câncer da boca requerer a máxima urgência resolutiva, $83 \%$ dos pacientes encontravam-se em fase avançada da doença no momento do diagnóstico e, desses, 26\% não apresentavam possibilidade terapêutica.

No Brasil, a taxa de mortalidade registrou um aumento de 1,32 para 1,82 por 100 mil habitantes no período 1979-1998, mas a tendência na ocorrência é de estabilidade. Tabagistas e etilistas do sexo masculino são os grupos mais vulneráveis. Entre os homens a taxa de mortalidade passou de 2,16 para 2,96 no período considerado (INCA 2006).

MARCHIONI (2003) analisou o papel da dieta no câncer de boca, em São Paulo, e concluiu que a dieta tradicional do brasileiro, composta por arroz e feijão, além do consumo de frutas, vegetais e quantidades moderadas de carnes, pode agir como fator de proteção contra esse tipo de câncer, independente do uso de tabaco e bebida alcoólica, reconhecidos fatores de risco.

BIAZEVIC (2003), estudou a tendência da evolução da mortalidade por câncer de boca no município de São Paulo (período de 1980 a 2000) concluindo que a língua foi a localização que mais contribuiu dentre as localizações bucais, sendo responsável por quase $50 \%$ dos óbitos, e que a maioria das localizações anatômicas apresentou tendência estável, com exceção de câncer de lábio e de gengiva, que apresentaram declínio, e partes não especificadas da cavidade bucal, que apresentou tendência de aumento.

Não são boas as condições de saúde bucal da população idosa brasileira. A falta de informação sobre higiene bucal, as dificuldades para conseguir acesso aos serviços de odontologia, e a predominância de práticas odontológicas mutiladoras, fazem dos nossos idosos pessoas desdentadas. 
Não obstante o interesse pela saúde bucal desse segmento da população, ações efetivas de tratamento curativo, preventivo e de promoção de saúde são escassas e invariavelmente relegadas ao segundo plano. Em 2007 foi lançado pelo Ministério da Saúde o Caderno de Atenção Básica no 19 cujo tema é Envelhecimento e Saúde da Pessoa Idosa (BRASIL, 2006). Não há orientações sobre como avaliar a saúde bucal do idoso. Foram descritas apenas as atribuições da equipe de saúde bucal no atendimento odontológico. Pode-se concluir que está institucionalizada a prática de se colocar a saúde bucal em segundo plano. Este é um dos principais motivos pelos quais a porcentagem de edêntulos entre os idosos no Brasil gira em torno de $40 \%$.

\subsection{2 - Saúde Bucal do Idoso no Projeto SABE}

As perguntas referentes à saúde bucal no projeto SABE (LEBRÃO e LAURENTI, 2005), estão no módulo percepção de saúde do instrumento de coleta de dados, perguntas C16 à C17K (Anexo A) e foram formuladas de forma a captar a autopercepção das condições e funções dentárias, considerando-se o período de 12 meses anteriores à entrevista. As respostas foram categorizadas da seguinte forma: sempre, frequentemente, algumas vezes, raramente e nunca. Sempre, correspondendo a ocorrência de um determinado evento nos 7 dias da semana; Frequentemente, correspondendo à ocorrência do evento em 3 a 6 dias da semana; Algumas vezes, correspondendo a ocorrência do evento uma a duas vezes na semana; e raramente correspondendo a ocorrência do evento em algumas ocasiões mas menos de uma vez por semana.

Os resultados mostraram que menos de $1 \%$ dos idosos referiram ter todos os dentes (NARVAI e ANTUNES, 2003). 


\section{2 - OBJETIVO GERAL}

O presente estudo teve como objetivo identificar as condições de saúde bucal dos idosos moradores do Município de São Paulo, em 2006.

\section{1 - Objetivos específicos}

Descrever as seguintes condições bucais de idosos residentes no Município de São Paulo, em 2006:

a) cárie e perdas dentárias, empregando o índice CPOD;

b) periodontais, empregando o Índice Comunitário Periodontal (CPI) e o indicador de Perda de Inserção Periodontal (PIP);

c) uso e necessidade de prótese dentária;

d) tecidos moles da boca, empregando a contagem de lesões. 


\title{
3 - MATERIAL E MÉTODO
}

\begin{abstract}
Este estudo é parte do Projeto SABE (LEBRÃO e LAURENTI, 2005) e caracteriza-se como uma pesquisa transversal, exploratória, com dados primários e de abordagem quantitativa. Foram realizadas entrevistas e exames bucais em idosos de 65 anos de idade e mais, participantes do projeto, residentes na zona urbana do Município de São Paulo em 2006.

Além do questionário utilizado pelo projeto (Anexo A), referente ao conhecimento da autopercepção, realizou-se exame da cavidade bucal dos idosos, utilizando-se os índices, critérios e recomendações contidos no manual sobre levantamento epidemiológico das condições de saúde bucal da Organização Mundial da Saúde (WHO, 1997) e um modelo de ficha de exame adaptada para a pesquisa (Anexo D).
\end{abstract}

A partir da padronização de códigos e critérios para as condições estudadas, apresentadas no "Caderno de Instruções" (Anexo C), foram realizados treinamentos de calibração dos examinadores. Foram treinados 15 cirurgiões-dentistas, sendo que a parte teórica do treinamento foi realizada em 4 horas e a parte prática em 16 horas. Os treinamentos de calibração tiveram como objetivo garantir a uniformidade de interpretação, compreensão e aplicação dos critérios para as várias condições estudadas, assegurar a uniformização e a padronização dos exames e minimizar as variações entre os diferentes examinadores.

Os cirurgiões-dentistas examinadores tiveram como anotadores as estudantes do curso de nutrição que após o exame bucal, procediam à verificação das medidas antropométricas dos idosos examinados. Os exames bucais e as medidas antropométricas foram realizados nos domicílios dos idosos. Procurou-se realizar os exames em local iluminado, amplo, com o idoso sentado e com a cabeça posicionada para trás e o examinador em frente a este.

Para a verificação da concordância interexaminadores para diagnóstico de cárie e condição periodontal, foi utilizado o coeficiente Kappa, sendo utilizada a concordância a cada elemento dentário entre os examinadores. Os valores da 
estatística Kappa obtidos foram de 0,90 para observação de cárie e de 0,83 para a condição periodontal.

Para os exames foram utilizadas sondas CPI, espelhos bucais planos número 5 e espátulas de madeira.

As análises estatísticas foram efetuadas usando-se três pacotes estatísticos: Epi Info 6.0, Stata versão 6 e SPSS versão 13.0. O programa Epi Info foi usado para o cálculo do índice CPOD e da freqüência de seus componentes. Os programas Stata e SPSS foram usados para verificar a distribuição das freqüências das variáveis em estudo, suas médias e variabilidade. Para todos os testes estatísticos adotou-se nível de significância de 5\%. 


\section{4 - RESULTADOS}

O tamanho da amostra examinada foi de 1.212 idosos entrevistados no ano 2000 e representaram 515.040 pessoas de 65 anos de idade e mais. A inferência é permitida devido às características do cálculo da amostra. Cada idoso participante representou um número de idosos com as mesmas características de idade, sexo, condição socioeconômica e setor censitário onde era domiciliado.

As fichas dos exames foram digitadas no programa Epi Data versão 3.0., num total de 153.924 toques, sendo 117 incorretos, perfazendo $0,08 \%$ de erros de digitação.

A idade média entre as mulheres foi de 74,37 anos $( \pm 6,89)$ e entre os homens foi de 73,45 anos $( \pm 6,17)$. Na composição da população, $61,4 \%$ eram mulheres e $38,6 \%$ eram homens. (Tabela 1 )

Tabela 1. Número de idosos, média de idade, desvio padrão e percentual na população segundo sexo. Município de São Paulo, 2006.

\begin{tabular}{ccccc}
\hline Sexo & $\mathrm{n}$ & $\begin{array}{c}\text { Média de } \\
\text { idade }\end{array}$ & DP & $\%$ \\
\hline Feminino & 316.168 & 74,37 & 6,89 & 61,40 \\
Masculino & 198.872 & 73,45 & 6,17 & 38,60 \\
\hline Total & 515.040 & 74,02 & 6,63 & 100,00 \\
\hline
\end{tabular}




\subsection{Cárie dentária}

As tabelas 2 e 3 mostram o número de dentes hígidos $(\mathrm{H})$, cariados $(\mathrm{C})$, perdidos $(\mathrm{P})$ e restaurados $(\mathrm{O})$ na população examinada. $\mathrm{O}$ número de dentes perdidos $(\mathrm{P})$ tanto em mulheres quanto em homens é consideravelmente maior do que a soma do número de dentes hígidos $(\mathrm{H})$, cariados e restaurados nas populações estudadas. Embora as perdas dentárias sejam grandes em ambos os sexos, as mulheres mostraram-se mais mutiladas em sua saúde bucal com maior número de dentes cariados, perdidos e restaurados.

Tabela 2 - Número de mulheres, dentes hígidos, cariados, perdidos, restaurados e CPOD em mulheres segundo faixa etária. Município de São Paulo, 2006.

\begin{tabular}{rcccccc}
\hline $\begin{array}{r}\text { Faixa } \\
\text { etária }\end{array}$ & $\mathrm{n}$ & $\mathrm{H}$ & $\mathrm{C}$ & $\mathrm{P}$ & $\mathrm{O}$ & $\mathrm{CPOD}$ \\
\hline $65 \mid-169$ & 95.870 & 268.018 & 145.736 & 2.421 .222 & 232.831 & 2.799 .789 \\
$70 \mid-174$ & 79.234 & 191.330 & 93.252 & 2.117 .296 & 267.342 & 2.344 .219 \\
$75 \mid-179$ & 72.752 & 141.479 & 64.868 & 2.019 .626 & 204.162 & 2.186 .575 \\
$80 \mathrm{e}+$ & 68.312 & 72.846 & 27.143 & 2.040 .327 & 91.370 & 2.113 .155 \\
\hline Total & 316.168 & 673.673 & 330.999 & 8.598 .471 & 795.705 & 9.443 .738 \\
\hline
\end{tabular}

Tabela 3 - Número de homens, dentes hígidos, cariados, perdidos, restaurados e CPOD em homens, segundo faixa etária. Município de São Paulo, 2006.

\begin{tabular}{lcccccc}
\hline $\begin{array}{r}\text { Faixa } \\
\text { etária }\end{array}$ & $\mathrm{n}$ & $\mathrm{H}$ & $\mathrm{C}$ & $\mathrm{P}$ & $\mathrm{O}$ & $\mathrm{CPOD}$ \\
\hline 65 -169 & 70.306 & 429.276 & 109.091 & 1.559 .471 & 149.386 & 1.817 .948 \\
$70 \mid-174$ & 52.721 & 252.951 & 84.070 & 1.241 .658 & 108.379 & 1.434 .107 \\
75 -I79 & 40.374 & 132.763 & 89.525 & 1.001 .452 & 68.211 & 1.159 .188 \\
80 e mais & 35.471 & 92.055 & 53.408 & 940.749 & 47.961 & 1.042 .118 \\
\hline Total & 198.872 & 907.045 & 336.094 & 4.743 .330 & 373.937 & 5.453 .361 \\
\hline
\end{tabular}


Tabela 4 - Média dos componentes e do índice CPOD em mulheres, segundo faixa etária. Município de São Paulo, 2006.

\begin{tabular}{lcccc} 
Faixa etária & $\overline{\mathrm{C}}$ & $\overline{\mathrm{P}}$ & $\overline{\mathrm{O}}$ & $\overline{\mathrm{CPOD}}$ \\
\hline 65I-|69 & 1,52 & 25,25 & 2,43 & 29,20 \\
70|-174 & 1,17 & 26,72 & 3,37 & 29,59 \\
75I-179 & 0,89 & 27,76 & 2,81 & 30,06 \\
80 e mais & 0,39 & 29,87 & 1,34 & 30,93 \\
\hline Total & 1,05 & 27,23 & 1,63 & 29,90 \\
\hline C = cariado; $\mathrm{P}=$ perdido; $\mathrm{O}=$ restaurado & & &
\end{tabular}

Tabela 5 - Média dos componentes e do índice CPOD em homens segundo faixa etária. Município de São Paulo, 2006.

\begin{tabular}{lcccc} 
Faixa etária & $\overline{\mathrm{C}}$ & $\overline{\mathrm{P}}$ & $\overline{\mathrm{O}}$ & $\overline{\mathrm{CPOD}}$ \\
\hline 65I-I69 & 1,55 & 22,18 & 2,12 & 25,86 \\
$70 \mid-174$ & 1,59 & 23,55 & 2,05 & 27,20 \\
75I-I79 & 2,21 & 24,80 & 1,68 & 28,71 \\
80 e mais & 1,50 & 26,52 & 1,35 & 29,38 \\
\hline Total & 1,68 & 23,81 & 1,87 & 27,37 \\
\hline C = cariado; P= perdido; $\mathrm{O}=$ restaurado
\end{tabular}

A média dos componentes do índice CPOD das populações estudadas mostra que os homens possuem maior número de dentes cariados e menor número de dentes perdidos e restaurados que as mulheres, resultando num menor índice CPOD em todas as faixas etárias.

Tabela 6 - Média dos componentes e do índice CPOD na população de idosos, segundo faixa etária. Município de São Paulo, 2006.

\begin{tabular}{lcccc}
\hline \multicolumn{1}{c}{ Faixa etária } & $\overline{\mathrm{C}}$ & $\overline{\mathrm{P}}$ & $\overline{\mathrm{O}}$ & $\overline{\mathrm{CPOD}}$ \\
\hline 65 -169 & 1,53 & 23,95 & 2,30 & 27,78 \\
$70 \mid-174$ & 1,34 & 25,46 & 1,83 & 28,63 \\
75|-179 & 1,36 & 26,71 & 1,51 & 29,58 \\
80 e mais & 0,78 & 28,72 & 0,90 & 30,40 \\
\hline Total & 4,31 & 25,90 & 1,72 & 28,92 \\
\hline C = cariado; P = perdido; O = restaurado & & &
\end{tabular}


Com o aumento da idade aumenta também o índice CPOD devido ao aumento do componente perdido (Tabela 6).

Tabela 7 - Composição percentual do índice CPOD em mulheres, segundo faixa etária. Município de São Paulo, 2006.

\begin{tabular}{lcccc}
\hline \multicolumn{1}{c}{ Faixa etária } & $\mathrm{C}$ & $\mathrm{P}$ & $\mathrm{O}$ & $\mathrm{CPOD}$ \\
\hline $65|-| 69$ & 6,0 & 86,0 & 8,0 & 100,0 \\
$70 \mid-174$ & 3,0 & 88,0 & 9,0 & 100,0 \\
$75|-| 79$ & 2,0 & 90,0 & 8,0 & 100,0 \\
80 e mais & 1,0 & 95,0 & 4,0 & 100,0 \\
Total & 1,2 & 96,5 & 2,3 & 100,0 \\
C = cariado; $\mathrm{P}=$ perdido; $\mathrm{O}=$ restaurado & & &
\end{tabular}

Tabela 8 - Composição percentual do índice CPOD em homens, segundo faixa etária. Município de São Paulo, 2006.

\begin{tabular}{lcccc}
\hline Faixa etária & $\mathrm{C}$ & $\mathrm{P}$ & $\mathrm{O}$ & $\mathrm{CPOD}$ \\
\hline $65|-| 69$ & 6,0 & 86,0 & 8,0 & 100,0 \\
$70 \mid-174$ & 5,0 & 87,0 & 8,0 & 100,0 \\
$75|-| 79$ & 8,0 & 86,0 & 6,0 & 100,0 \\
80 e mais & 5,0 & 90,0 & 5,0 & 100,0 \\
\hline Total & 6,2 & 87,0 & 6,8 & 100,0 \\
\hline C cariado; $\mathrm{P}=$ perdido; $\mathrm{O}=$ restaurado & & &
\end{tabular}

Quanto à composição percentual do índice CPOD, as tabelas 7 e 8 mostram que o componente cariado teve maior participação no índice CPOD dos homens. $\mathrm{O}$ componente $\mathrm{P}$ teve alta participação em ambas as populações embora tenha sido maior nas mulheres. O componente restaurado $(\mathrm{O})$ teve maior participação na população feminina. 
Tabela 9 - Média do índice CPOD e desvio padrão segundo sexo e faixa etária.

Município de são Paulo, 2006.

\begin{tabular}{lcccccccccc}
\hline \multicolumn{1}{c}{$\begin{array}{c}\text { Faixa } \\
\text { etária }\end{array}$} & $\mathrm{n}$ & $\begin{array}{c}\text { Média } \\
\text { CPOD }\end{array}$ & DP & LI & LS & $\mathrm{n}$ & Média & DP & LI & LS \\
\hline $65 \mid-169$ & 95.870 & 29,20 & 3,96 & 29,18 & 29,23 & 70.306 & 25,86 & 6,42 & 25,81 & 25,91 \\
$70 \mid-174$ & 79.234 & 29,59 & 4,42 & 29,55 & 29,61 & 52.720 & 27,02 & 6,30 & 27,15 & 27,26 \\
$75 \mid-179$ & 72.752 & 30,06 & 3,72 & 30,03 & 30,08 & 40.373 & 28,71 & 4,29 & 28,68 & 28,76 \\
80 e mais & 68.311 & 30,93 & 2,37 & 30,92 & 30,96 & 35.470 & 29,38 & 4,16 & 29,33 & 29,42 \\
\hline Total & 316.168 & 29,87 & 3,80 & 29,85 & 29,89 & 198.872 & 27,42 & 5,82 & 27,40 & 27,44
\end{tabular}

$\mathrm{DP}=$ desvio padrão; $\mathrm{LI}=$ limite inferior; $\mathrm{LS}=$ limite superior

A média do índice CPOD foi maior entre as mulheres. À medida que a idade aumentou, aumentou também o valor da média do índice com crescente participação do componente perdido, como mostrado em tabelas anteriores. 
Tabela 10 - Distribuição percentual dos valores do índice CPOD, em mulheres, segundo faixa etária. Município de São Paulo, 2006.

\begin{tabular}{|c|c|c|c|c|}
\hline \multirow{2}{*}{ CPOD } & \multicolumn{4}{|c|}{ Faixa etária } \\
\hline & $65|-| 69$ & $70 \mid-174$ & $75|-| 79$ & 80 e mais \\
\hline 7 & 0,68 & - & - & - \\
\hline 13 & - & 0,88 & - & - \\
\hline 14 & 0,50 & 0,65 & - & - \\
\hline 15 & 0,63 & 0,64 & - & - \\
\hline 16 & 0,59 & 1,37 & 2,54 & - \\
\hline 17 & - & 0,59 & - & - \\
\hline 18 & - & 1,27 & 0,59 & 0,21 \\
\hline 19 & - & 0,63 & - & 0,21 \\
\hline 20 & - & 1,96 & - & - \\
\hline 21 & 0,59 & 0,82 & 0,90 & - \\
\hline 22 & 1,94 & 0,64 & 2,04 & 1,04 \\
\hline 23 & 1,77 & 0,35 & 1,22 & 0,39 \\
\hline 24 & 2,45 & 0,74 & 2,81 & 0,87 \\
\hline 25 & 4,09 & 0,54 & 0,09 & 1,08 \\
\hline 26 & 10,02 & 7,46 & 6,98 & 5,59 \\
\hline 27 & 6,49 & 2,81 & 1,96 & 3,22 \\
\hline 28 & 6,12 & 3,35 & 4,54 & 3,06 \\
\hline 29 & 3,39 & 3,58 & 2,01 & 2,77 \\
\hline 30 & 5,87 & 2,63 & 1,95 & 0,82 \\
\hline 31 & 4,99 & 5,44 & 1,26 & 0,77 \\
\hline 32 & 49,87 & 63,65 & 71,10 & 79,97 \\
\hline
\end{tabular}


Tabela 11 - Distribuição percentual dos valores do índice CPOD, em homens, segundo faixa etária. Município de São Paulo, 2006.

\begin{tabular}{|c|c|c|c|c|}
\hline \multirow{2}{*}{ CPOD } & \multicolumn{4}{|c|}{ Faixa etária } \\
\hline & $65|-| 69$ & $70|-| 74$ & $75|-| 79$ & $801-+$ \\
\hline 8 & - & 1,46 & - & - \\
\hline 9 & 1,37 & 1,24 & - & - \\
\hline 10 & - & 1,43 & - & - \\
\hline 11 & 1,05 & - & - & - \\
\hline 12 & - & 0,97 & - & - \\
\hline 13 & 3,97 & - & - & 0,63 \\
\hline 14 & 1,01 & 1,44 & - & 0,61 \\
\hline 15 & 1,93 & 2,84 & 1,26 & - \\
\hline 16 & - & - & - & 0,65 \\
\hline 17 & 4,20 & 0,22 & - & 0,62 \\
\hline 18 & 5,32 & - & 3,42 & 0,59 \\
\hline 19 & 2,01 & 1,17 & 1,50 & 1,11 \\
\hline 20 & - & 0,18 & - & - \\
\hline 21 & 3,89 & 1,35 & 1,08 & 3,09 \\
\hline 22 & 3,51 & 8,00 & 3,30 & 1,47 \\
\hline 23 & 2,79 & 6,55 & 3,63 & 1,87 \\
\hline 24 & 4,63 & 1,52 & 4,76 & 3,75 \\
\hline 25 & 6,01 & 4,13 & 1,29 & 3,26 \\
\hline 26 & 6,73 & 3,87 & 5,12 & 3,88 \\
\hline 27 & 5,27 & 5,05 & 7,90 & 0,83 \\
\hline 28 & 1,07 & 3,62 & 4,24 & 5,11 \\
\hline 29 & 3,13 & 1,21 & 5,11 & 5,37 \\
\hline 30 & 1,80 & 4,08 & 2,69 & 5,81 \\
\hline 31 & 4,36 & 1,16 & 7,55 & 2,69 \\
\hline 32 & 35,94 & 48,53 & 47,15 & 58,66 \\
\hline
\end{tabular}


As tabelas 10 e 11 mostram que a maioria da população de idosos do Município de São Paulo, apresentou índice CPOD igual a 32.

\section{2 - Necessidades de tratamento}

Tabela 12 - Número e porcentagem de dentes com e sem necessidades de tratamento em mulheres segundo faixa etária. Município de São Paulo, 2006.

\begin{tabular}{lccccccccc}
\hline \multirow{2}{*}{$\begin{array}{c}\text { Necessidades de } \\
\text { tratamento }\end{array}$} & \multicolumn{1}{c}{$65|-| 69$} & \multicolumn{9}{c}{ Faixa etária } \\
& $\mathrm{n}$ & $\%$ & $\mathrm{n}$ & $\%$ & $\mathrm{n}$ & $\%$ & $\mathrm{n}$ & $\%$ \\
\hline Com necessidades & 29.629 & 5,00 & 40.645 & 10,00 & 30.676 & 10,00 & 14.618 & 10,00 \\
& & & & & & & & \\
Sem necessidades & 618.716 & 95,00 & 369.899 & 90,00 & 281.978 & 90,00 & 131.652 & 90,00 \\
\hline Total & 648.345 & 100,00 & 410.544 & 100,00 & 312.654 & 100,00 & 146.270 & 100,00 \\
\hline
\end{tabular}

Tabela 13 - Número e porcentagem de dentes com e sem necessidades de tratamento em homens segundo faixa etária. Município de São Paulo, 2006.

\begin{tabular}{lccccccccc}
\hline $\begin{array}{c}\text { Necessidades de } \\
\text { tratamento }\end{array}$ & \multicolumn{1}{c}{$65 \mid-169$} & \multicolumn{9}{c}{ Faixa etária } \\
& $\mathrm{n}$ & $\%$ & $\mathrm{n}$ & $\%$ & $\mathrm{n}$ & $\%$ & $\mathrm{n}$ & $\%$ \\
\hline Com necessidades & 54.961 & 8,00 & 44.723 & 6,77 & 39.770 & 13,67 & 50.103 & 25,65 \\
& & & & & & & & \\
Sem necessidades & 636.086 & 92,00 & 616.282 & 93,23 & 251.178 & 86,33 & 145.225 & 74,35 \\
\hline Total & 691.047 & 100,00 & 661.005 & 100,00 & 290.948 & 100,00 & 195.328 & 100,00 \\
\hline
\end{tabular}

Com exceção da faixa etária de 70 a 74 anos, os homens demandaram maior necessidades de tratamento que as mulheres, tendo em vista possuírem um maior número de dentes remanescentes. 
Tabela 14 - Número e porcentagem de necessidades de tratamento em mulheres segundo o tipo de necessidade e faixa etária. Município de São Paulo, 2006.

\begin{tabular}{|c|c|c|c|c|c|c|c|c|}
\hline \multirow{3}{*}{$\begin{array}{c}\text { Tipo de } \\
\text { Necessidades }\end{array}$} & \multicolumn{8}{|c|}{ Faixa etária } \\
\hline & \multicolumn{2}{|c|}{$65|-| 69$} & \multicolumn{2}{|c|}{$70 \mid-174$} & \multicolumn{2}{|c|}{$75 \mid-179$} & \multicolumn{2}{|c|}{80 e mais } \\
\hline & $\mathrm{n}$ & $\%$ & $\mathrm{n}$ & $\%$ & $\mathrm{n}$ & $\%$ & $\mathrm{n}$ & $\%$ \\
\hline $\begin{array}{l}\text { Restauração de } \\
\text { uma superfície }\end{array}$ & 13.877 & 38,65 & 14.834 & 30,69 & 14.454 & 54,66 & 5.706 & 39,03 \\
\hline $\begin{array}{l}\text { Restauração de } \\
\text { duas ou mais } \\
\text { superfícies }\end{array}$ & 5.697 & 15,87 & 11.521 & 23,84 & 6.847 & 25,89 & 848 & 5,80 \\
\hline $\begin{array}{l}\text { Coroa por } \\
\text { qualquer razão }\end{array}$ & 2.429 & 6,77 & 2.208 & 4,57 & - & - & - & - \\
\hline $\begin{array}{l}\text { Tratamento } \\
\text { endodôntico } \\
\text { mais restauração }\end{array}$ & 578 & 1,61 & - & - & 667 & 2,52 & 141 & 0,96 \\
\hline Exodontia & 13.322 & 37,11 & 19.773 & 40,91 & 4.476 & 16,93 & 7.923 & 54,20 \\
\hline Total & 35.903 & 100,00 & 48.336 & 100,00 & 26.444 & 100,00 & 14.618 & 100,00 \\
\hline
\end{tabular}

Tabela 15 - Número e porcentagem de necessidades de tratamento em homens segundo o tipo de necessidade e faixa etária. Município de São Paulo, 2006.

\begin{tabular}{|c|c|c|c|c|c|c|c|c|}
\hline \multirow{3}{*}{$\begin{array}{c}\text { Tipo de } \\
\text { Necessidades }\end{array}$} & \multicolumn{8}{|c|}{ Faixa etária } \\
\hline & \multicolumn{2}{|c|}{$65 \mid-169$} & \multicolumn{2}{|c|}{$70 \mid-174$} & \multicolumn{2}{|c|}{$75 \mid-179$} & \multicolumn{2}{|c|}{80 e mais } \\
\hline & $\mathrm{n}$ & $\%$ & $\mathrm{n}$ & $\%$ & $\mathrm{n}$ & $\%$ & $\mathrm{n}$ & $\%$ \\
\hline $\begin{array}{l}\text { Restauração de uma } \\
\text { superfície }\end{array}$ & 31.970 & 58,17 & 18.071 & 40,41 & 12.191 & 30,65 & 19.158 & 38,24 \\
\hline $\begin{array}{l}\text { Restauração de duas } \\
\text { ou mais superfícies }\end{array}$ & 4.932 & 8,97 & 2.901 & 6,49 & 7.189 & 18,08 & 8.366 & 16,70 \\
\hline $\begin{array}{l}\text { Coroa por qualquer } \\
\text { razão }\end{array}$ & 1.965 & 3,58 & 2.719 & 6,08 & 3.415 & 8,59 & 605 & 1,21 \\
\hline $\begin{array}{l}\text { Tratamento } \\
\text { endodôntico mais } \\
\text { restauração }\end{array}$ & 711 & 1,29 & 672 & 1,50 & - & - & 555 & 1,11 \\
\hline Exodontia & 15.383 & 27,99 & 20.360 & 45,52 & 16.975 & 42,68 & 21.419 & 42,75 \\
\hline Total & 54.961 & 100,00 & 44.723 & 100,00 & 39.770 & 100,00 & 50.103 & 100,00 \\
\hline
\end{tabular}


As tabelas 14 e 15 mostram que mais da metade da demanda por serviços odontológicos foi para restaurações de uma ou mais superfícies, coroa e tratamento endodôntico. 


\section{3 - Condição periodontal \\ 4.3.1 - Doença Periodontal}

Tabela 16 - Número e percentual de sextantes superiores em mulheres segundo condição do sextante e faixa etária. Município de São Paulo, 2006.

\begin{tabular}{|c|c|c|c|c|c|c|c|c|c|c|}
\hline \multirow{3}{*}{$\begin{array}{l}\text { Condição do } \\
\text { sextante }\end{array}$} & \multicolumn{8}{|c|}{ Faixa etária } & \multirow{2}{*}{\multicolumn{2}{|c|}{ Total }} \\
\hline & \multicolumn{2}{|c|}{$65|-| 69$} & \multicolumn{2}{|c|}{$70 \mid-174$} & \multicolumn{2}{|c|}{$75|-| 79$} & \multicolumn{2}{|c|}{80 e mais } & & \\
\hline & $\mathrm{n}$ & $\%$ & $\mathrm{n}$ & $\%$ & $\mathrm{n}$ & $\%$ & $\mathrm{n}$ & $\%$ & $\mathrm{n}$ & $\%$ \\
\hline Sadio & 14.270 & 4,96 & 11.872 & 4,13 & 8.252 & 2,87 & 3.270 & 1,14 & 37.664 & 3,98 \\
\hline Sangramento & 9.061 & 3,15 & 6.280 & 2,64 & 3.842 & 1,76 & 2.374 & 1,16 & 21.557 & 2,27 \\
\hline Cálculo & 5.599 & 1,95 & 3.228 & 1,36 & 4.540 & 2,08 & 795 & 0,39 & 14.162 & 1,49 \\
\hline Bolsa de 3 a $4 \mathrm{~mm}$ & 5.336 & 1,86 & 2.699 & 1,14 & 3.043 & 1,39 & 901 & 0,44 & 11.979 & 1,26 \\
\hline Bolsa mais $6 \mathrm{~mm}$ & 653 & 0,23 & - & - & 747 & 0,34 & 141 & 0,07 & 1.541 & 0,16 \\
\hline Nulos & 252.691 & 87,86 & 213.623 & 89,87 & 197.832 & 90,64 & 197.452 & 96,35 & 861.598 & 90,84 \\
\hline Total & 287.605 & 100,00 & 237.707 & 100,00 & 218.260 & 100,00 & 204.935 & 100,00 & 948.507 & 100,00 \\
\hline
\end{tabular}


Tabela 17 - Número e percentual de sextantes superiores em homens segundo condição do sextante e faixa etária. Município de São Paulo, 2006.

\begin{tabular}{|c|c|c|c|c|c|c|c|c|c|c|}
\hline \multirow{3}{*}{ Condição do sextante } & \multicolumn{8}{|c|}{ Faixa etária } & \multirow{2}{*}{\multicolumn{2}{|c|}{ Total }} \\
\hline & \multicolumn{2}{|c|}{$65|-| 69$} & \multicolumn{2}{|c|}{$70 \mid-174$} & \multicolumn{2}{|c|}{$75 \mid-179$} & \multicolumn{2}{|c|}{80 e mais } & & \\
\hline & $\mathrm{n}$ & $\%$ & $\mathrm{n}$ & $\%$ & $\mathrm{n}$ & $\%$ & $\mathrm{n}$ & $\%$ & $\mathrm{n}$ & $\%$ \\
\hline Sadio & 23.618 & 11,20 & 13.799 & 8,72 & 5.461 & 4,51 & 4.785 & 4,50 & 47.663 & 7,99 \\
\hline Sangramento & 7.541 & 3,58 & 7.048 & 4,46 & 6.894 & 5,69 & 4.476 & 4,21 & 25.959 & 4,35 \\
\hline Cálculo & 6.151 & 2,92 & 4.296 & 2,72 & 4.542 & 3,75 & 2.378 & 2,23 & 17.367 & 2,91 \\
\hline Bolsa de 3 a $4 \mathrm{~mm}$ & 4.924 & 2,33 & 3.371 & 2,13 & 1.799 & 1,49 & 1.491 & 1,40 & 11.585 & 1,94 \\
\hline Bolsa mais $6 \mathrm{~mm}$ & 3.448 & 1,63 & - & - & 474 & 0,39 & 241 & 0,23 & 4.163 & 0,70 \\
\hline Nulos & 165.236 & 78,34 & 129.649 & 81,97 & 101.952 & 84,17 & 93.042 & 87,43 & 489.879 & 82,11 \\
\hline Total & 210.940 & 100,00 & 158.181 & 100,00 & 121.138 & 100,00 & 106.426 & 100,00 & 596.645 & 100,00 \\
\hline
\end{tabular}


Tabela 18 - Número e percentual de sextantes inferiores em mulheres segundo condição do sextante e faixa etária. Município de São Paulo, 2006.

\begin{tabular}{|c|c|c|c|c|c|c|c|c|c|c|}
\hline \multirow{3}{*}{ Condição do sextante } & \multicolumn{8}{|c|}{ Faixa etária } & \multirow{2}{*}{\multicolumn{2}{|c|}{ Total }} \\
\hline & \multicolumn{2}{|c|}{$65 \mid-169$} & \multicolumn{2}{|c|}{$70 \mid-174$} & \multicolumn{2}{|c|}{$751-179$} & \multicolumn{2}{|c|}{80 e mais } & & \\
\hline & $\mathrm{n}$ & $\%$ & $\mathrm{n}$ & $\%$ & $\mathrm{n}$ & $\%$ & $\mathrm{n}$ & $\%$ & $\mathrm{n}$ & $\%$ \\
\hline Sadio & 24.254 & 8,43 & 16.156 & 6,80 & 9.720 & 4,45 & 5.580 & 2,72 & 55.710 & 5,87 \\
\hline Sangramento & 14.381 & 5,00 & 9.109 & 3,83 & 6.603 & 3,03 & 4.152 & 2,03 & 34.245 & 3,61 \\
\hline Cálculo & 14.487 & 5,04 & 10.916 & 4,59 & 10.255 & 4,70 & 4.884 & 2,38 & 40.542 & 4,27 \\
\hline Bolsa de 3 a $4 \mathrm{~mm}$ & 4.361 & 1,52 & 4.173 & 1,76 & 1.845 & 0,85 & 1.775 & 0,87 & 12.154 & 1,28 \\
\hline Bolsa mais $6 \mathrm{~mm}$ & 1.999 & 0,70 & 516 & 0,22 & 1.113 & 0,51 & 141 & 0,07 & 3.769 & 0,40 \\
\hline Nulos & 228.123 & 79,31 & 196.837 & 82,80 & 188.724 & 86,46 & 188.403 & 91,93 & 802.087 & 84,56 \\
\hline Total & 287.605 & 100,00 & 237.707 & 100,00 & 218.260 & 100,00 & 204.935 & 100,00 & 948.507 & 100,00 \\
\hline
\end{tabular}


Tabela 19 - Número e percentual de sextantes inferiores em homens segundo condição do sextante e faixa etária. Município de São Paulo, 2006.

\begin{tabular}{|c|c|c|c|c|c|c|c|c|c|c|}
\hline \multirow{3}{*}{ Condição do sextante } & \multicolumn{8}{|c|}{ Faixa etária } & \multirow{2}{*}{\multicolumn{2}{|c|}{ Total }} \\
\hline & \multicolumn{2}{|c|}{$65 \mid-169$} & \multicolumn{2}{|c|}{$70 \mid-174$} & \multicolumn{2}{|c|}{$75 \mid-179$} & \multicolumn{2}{|c|}{80 e mais } & & \\
\hline & $\mathrm{n}$ & $\%$ & $\mathrm{n}$ & $\%$ & $\mathrm{n}$ & $\%$ & $\mathrm{n}$ & $\%$ & $\mathrm{n}$ & $\%$ \\
\hline Sadio & 19.739 & 9,36 & 13.401 & 8,47 & 7.305 & 6,03 & 5.204 & 4,89 & 45.649 & 7,65 \\
\hline Sangramento & 13.266 & 6,29 & 11.796 & 7,46 & 8.921 & 7,36 & 5.525 & 5,19 & 39.508 & 6,62 \\
\hline Cálculo & 19.955 & 9,46 & 8.995 & 5,69 & 10.513 & 8,68 & 4.435 & 4,17 & 43.898 & 7,36 \\
\hline Bolsa de 3 a $4 \mathrm{~mm}$ & 7.376 & 3,50 & 3.002 & 1,90 & 2.784 & 2,30 & 2.304 & 2,16 & 15.466 & 2,59 \\
\hline Bolsa mais $6 \mathrm{~mm}$ & 3.803 & 1,80 & - & - & - & & 924 & 0,87 & 4.727 & 0,79 \\
\hline Nulos & 146.801 & 69,59 & 120.987 & 76,48 & 91.615 & 75,63 & 87.854 & 82,55 & 447.257 & 74,96 \\
\hline Total & 210.940 & 100,00 & 158.181 & 100,00 & 121.138 & 100,00 & 106.426 & 100,00 & 596.685 & 100,00 \\
\hline
\end{tabular}


A avaliação periodontal foi realizada em $17,89 \%$ dos sextantes superiores e 15,43\% dos sextantes inferiores nas mulheres, e em $21,78 \%$ dos sextantes superiores e 33,36\% dos sextantes inferiores nos homens.

As mulheres apresentaram maior número de sextantes nulos e menor número de sextantes sadios.

Sangramento, cálculo e bolsas periodontais foram mais prevalentes nos homens. 


\subsection{2 - Perda de inserção periodontal}

Tabela 20 - Número e percentual de sextantes superiores em mulheres segundo condição do sextante e faixa etária. Município de São Paulo, 2006.

\begin{tabular}{|c|c|c|c|c|c|c|c|c|c|c|}
\hline \multirow{3}{*}{$\begin{array}{l}\text { Condição do } \\
\text { sextante }\end{array}$} & \multicolumn{8}{|c|}{ Faixa etária } & \multirow{2}{*}{\multicolumn{2}{|c|}{ Total }} \\
\hline & \multicolumn{2}{|c|}{$65|-| 69$} & \multicolumn{2}{|c|}{$70 \mid-174$} & \multicolumn{2}{|c|}{$75 \mid-179$} & \multicolumn{2}{|c|}{80 e mais } & & \\
\hline & $\mathrm{n}$ & $\%$ & $\mathrm{n}$ & $\%$ & $\mathrm{n}$ & $\%$ & $\mathrm{n}$ & $\%$ & $\mathrm{n}$ & $\%$ \\
\hline Perda de $0|-| 3 \mathrm{~mm}$ & 41.008 & 14,26 & 27.899 & 11,74 & 20.482 & 9,38 & 5.069 & 2,46 & 94.458 & 9,96 \\
\hline Perda de $4 \mid-15 \mathrm{~mm}$ & 10.867 & 3,78 & 9.012 & 3,79 & 5.209 & 2,39 & 3.058 & 1,48 & 28.146 & 2,97 \\
\hline Perda de $61-18 \mathrm{~mm}$ & 7.583 & 2,64 & 1.562 & 0,66 & 3.383 & 1,55 & 1.439 & 0,70 & 13.967 & 1,47 \\
\hline Perda de 9|-|11 mm & 1.281 & 0,45 & - & - & 236 & 0,11 & 578 & 0,27 & 2.095 & 0,22 \\
\hline Perda de $12 \mathrm{l}-\mathrm{mm}$ & 599 & 0,21 & - & - & - & - & - & - & 599 & 0,06 \\
\hline Não examinados & - & - & - & - & - & - & 468 & 0,22 & 468 & 0,05 \\
\hline Nulos & 226.267 & 78,66 & 199.234 & 83,81 & 188.950 & 86,57 & 194.791 & 95,05 & 809.242 & 85,32 \\
\hline Total & 287.605 & 100,00 & 237.707 & 100,00 & 218.260 & 100,00 & 204.935 & 100,00 & 948.507 & 100,00 \\
\hline
\end{tabular}


Tabela 21 - Número e percentual de sextantes superiores em homens segundo condição do sextante e faixa etária. Município de São Paulo, 2006.

\begin{tabular}{|c|c|c|c|c|c|c|c|c|c|c|}
\hline \multirow{3}{*}{$\begin{array}{l}\text { Condição do } \\
\text { sextante }\end{array}$} & \multicolumn{8}{|c|}{ Faixa etária } & \multirow{2}{*}{\multicolumn{2}{|c|}{ Total }} \\
\hline & \multicolumn{2}{|c|}{$65|-| 69$} & \multicolumn{2}{|c|}{$70 \mid-174$} & \multicolumn{2}{|c|}{ 75I-179 } & \multicolumn{2}{|c|}{80 e mais } & & \\
\hline & $\mathrm{n}$ & $\%$ & $\mathrm{n}$ & $\%$ & $\mathrm{n}$ & $\%$ & $\mathrm{n}$ & $\%$ & $\mathrm{n}$ & $\%$ \\
\hline Perda de $0 \mathrm{I}-13 \mathrm{~mm}$ & 31.187 & 14,78 & 27.255 & 17,23 & 16.709 & 13,79 & 10.378 & 9,75 & 85.529 & 14,32 \\
\hline Perda de $4 \mid-51 \mathrm{~mm}$ & 19.332 & 9,16 & 10.367 & 6,55 & 6.211 & 5,13 & 3.951 & 3,71 & 39.861 & 6,67 \\
\hline Perda de $61-18 \mathrm{~mm}$ & 8.916 & 4,23 & 5.870 & 3,71 & 2.322 & 1,92 & 3.137 & 2,95 & 20.245 & 3,38 \\
\hline Perda de $9 /-\mid 11 \mathrm{~mm}$ & 7.047 & 3,34 & 904 & 0,57 & 1.304 & 1,08 & 205 & 0,19 & 9.460 & 1,58 \\
\hline Perda de $121-\mathrm{mm}$ & 662 & 0,31 & & - & - & - & 714 & 0,67 & 1.376 & 0,23 \\
\hline Não examinados & - & - & - & - & - & - & 116 & 0,10 & 116 & 0,02 \\
\hline Nulos & 143.796 & 68,18 & 113.785 & 71,94 & 94.592 & 78,08 & 88.041 & 82,72 & 440.330 & 73,80 \\
\hline Total & 210.940 & 100,00 & 158.181 & 100,00 & 121.138 & 100,00 & 106.426 & 100,00 & 596.645 & 100,00 \\
\hline
\end{tabular}


Tabela 22 - Número e percentual de sextantes inferiores em mulheres segundo condição do sextante e faixa etária. Município de São Paulo, 2006.

\begin{tabular}{|c|c|c|c|c|c|c|c|c|c|c|}
\hline \multirow{3}{*}{$\begin{array}{l}\text { Condição do } \\
\text { sextante }\end{array}$} & \multicolumn{8}{|c|}{ Faixa etária } & \multirow{2}{*}{\multicolumn{2}{|c|}{ Total }} \\
\hline & \multicolumn{2}{|c|}{$65|-| 69$} & \multicolumn{2}{|c|}{$70 \mid-174$} & \multicolumn{2}{|c|}{$75 \mid-179$} & \multicolumn{2}{|c|}{80 e mais } & & \\
\hline & $\mathrm{n}$ & $\%$ & $\mathrm{n}$ & $\%$ & $\mathrm{n}$ & $\%$ & $\mathrm{n}$ & $\%$ & $\mathrm{n}$ & $\%$ \\
\hline Perda de $0|-| 3 \mathrm{~mm}$ & 43.822 & 15,24 & 34.058 & 14,33 & 21.962 & 10,06 & 8.531 & 4,15 & 108.373 & 11,42 \\
\hline Perda de $4|-5| \mathrm{mm}$ & 22.525 & 7,83 & 16.654 & 7,01 & 13.589 & 6,23 & 6.673 & 3,24 & 59.441 & 6,26 \\
\hline Perda de $61-18 \mathrm{~mm}$ & 8.689 & 3,02 & 3.550 & 1,49 & 4.912 & 2,25 & 4.262 & 2,04 & 21.413 & 2,25 \\
\hline Perda de 9|-I11 mm & 1.663 & 0,58 & 1.923 & 0,81 & 381 & 0,17 & 1.518 & 0,74 & 5.485 & 0,57 \\
\hline Perda de $121-\mathrm{mm}$ & 0 & 0 & 646 & 0,27 & 0 & 0 & 0 & 0 & 646 & 0,06 \\
\hline Não examinados & 0 & 0 & 0 & 0 & 0 & 0 & 468 & 0,21 & 468 & 0,05 \\
\hline Nulos & 210.906 & 73,33 & 180.876 & 76,09 & 177.416 & 81,29 & 184.419 & 89,98 & 753.149 & 79,40 \\
\hline Total & 287.605 & 100,00 & 237.707 & 100,00 & 218.260 & 100,00 & 204.935 & 100,00 & 948.507 & 100,00 \\
\hline
\end{tabular}


Tabela 23 - Número e percentual de sextantes inferiores em homens segundo condição do sextante e faixa etária. Município de São Paulo, 2006.

\begin{tabular}{|c|c|c|c|c|c|c|c|c|c|c|}
\hline \multirow{3}{*}{$\begin{array}{l}\text { Condição do } \\
\text { sextante }\end{array}$} & \multicolumn{8}{|c|}{ Faixa etária } & \multirow{2}{*}{\multicolumn{2}{|c|}{ Total }} \\
\hline & \multicolumn{2}{|c|}{$65 \mid-169$} & \multicolumn{2}{|c|}{$70|-| 74$} & \multicolumn{2}{|c|}{$75 \mid-179$} & \multicolumn{2}{|c|}{80 e mais } & & \\
\hline & $\mathrm{n}$ & $\%$ & $\mathrm{n}$ & $\%$ & $\mathrm{n}$ & $\%$ & $\mathrm{n}$ & $\%$ & $\mathrm{n}$ & $\%$ \\
\hline Perda de $0|-| 3 \mathrm{~mm}$ & 33.139 & 15,71 & 29.474 & 18,63 & 15.879 & 13,11 & 7.890 & 7,39 & 86.382 & 14,47 \\
\hline Perda de $4|-5| \mathrm{mm}$ & 29.827 & 14,13 & 16.654 & 10,53 & 12.950 & 10,69 & 11.069 & 10,39 & 70.500 & 11,82 \\
\hline Perda de $61-18 \mathrm{~mm}$ & 19.236 & 9,12 & 5.589 & 3,53 & 8.616 & 7,11 & 2.658 & 2,47 & 36.099 & 6,04 \\
\hline Perda de $9|-| 11 \mathrm{~mm}$ & 4.801 & 2,28 & 2.078 & 1,32 & 1.611 & 1,33 & 1.481 & 1,38 & 9.971 & 1,67 \\
\hline Perda de $12 \mathrm{l}-\mathrm{mm}$ & 2.079 & 0,99 & - & - & - & - & 515 & 0,46 & 2.594 & 0,43 \\
\hline Não examinados & - & - & - & - & - & - & 116 & 0,1 & 116 & 0,02 \\
\hline Nulos & 121.858 & 57,77 & 104.386 & 65,99 & 82.082 & 67,76 & 82.813 & 77,81 & 391.139 & 65,55 \\
\hline Total & 210.940 & 100,00 & 158.181 & 100,00 & 121.138 & 100,00 & 106.426 & 100,00 & 596.645 & 100,00 \\
\hline
\end{tabular}


A verificação da perda de inserção periodontal foi realizada em $14,63 \%$ dos sextantes superiores e $20,55 \%$ dos sextantes inferiores nas mulheres, e em $26,18 \%$ dos sextantes superiores e em $34,01 \%$ dos sextantes inferiores, nos homens.

Perda de inserção de até $5 \mathrm{~mm}$ foi identificada em $77,89 \%$ dos sextantes.

Perda óssea de até $3 \mathrm{~mm}$ foi mais prevalente em ambos os sexos. 


\section{4 - Uso de Prótese Dentária}

Tabela 24 - Número e porcentagem de mulheres segundo o uso de prótese dentária superior e faixa etária. Município de São Paulo, 2006.

\begin{tabular}{|c|c|c|c|c|c|c|c|c|c|c|}
\hline \multirow{3}{*}{ Uso de prótese } & \multicolumn{8}{|c|}{ Faixa etária } & \multirow{2}{*}{\multicolumn{2}{|c|}{ Total }} \\
\hline & \multicolumn{2}{|c|}{$651-169$} & \multicolumn{2}{|c|}{$70 \mid-174$} & \multicolumn{2}{|c|}{ 75|-|79 } & \multicolumn{2}{|c|}{80 e mais } & & \\
\hline & $\mathrm{n}$ & $\%$ & $\mathrm{n}$ & $\%$ & $\mathrm{n}$ & $\%$ & $\mathrm{n}$ & $\%$ & $\mathrm{~N}$ & $\%$ \\
\hline Não usa prótese & 11.058 & 11,53 & 8.728 & 11,02 & 8.095 & 11,13 & 9.341 & 13,67 & 37.222 & 11,77 \\
\hline Usa prótese fixa & 7.059 & 7,37 & 3.322 & 4,19 & 1.966 & 2,70 & 977 & 1,43 & 13.324 & 4,21 \\
\hline Usa prótese removível & 9.940 & 10,36 & 6.752 & 8,52 & 6.402 & 8,80 & 4.720 & 6,91 & 27.814 & 8,80 \\
\hline Usa prótese fixa e removível & 665 & 0,69 & - & - & 1.072 & 1,47 & 588 & 0,86 & 2.325 & 0,74 \\
\hline Usa prótese total & 67.148 & 70,04 & 60.432 & 76,27 & 55.217 & 75,90 & 52.686 & 77,13 & 235.483 & 74,48 \\
\hline Total & 95.870 & 100,00 & 79.234 & 100,00 & 72.752 & 100,00 & 68.312 & 100,00 & 316.168 & 100,00 \\
\hline
\end{tabular}


Tabela 25 - Número e porcentagem de homens segundo o uso de prótese dentária superior e faixa etária. Município de São Paulo, 2006.

\begin{tabular}{|c|c|c|c|c|c|c|c|c|c|c|}
\hline \multirow{3}{*}{ Uso de prótese } & \multicolumn{8}{|c|}{ Faixa etária } & \multirow{2}{*}{\multicolumn{2}{|c|}{ Total }} \\
\hline & \multicolumn{2}{|c|}{$65|-| 69$} & \multicolumn{2}{|c|}{$70 \mid-174$} & \multicolumn{2}{|c|}{$75 \mid-179$} & \multicolumn{2}{|c|}{80 e mais } & & \\
\hline & $\mathrm{n}$ & $\%$ & $\mathrm{n}$ & $\%$ & $\mathrm{n}$ & $\%$ & $\mathrm{n}$ & $\%$ & $\mathrm{n}$ & $\%$ \\
\hline Não usa prótese & 22.256 & 31,70 & 17.695 & 33,56 & 10.855 & 26,88 & 8.642 & 24,36 & 59.448 & 29,89 \\
\hline Usa prótese fixa & 1.289 & 1,82 & 609 & 1,16 & 2.524 & 6,25 & 410 & 1,16 & 4.832 & 2,43 \\
\hline Usa prótese parcial removível & 10.432 & 14,82 & 6.752 & 11,86 & 5.957 & 14,75 & 4.961 & 13,99 & 27.602 & 13,88 \\
\hline Usa prótese fixa e removível & 740 & 1,04 & - & - & - & - & - & - & 740 & 0,37 \\
\hline Usa prótese total & 35.589 & 50,62 & 28.165 & 53,42 & 21.037 & 52,12 & 21.459 & 60,50 & 106.250 & 53,43 \\
\hline Total & 70.306 & 100,00 & 52.721 & 100,00 & 40.373 & 100,00 & 35.472 & 100,00 & 198.872 & 100,00 \\
\hline
\end{tabular}


Tabela 26 - Número e porcentagem de mulheres segundo o uso de prótese dentária inferior e faixa etária. Município de São Paulo, 2006.

\begin{tabular}{|c|c|c|c|c|c|c|c|c|c|c|}
\hline \multirow{3}{*}{ Uso de prótese } & \multicolumn{8}{|c|}{ Faixa etária } & & \\
\hline & \multicolumn{2}{|c|}{$65|-| 69$} & \multicolumn{2}{|c|}{$70 \mid-174$} & \multicolumn{2}{|c|}{$751-179$} & \multicolumn{2}{|c|}{80 e mais } & \multicolumn{2}{|c|}{ Total } \\
\hline & $\mathrm{n}$ & $\%$ & $\mathrm{n}$ & $\%$ & $\mathrm{n}$ & $\%$ & $\mathrm{n}$ & $\%$ & $\mathrm{n}$ & $\%$ \\
\hline Não usa prótese & 30.879 & 32,21 & 28.058 & 35,41 & 24.998 & 34,36 & 24.632 & 36,06 & 108.567 & 34,34 \\
\hline Usa prótese fixa & 4.980 & 5,19 & 981 & 1,23 & 876 & 1,20 & 977 & 1,43 & 7.814 & 2,47 \\
\hline Usa prótese parcial removível & 23.176 & 24,17 & 11.966 & 15,10 & 9.973 & 13,71 & 6.665 & 9,75 & 51.780 & 16,38 \\
\hline Usa prótese fixa e removível & 1.903 & 1,98 & 1.067 & 1,35 & 1.006 & 1,38 & 142 & 0,21 & 4.118 & 1,30 \\
\hline Usa prótese total & 34.932 & 36,45 & 37.162 & 46,91 & 35.899 & 49,35 & 35.896 & 52,55 & 143.889 & 45,51 \\
\hline Total & 95.870 & 100,00 & 79.234 & 100,00 & 72.752 & 100,00 & 68.312 & 100,00 & 316.168 & 100,00 \\
\hline
\end{tabular}


Tabela 27 - Número e porcentagem de homens segundo o uso de prótese dentária inferior e faixa etária. Município de São Paulo, 2006.

\begin{tabular}{|c|c|c|c|c|c|c|c|c|c|c|}
\hline \multirow{3}{*}{ Uso de prótese } & \multicolumn{8}{|c|}{ Faixa etária } & \multirow{2}{*}{\multicolumn{2}{|c|}{ Total }} \\
\hline & \multicolumn{2}{|c|}{$651-69$} & \multicolumn{2}{|c|}{ 701-174 } & \multicolumn{2}{|c|}{ 75I-179 } & \multicolumn{2}{|c|}{80 e mais } & & \\
\hline & $\mathrm{n}$ & $\%$ & $\mathrm{n}$ & $\%$ & $\mathrm{n}$ & $\%$ & $\mathrm{n}$ & $\%$ & $\mathrm{n}$ & $\%$ \\
\hline Não usa prótese & 30.795 & 43,80 & 25.712 & 48,77 & 15.977 & 39,57 & 14.198 & 40,02 & 86.682 & 43,59 \\
\hline Usa prótese fixa & 2.026 & 2,88 & 1.304 & 2,47 & 2.248 & 5,56 & - & - & 5.578 & 2,80 \\
\hline Usa prótese parcial removível & 13.629 & 19,39 & 6.871 & 13,03 & 11.454 & 28,38 & 7.494 & 21,13 & 39.448 & 19,84 \\
\hline Usa prótese total & 23.856 & 33,93 & 18.834 & 35,73 & 10.695 & 26,49 & 13.779 & 38,85 & 67.164 & 33,77 \\
\hline Total & 70.306 & 100,00 & 52.721 & 100,00 & 40.374 & 100,00 & 35.471 & 100,00 & 198.872 & 100,00 \\
\hline
\end{tabular}


Entre as mulheres, $74,48 \%$ usam prótese total na arcada superior enquanto que entre os homens o uso atinge $53,43 \%$. Na arcada inferior a prótese total é usada por $45,51 \%$ das mulheres e $33,77 \%$ dos homens.

$\mathrm{Na}$ arcada superior, $11,77 \%$ das mulheres e $29,89 \%$ dos homens não usam prótese enquanto que na arcada inferior o percentual foi de 34,34\% e 43,59 respectivamente.

Quanto à prótese removível, 8,80\% das mulheres e 13,88\% dos homens usavam na arcada superior e 16,38\% das mulheres e 19,84\% dos homens usavam na arcada inferior. 


\section{5 - Necessidade de Prótese Dentária}

Tabela 28 - Número e porcentagem de mulheres que necessitam de prótese dentária superior segundo o tipo de prótese e faixa etária. Município de São Paulo, 2006.

\begin{tabular}{|c|c|c|c|c|c|c|c|c|c|c|}
\hline \multirow{3}{*}{ Necessidade de prótese } & \multicolumn{8}{|c|}{ Faixa etária } & \multirow{2}{*}{\multicolumn{2}{|c|}{ Total }} \\
\hline & \multicolumn{2}{|c|}{$65 \mid-169$} & \multicolumn{2}{|c|}{ 70|-174 } & \multicolumn{2}{|c|}{$75 \mid-179$} & \multicolumn{2}{|c|}{80 e mais } & & \\
\hline & $\mathrm{n}$ & $\%$ & $\mathrm{n}$ & $\%$ & $\mathrm{n}$ & $\%$ & $\mathrm{n}$ & $\%$ & $\mathrm{n}$ & $\%$ \\
\hline Não necessita & 77.550 & 80,89 & 61.938 & 78,17 & 58.394 & 80,26 & 50.671 & 74,18 & 248.553 & 78,61 \\
\hline Necessita 1 prótese fixa & 2.194 & 2,29 & 470 & 0,59 & - & - & - & - & 2.664 & 0,84 \\
\hline $\begin{array}{l}\text { Necessita prótese parcial } \\
\text { removível }\end{array}$ & 3.523 & 3,68 & 2.521 & 3,19 & 1.407 & 1,93 & 976 & 1,43 & 8.427 & 2,67 \\
\hline $\begin{array}{l}\text { Necessita de combinação } \\
\text { de prótese }\end{array}$ & 3.579 & 3,73 & 3.733 & 4,71 & 3.671 & 5,05 & 742 & 1,09 & 11.725 & 3,71 \\
\hline Necessita prótese total & 9.024 & 9,41 & 10.573 & 13,34 & 9.280 & 12,76 & 15.576 & 22,79 & 44.453 & 14,06 \\
\hline Sem informação & - & - & - & - & - & - & 346 & 0,51 & 346 & 0,11 \\
\hline Total & 95.870 & 100,00 & 79.235 & 100,00 & 72.752 & 100,00 & 68.311 & 100,00 & 316.168 & 100,00 \\
\hline
\end{tabular}


Tabela 29 - Número e porcentagem de homens que necessitam de prótese dentária superior segundo o tipo de prótese e faixa etária. Município de São Paulo, 2006.

\begin{tabular}{|c|c|c|c|c|c|c|c|c|c|c|}
\hline \multirow{3}{*}{ Necessidade de prótese } & \multicolumn{8}{|c|}{ Faixa etária } & \multirow{2}{*}{\multicolumn{2}{|c|}{ Total }} \\
\hline & \multicolumn{2}{|c|}{$651-169$} & \multicolumn{2}{|c|}{$70 \mid-174$} & \multicolumn{2}{|c|}{$75 \mid-179$} & \multicolumn{2}{|c|}{80 e mais } & & \\
\hline & $\mathrm{n}$ & $\%$ & $\mathrm{n}$ & $\%$ & $\mathrm{n}$ & $\%$ & $\mathrm{n}$ & $\%$ & $\mathrm{n}$ & $\%$ \\
\hline Não necessita & 48.428 & 68,88 & 30.930 & 58,67 & 25.871 & 64,08 & 22.286 & 62,83 & 127.515 & 64,12 \\
\hline Necessita 1 prótese fixa & 808 & 1,15 & 774 & 1,47 & 1.260 & 3,12 & - & - & 2.842 & 1,43 \\
\hline $\begin{array}{l}\text { Necessita prótese parcial } \\
\text { removível }\end{array}$ & 5.368 & 7,64 & 8.111 & 15,38 & 2.145 & 5,31 & 2.814 & 7,93 & 18.438 & 9,27 \\
\hline $\begin{array}{l}\text { Necessita de combinação } \\
\text { de prótese }\end{array}$ & 10.343 & 14,71 & 3.008 & 5,71 & 3.315 & 8,21 & 3.846 & 10,84 & 20.512 & 10,31 \\
\hline Necessita prótese total & 5.359 & 7,62 & 9.898 & 18,77 & 7.783 & 19,28 & 6.525 & 18,40 & 29.565 & 14,87 \\
\hline Total & 70.306 & 100,00 & 52.721 & 100,00 & 40.374 & 100,00 & 35.471 & 100,00 & 198.872 & 100,00 \\
\hline
\end{tabular}


Tabela 30 - Número e porcentagem de mulheres que necessitam de prótese dentária inferior segundo o tipo de prótese e faixa etária. Município de São Paulo, 2006.

\begin{tabular}{|c|c|c|c|c|c|c|c|c|c|c|}
\hline \multirow{3}{*}{ Necessidade de prótese } & \multicolumn{8}{|c|}{ Faixa etária } & \multirow{2}{*}{\multicolumn{2}{|c|}{ Total }} \\
\hline & \multicolumn{2}{|c|}{$65 \mid-169$} & \multicolumn{2}{|c|}{ 70|--174 } & \multicolumn{2}{|c|}{ 75|-|79 } & \multicolumn{2}{|c|}{80 e mais } & & \\
\hline & $\mathrm{n}$ & $\%$ & $\mathrm{n}$ & $\%$ & $\mathrm{n}$ & $\%$ & $\mathrm{n}$ & $\%$ & $\mathrm{n}$ & $\%$ \\
\hline Não necessita & 59.484 & 62,05 & 46.790 & 59,05 & 44.034 & 60,53 & 37.078 & 54,28 & 187.387 & 59,28 \\
\hline Necessita 1 prótese fixa & 2.080 & 2,17 & 468 & 0,59 & 863 & 1,19 & 323 & 0,47 & 3.734 & 1,20 \\
\hline $\begin{array}{l}\text { Necessita prótese parcial } \\
\text { removível }\end{array}$ & 12.386 & 12,92 & 8.008 & 10,11 & 8.052 & 11,07 & 4.715 & 6,90 & 33.161 & 10,49 \\
\hline $\begin{array}{l}\text { Necessita de combinação } \\
\text { de prótese }\end{array}$ & 7.320 & 7,63 & 7.468 & 9,43 & 2.344 & 3,21 & 3.459 & 5,06 & 20.590 & 6,50 \\
\hline Necessita prótese total & 14.600 & 15,23 & 16.500 & 20,82 & 17.459 & 24,00 & 22.389 & 32,78 & 70.948 & 22,43 \\
\hline Sem informação & - & - & - & - & - & - & 348 & 0,51 & 348 & 0,10 \\
\hline Total & 95.870 & 100,00 & 79.234 & 100,00 & 72.752 & 100,00 & 68.312 & 100,00 & 316.168 & 100,00 \\
\hline
\end{tabular}


Tabela 31 - Número e porcentagem de homens que necessitam de prótese dentária inferior segundo o tipo de prótese e faixa etária. Município de São Paulo, 2006.

\begin{tabular}{|c|c|c|c|c|c|c|c|c|c|c|}
\hline \multirow{3}{*}{ Necessidade de prótese } & \multicolumn{8}{|c|}{ Faixa etária } & \multirow{2}{*}{\multicolumn{2}{|c|}{ Total }} \\
\hline & \multicolumn{2}{|c|}{$65 \mid-169$} & \multicolumn{2}{|c|}{$70 \mid-174$} & \multicolumn{2}{|c|}{$75 \mid-179$} & \multicolumn{2}{|c|}{80 e mais } & & \\
\hline & $\mathrm{n}$ & $\%$ & $\mathrm{n}$ & $\%$ & $\mathrm{n}$ & $\%$ & $\mathrm{n}$ & $\%$ & $\mathrm{n}$ & $\%$ \\
\hline Não necessita & 38.358 & 54,56 & 24.309 & 46,11 & 22.221 & 55,04 & 17.767 & 50,65 & 102.855 & 51,72 \\
\hline Necessita 1 prótese fixa & 772 & 1,10 & - & - & 538 & 1,33 & - & - & 1.309 & 0,66 \\
\hline $\begin{array}{l}\text { Necessita prótese parcial } \\
\text { removível }\end{array}$ & 15.903 & 22,62 & 11.778 & 22,34 & 5.438 & 13,47 & 6.230 & 17,56 & 39.349 & 19,79 \\
\hline $\begin{array}{l}\text { Necessita de combinação } \\
\text { de prótese }\end{array}$ & 10.835 & 15,41 & 7.257 & 13,76 & 5.028 & 12,45 & 2.898 & 8,17 & 26.018 & 13,08 \\
\hline Necessita prótese total & 4.438 & 6,31 & 9.377 & 17,79 & 7.149 & 17,71 & 8.376 & 23,62 & 29.339 & 14,75 \\
\hline Total & 70.306 & 100,00 & 52.721 & 100,00 & 40.374 & 100,00 & 35.471 & 100,00 & 198.872 & 100,00 \\
\hline
\end{tabular}


Quanto à necessidade de prótese dentária superior, 14,06\% das mulheres necessitavam de prótese dentária total enquanto nos homens a necessidade foi de $14,87 \%$.

A necessidade de prótese dentária parcial removível superior nas mulheres foi de $2,67 \%$ e nos homens de 9,27\%. A necessidade de combinação de próteses, isto é, necessidade de prótese dentária fixa e removível superior, nas mulheres foi de $3,71 \%$ enquanto que nos homens foi de $10,31 \%$.

No arco dentário inferior a necessidade de prótese total nas mulheres foi de $22,43 \%$ e nos homens de $14,75 \%$.

A necessidade de prótese dentária removível no arco inferior nas mulheres foi de 10,49\% e nos homens de 19,79\%. A necessidade de combinação de prótese inferior nas mulheres foi de $6,50 \%$ e nos homens $13,08 \%$. 


\section{6 - Lesão de tecidos moles da cavidade bucal}

Tabela 32 - Número e porcentagem de idosos que apresentaram algum tipo de lesão de tecidos moles da cavidade bucal segundo sexo e faixa etária. Município de São Paulo, 2006.

\begin{tabular}{lcccc}
\hline \multicolumn{1}{c}{ Faixa etária } & \multicolumn{2}{c}{ Mulheres } & \multicolumn{2}{c}{ Homens } \\
\hline 65 I-I69 & 16.505 & 17,22 & 11.588 & 16,48 \\
70 -I74 & 17.528 & 22,12 & 8.551 & 16,22 \\
75 -I79 & 11.618 & 15,97 & 5.480 & 13,57 \\
\multirow{2}{*}{80 e mais } & 14.185 & 20,77 & 6.092 & 17,17 \\
\hline Total & 59.836 & 18,93 & 31.711 & 15,95 \\
\hline
\end{tabular}

As mulheres apresentaram maior número de lesões da cavidade bucal que os homens em todas as faixas etárias. Entre as mulheres 18,93\% apresentaram algum tipo de lesão nos tecidos moles da cavidade bucal. Quanto aos homens a porcentagem foi de, $15,95 \%$.

Como mostrado, o estudo SABE produziu um extenso banco de dados com várias possibilidades de investigação.

Assim, o objetivo deste estudo foi verificar as condições de saúde bucal na população idosa de 65 anos de idade e mais residente no município de São Paulo em 2006, separando-se as populações em pessoas totalmente edêntulas daquelas com pelo menos um remanescente dentário a fim de evitar que as necessidades desta população fossem subestimadas.

Dois artigos foram produzidos a partir desta divisão; um trata das pessoas com pelo menos um remanescente dentário com enfoque no número de dentes presentes, hígidos, cariados, restaurados e necessidade de tratamento; e outro, do uso e necessidade de prótese dos idosos participantes do estudo. 
PARTE II

\section{MINUTAS DOS ARTIGOS}

ARTIGO 1 - Condições dentárias dos idosos moradores no Município de São Paulo em 2006

ARTIGO 2 - Uso e necessidade de prótese em idosos moradores no Município de São Paulo em 2006 


\section{ARTIGO 1}

\section{CONDIÇÕES DENTÁRIAS DOS IDOSOS MORADORES NO MUNICÍPIO DE SÃO PAULO EM 2006}




\section{RESUMO}

Introducão - $\mathrm{O}$ envelhecimento da população tem implicações significativas para a atenção em saúde bucal. $\mathrm{O}$ aumento da espectativa de vida da população resultou em diversas mudanças físicas e patológicas que influenciam no tratamento dentário. Objetivo - Verificar a condição dentária de idosos residentes no Município de São Paulo no ano de 2006. Método - Estudo transversal, de base populacional, com exame da cavidade bucal de idosos de 65 anos de idade e mais, em domicílio. Utilizou-se amostra ponderada composta por dois segmentos: o primeiro resultante de sorteio, correspondendo à amostra probabilística e o segundo por composição livre da amostra para grupos ampliados. Foram examinados 1.212 idosos residentes na área urbana do Município de São Paulo. Os exames foram realizados por 15 cirurgiões-dentistas calibrados segundo os critérios metodológicos recomendados pela Organização Mundial da Saúde. Dos 1.212 idosos examinados fizeram parte deste estudo os que possuíam pelo menos um elemento dentário remanescente na cavidade bucal à época do exame.

Resultados - 50,10\% das mulheres na faixa etária de 65I-169 anos apresentaram mais de 10 dentes presentes. Na faixa etária de 70|-174 anos a porcentagem foi de 45,50\%, na faixa etária de 75|-I79 anos a porcentagem foi de $45 \%$ e nos idosos de mais de 80 anos de idade foi de $37,10 \%$. Em todas as faixas etárias mais de $50 \%$ dos homens apresentaram mais de 10 dentes presentes. A média de dentes hígidos foi de 5,09 em mulheres e 7,83 nos homens. A média dos dentes cariados foi de 2,55 nas mulheres e 2,86 nos homens. A média dos dentes restaurados foi de 3,97 nas mulheres e 3,18 nos homens. Quanto aos dentes presentes a média nas mulheres foi de 11,62 e nos homens de 13,87. A média da proporção de dentes hígidos em relação aos dentes presentes foi de $47,76 \%(p=0,00)$ entre as mulheres e de $57,24 \%(p=0,00)$ entre os homens. A média da proporção de dentes cariados em relação aos dentes presentes foi igual entre os sexos: $23 \%(\mathrm{p}=0,84)$. Quanto à média da proporção de dentes restaurados em relação ao dentes presentes, em mulheres foi de $28,91 \%$ ( $\mathrm{p}=0,00$ ) e nos homens de $19,41 \%$ ( $\mathrm{p}=0,00)$. Com relação à necessidade de tratamento nas mulheres $37,11 \%$ necessitam de exodontias $\mathrm{e}$ $38,65 \%$ de restaurações de uma superfície. Entre os homens, 27,99\% necessitam de exodontias e $58,17 \%$ de restaurações de uma superfície. Conclusão - As mulheres possuíam menor número de dentes presentes que os homens. Dentre os dentes presentes as mulheres tinham maior número de dentes restaurados e os homens maior número de dentes hígidos. A média de dentes cariados foi maior nos homens, porém a média da proporção de dentes cariados em relação aos presentes foi igual entre os sexos. Não foram encontrados idosos com todos os dentes presentes. As maiores necessidades de tratamento foram de restaurações de uma superfície e exodontias, sendo que nas mulheres as porcentagens dessas necessidades foram semelhantes.

Descritores: Saúde bucal. Idoso. Cárie dentária. Estudos populacionais em saúde pública. 


\section{SUMMARY}

Introduction - The aging of the population has material effects on the oral health care organization. The improvement of population life expectancy results in several physiological and pathological changes that have its influences on dental treatment. Purpose - To verify the dental conditions of the elderly population living in the city of São Paulo during 2006. Methodology - Transversal study conducted with the elderly population based on take-home clinical exams in the oral cavity of the population with 65 years of age or more. It was used a weighted sample composed by two segments: the first one was selected randomly, which corresponds to the probabilistic sample, and the second was selected by a sample free composition for enlarged groups. 15 dental surgeons examined 1,212 elderly residents in the metropolitan area of the City of São Paulo according to methodological criteria established by the World Wealth Organization. From 1,212 elderly examined, those who have at that time at least one remaining tooth at the oral cavity were included in the clinical study. Results - $50.1 \%$ of female population with 65-69 years old have more than 10 remaining teeth; with 70-74 years old the percentage was $45.5 \%$; with $75-79$ years old $45 \%$ and with 80 years old or more the percentage was $37.1 \%$. The average of healthy teeth was 5.09 for female population and 7.83 for the male population. The average of teeth with caries was 2.55 for female population and 2.86 for male population and the average of restoration was 3.97 for female population and 3.18 for male population. In relation to present teeth the average was 11.62 for female population and 13.87 for male population. The average ratio of healthy to present teeth was $47.76 \%(\mathrm{p}=0.00)$ for female population and $57.24 \%$ $(\mathrm{p}=0.00)$ for male population. The average ratio of present teeth to teeth caries was the same for both sexes: $23 \%(\mathrm{p}=0.84)$. The average ratio of restored teeth to present teeth was $28.91 \%(\mathrm{p}=0.00)$ for female population and $19.41 \%(\mathrm{p}=0.00)$ for male population. As for treatment necessities, $37.11 \%$ of female population need extraction and $38.65 \%$ need restoration of one surface; among male population $27.99 \%$ need extraction and $58.17 \%$ need restoration of one surface. Conclusion - It was observed that the female population has less present teeth than the male population. As to present teeth, female population has a large number of restorations and male population has a large number of health teeth. The average of teeth with caries was larger among the male population, but the average ratio in relation to present teeth was the same for both sexes. There were no elderly with all present teeth. The primary treatment necessities were restoration of one surface and extraction, and among the female population the percentage of these necessities were similar.

Descriptors: Oral health; Elderly population; Dental caries; Population studies in Public Health. 


\section{INTRODUÇÃO}

O envelhecimento da população tem implicações significativas para a organização da atenção em saúde bucal. Ainda que as prioridades dos programas nesta área continuem recaindo sobre os grupos de crianças e adolescentes, tanto no Brasil quanto em outros países, são crescentes as preocupações com a atenção à saúde bucal dos idosos. Não obstante esta preocupação, não é boa a condição de saúde bucal desta faixa etária da população. No Brasil, o sucesso obtido na prevenção da cárie em crianças ainda não tem seus reflexos na população idosa.

Perdas dentárias, experiência de cárie, alta prevalência de doença periodontal, além da xerostomia e do câncer bucal, são os principais problemas que acometem a população idosa. Em alguns países desenvolvidos há uma tendência de declínio de perda dentária entre adultos, inclusive em idosos, mas as iniqüidades sociais no que diz respeito à saúde bucal, ainda persistem mesmo naqueles países que possuem programas avançados de saúde pública voltados para a saúde bucal (PETERSEN e YAMAMOTO, 2005).

Embora sejam ainda escassos os estudos de base populacional (NARVAI e ANTUNES, 2003), o edentulismo, que neste estudo será definido como ausência total de dentes, tem sido a condição mais prevalente nas várias pesquisas realizadas com idosos no Brasil e no exterior.

Não obstante sua alta prevalência, o uso de próteses dentárias parece dar conta deste problema. Na análise dos dados de autopercepção de saúde bucal do estudo SABE, NARVAI e ANTUNES (2003), concluiram que os idosos que faziam uso de algum tipo de prótese relataram melhor condição bucal.

Por outro lado, a cárie e a doença periodontal interferem negativamente na avaliação da saúde bucal. Dor e sangramento são os principais preditores de autoavaliação de condição bucal ruim (SILVA, 2001). Além disso, problemas bucais estão relacionados a problemas nutricionais (MARCENE e col., 2003) e a fatores de risco comuns para doenças sistêmicas (DeSTEFANO, 1993).

Num estudo realizado na Suécia, HOLM-PEDERSEN e col. (2005) analisaram a associação da cárie dentária e da doença periodontal com arritmia cardíaca 
em pessoas dentadas $(n=125)$, com mais de 80 anos de idade. Constataram que as pessoas com três ou mais lesões de cárie de raiz ativa apresentaram um risco duas vezes maior de apresentar arritmia cardíaca. O risco foi de 2,8 vezes quando a cárie atingia a coroa de um ou dois dentes, e não aumentou quando as pessoas tinham mais de três lesões de cárie de coroa. Estes achados indicaram que poderia haver relação entre cárie e arritmia cardíaca.

Estudos sobre condições de saúde bucal invariavelmente utilizam o índice CPOD (número de dentes cariados $(\mathrm{C})$, perdidos $(\mathrm{P})$ e restaurados $(\mathrm{O})$ ) para medir a experiência de cárie das pessoas. Em idosos, o índice CPOD apresenta o componente P com alto valor devido ao grande número de dentes perdidos nessa população. Isto faz com que as médias do índice sejam altas. Soma-se a isso a pequena participação do componente cariado e obturado. Estes três fatores contribuem para mascarar a real necessidade daqueles idosos que possuem dentes, pois a alta prevalência dos edêntulos dá força ao componente perdido. Em que pese a alta prevalência de idosos com índice CPOD igual a 32, quando os dados são inferidos para a população, como no caso do presente estudo, descortina-se uma razoável parcela de idosos carentes de cuidados em saúde bucal voltados para a educação em saúde, prevenção, próteses removíveis, tratamento periodontal, implantes e o que mais se possa oferecer a pessoas com dentes.

É de se esperar que cada vez mais as pessoas envelheçam com mais dentes presentes. Desta forma, o presente estudo teve como objetivo analisar as condições de saúde bucal dos idosos participantes do Projeto SABE - Saúde, Bem-Estar e Envelhecimento (LEBRÃO e LAURENTI, 2005), que ao exame epidemiológico apresentaram pelo menos um elemento dentário remanescente. 


\section{METODOLOGIA}

A pesquisa SABE - Saúde Bem Estar e Envelhecimento (LEBRÃO e LAURENTI, 2005), de base populacional, foi planejada e organizada pela Organização Pan-Americana de Saúde (OPAS), entre os anos de 1997 e 2003, em sete grandes cidades: Bridgetown (Barbados); Buenos Aires (Argentina); Havana (Cuba); México (México); Montevidéu (Uruguai); Santiago (Chile) e São Paulo (Brasil). O estudo caracterizado por ser multicêntrico, transversal, simultâneo e rigorosamente comparável foi o primeiro dessa natureza na região da América Latina e Caribe.

O questionário do estudo foi aplicado em 2.143 pessoas de 60 anos e mais, residentes no Município de São Paulo (Brasil) no ano de 2000. Essa amostra foi composta por dois segmentos: o primeiro, resultante de sorteio, correspondente à amostra probabilística formada por 1.568 entrevistas. O segundo, formado por 575 residentes nos distritos em que foram realizadas as entrevistas anteriores, correspondeu ao acréscimo efetuado para compensar a mortalidade na população de maiores de 75 anos e completar o número desejado de entrevistas nesta faixa etária. Para sorteio de domicílios usou-se o método de amostragem por conglomerados em dois estágios sob o critério de partilha proporcional ao tamanho. Um cadastro permanente de 72 setores censitários, existente no Departamento de Epidemiologia da Faculdade de Saúde Pública, foi considerado a amostra de primeiro estágio. Essa amostra foi tomada do cadastro da Pesquisa Nacional por Amostra de Domicílios (PNAD), 1995, composto por 263 setores censitários sorteados sob o critério de probabilidade proporcional ao número de domicílios. O número mínimo de domicílios sorteados no segundo estágio foi aproximado para 90. A complementação da amostra de pessoas de 75 anos e mais foi realizada através da localização de moradias próximas aos setores selecionados ou, no máximo, dentro dos limites dos distritos aos quais pertenciam os setores sorteados. Cada questionário teve um peso calculado de acordo com o setor censitário de que fazia parte (peso $=1 / \mathrm{f}$ ) e, para os questionários realizados com indivíduos em domicílios que foram selecionados, porém não sorteados (faixa etária 75 anos e mais), o cálculo do peso foi realizado de acordo com a relação da população de idosos (de ambos os sexos) nessas 
faixas etárias, residentes no Município de São Paulo em 1998, e o número de idosos nessas mesmas faixas encontradas na amostra final do estudo.

Em 2006, a pesquisa teve continuidade no Município de São Paulo, transformando-se em um estudo longitudinal que buscou as pessoas entrevistadas em 2000 para aplicação do questionário para coleta de informações sobre as atuais condições de vida e saúde, exame bucal e tomada de medidas antropométricas.

A coleta de dados foi realizada de março de 2006 a maio de 2007.

O exame da cavidade bucal dos idosos foi realizado utilizando-se os índices, critérios e recomendações, contidos no manual sobre levantamento epidemiológico das condições de saúde bucal da Organização Mundial da Saúde (WHO, 1997).

Foram treinados 15 cirurgiões-dentistas, sendo que a parte teórica do treinamento foi realizada em 4 horas e a parte prática em 16 horas.

Os exames bucais e as medidas antropométricas foram realizados nos domicílios dos idosos. Procurou-se realizar os exames em local iluminado, amplo, com o idoso sentado e com a cabeça posicionada para trás e o examinador em frente a este.

Para a verificação da concordância inter-examinadores para diagnóstico de cárie foi utilizado o coeficiente Kappa sendo utilizada a concordância a cada elemento dentário entre os examinadores. O valor da estatística Kappa obtido foi de 0,90 para observação de cárie, considerado de ótima concordância.

Para os exames foram utilizadas sondas CPI, espelhos bucais planos número 5 e espátulas de madeira. $\mathrm{O}$ tamanho da amostra examinada foi de 1.212 idosos (coorte A06), que correspondeu aos sobreviventes da coorte entrevistada no ano 2000 (coorte A00) e representou 515.040 pessoas com mais de 65 anos de idade. Os dados contidos nas fichas dos exames foram digitados utilizando-se o programa Epi Data versão 3.0, num total de 153.924 toques sendo 117 incorretos, perfazendo $0,08 \%$ de erros de digitação. As análises estatísticas foram efetuadas usando-se três pacotes estatísticos: Epi Info 6.0, Stata versão 7 e SPSS versão 13.0. 
A análise dos dados foi feita aplicando-se os testes de Kruscal-Wallis e Mann-Whitney. Para todos os testes estatísticos adotou-se um nível de significância de $5 \%$.

Os dados podem ser inferidos para a população de 65 anos e mais residente no município de São Paulo no ano de 2006. 


\section{RESULTADOS}

Os resultados descritos a seguir se referem aos idosos que ao exame bucal, apresentaram pelo menos um elemento dentário remanescente. Dos 1.212 idosos examinados 505 apresentaram essa condição. As 505 pessoas examinadas representaram 246.517 idosos (41,7\%). Todas as tabelas e figuras serão apresentadas com os dados expandidos para a população de idosos com mais de 65 anos de idade moradores no município de São Paulo em 2006. Dentre esses, 52,6\% eram mulheres cuja média de idade foi de 72,5 anos $( \pm 5,61)$ e 47,4\% eram homens com a média de idade de 72,8 $\operatorname{anos}( \pm 5,60)$.

Tabela 1- Número, média de idade, desvio padrão e percentual de idosos segundo sexo. São Paulo, SP. 2006 (n=247.218).

\begin{tabular}{cccccc}
\hline Sexo & $\mathrm{n}$ & $\begin{array}{c}\text { Média de } \\
\text { idade }\end{array}$ & DP & $\%$ & Valor de $\mathrm{p}$ \\
\hline Mulheres & 129.618 & 72,50 & 5,61 & 52,60 & $\mathrm{p}=0,00$ \\
Homens & 117.600 & 72,80 & 5,60 & 47,40 & $\mathrm{p}=0,00$ \\
\hline Total & 247.218 & 72,60 & 5,61 & 100,00 & $\mathrm{p}=0,00$ \\
\hline
\end{tabular}

Dentre os idosos que apresentaram ao exame da cavidade bucal pelo menos um elemento dentário remanescente, 52,60\% eram mulheres cuja média de idade foi de 72,5 anos $( \pm 5,61)$ e $47,40 \%$ eram homens com a média de idade de 72,8 anos $( \pm$ $5,60)$. 
Figura 1 - Porcentagemde mulheres segundo o número de dentes presentes por faixa etária. São Paulo, SP. 2006.
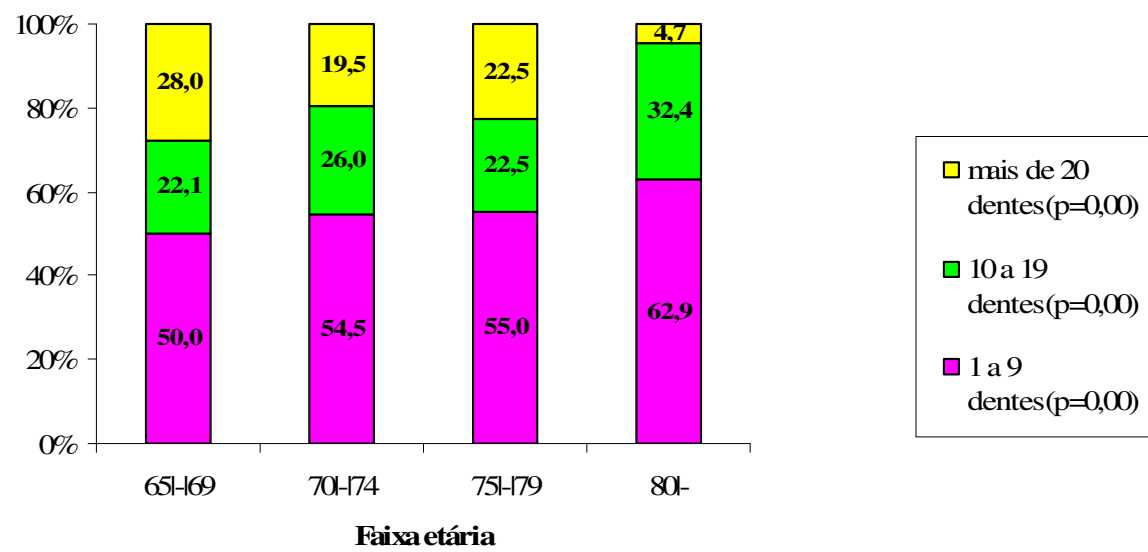

A Figura 1 mostra que 50,1\% das mulheres na faixa etária de 65I-I69 anos apresentaram mais de 10 dentes presentes. Na faixa etária de 70|-174 anos a porcentagem de mais de 10 dentes presentes foi de 45,50\%, na faixa etária de 75I-179 anos esta porcentagem foi de $45 \%$ e na faixa etária de 80 anos e mais de $37,10 \%$.

Figura 2 - Porcentagemde homens segundo o número de dentes presentes por faixa etária. São Paulo, SP. 2006.

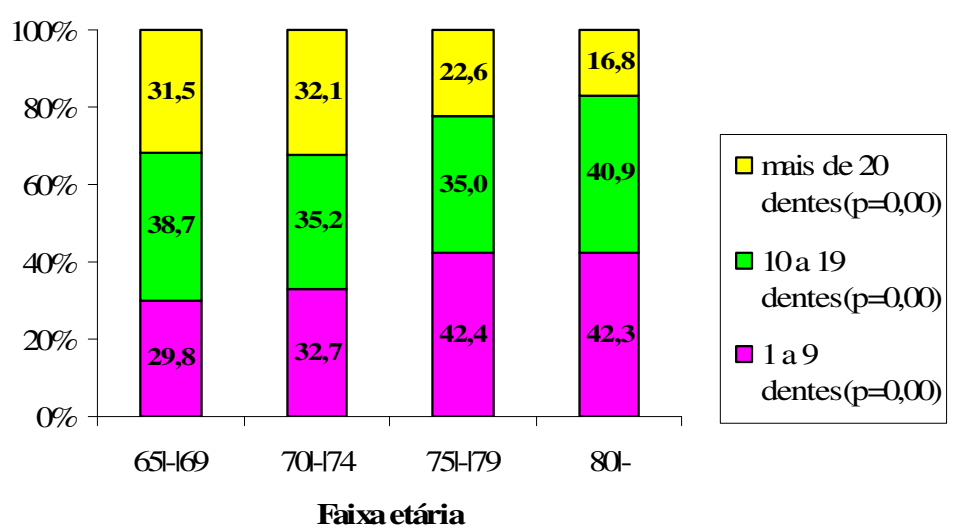

A Figura 2 mostra que em todas as faixas etárias, mais de $50 \%$ dos homens apresentaram mais de 10 dentes presentes. 
Tabela 2 - Médias, desvios padrão e proporções de dentes hígidos, cariados, restaurados e presentes segundo sexo. São Paulo, SP. 2006 ( $\mathrm{n}=247.218)$.

\begin{tabular}{|c|c|c|c|c|c|c|c|c|c|}
\hline \multirow{2}{*}{ Dentes } & \multicolumn{3}{|c|}{ Mulheres } & \multicolumn{3}{|c|}{ Homens } & \multicolumn{3}{|c|}{ Total } \\
\hline & Média & DP & $\%$ & Média & DP & $\%$ & Média & DP & $\%$ \\
\hline Hígidos & 5,09 & 4,30 & 43,80 & 7,83 & 5,75 & 56,45 & 6,40 & 5,22 & 50,43 \\
\hline Cariados & 2,55 & 3,56 & 21,94 & 2,86 & 3,64 & 20,62 & 2,70 & 3,60 & 21,28 \\
\hline Restaurados & 3,97 & 4,70 & 34,17 & 3,18 & 4,36 & 22,93 & 3,59 & 4,56 & 28,29 \\
\hline Presentes & 11,62 & 7,49 & 100,00 & 13,87 & 7,69 & 100,00 & 12,69 & 7,67 & 100,00 \\
\hline
\end{tabular}

A Tabela 2 mostra que a média de dentes hígidos e restaurados se apresentou maior do que a média de dentes cariados nos dois sexos.

Entre as mulheres $77,97 \%$ dos dentes presentes estavam hígidos ou restaurados $(\mathrm{p}=0,00)$. Entre os homens, a porcentagem de dentes hígidos ou restaurados foi de $79,38 \%(\mathrm{p}=0,00)$.

Tabela 3 - Média, desvio padrão, limite inferior e limite superior de dentes presentes, cariados e restaurados em mulheres. Município de São Paulo. SP. 2006 ( $n=129.618)$.

\begin{tabular}{|c|c|c|c|c|c|c|c|}
\hline Faixa etária & $\mathrm{n}$ & Dentes & Média & DP & LI & $\mathrm{LS}$ & Valor de $\mathrm{p}$ \\
\hline \multirow[t]{3}{*}{$65 \mid-169$} & \multirow{3}{*}{51.830} & Cariados & 2,81 & 4,28 & 2,77 & 2,85 & 0,00 \\
\hline & & Restaurados & 4,49 & 5,21 & 4,45 & 4,53 & 0,00 \\
\hline & & Presentes & 12,48 & 7,94 & 12,41 & 12,55 & 0,00 \\
\hline \multirow[t]{3}{*}{$70 \mid-174$} & \multirow{3}{*}{34.661} & Cariados & 2,69 & 3,12 & 2,66 & 2,72 & 0,00 \\
\hline & & Restaurados & 3,86 & 4,38 & 3,81 & 3,91 & 0,00 \\
\hline & & Presentes & 11,68 & 7,40 & 11,60 & 11,76 & 0,00 \\
\hline \multirow[t]{3}{*}{$75 \mid-179$} & \multirow{3}{*}{26.826} & Cariados & 2,42 & 3,01 & 2,38 & 2,46 & 0,00 \\
\hline & & Restaurados & 3,81 & 4,61 & 3,75 & 3,87 & 0,00 \\
\hline & & Presentes & 11,50 & 7,36 & 11,41 & 11,59 & 0,00 \\
\hline \multirow[t]{3}{*}{$801-$} & \multirow{3}{*}{16.301} & Cariados & 1,66 & 2,44 & 1,62 & 1,70 & 0,00 \\
\hline & & Restaurados & 2,80 & 3,36 & 2,75 & 2,85 & 0,00 \\
\hline & & Presentes & 8,94 & 5,50 & 8,86 & 9,02 & 0,00 \\
\hline \multirow[t]{3}{*}{ Total } & \multirow{3}{*}{129.618} & Cariados & 2,55 & 3,56 & 2,53 & 2,57 & 0,00 \\
\hline & & Restaurados & 3,97 & 4,70 & 3,94 & 4,00 & 0,00 \\
\hline & & Presentes & 11,62 & 7,49 & 11,58 & 11,66 & 0,00 \\
\hline
\end{tabular}

$\overline{\mathrm{DP}}=$ Desvio padrão $; \overline{\mathrm{LI}}=$ Limite inferior; $\overline{\mathrm{LS}}$ = Limite superior

Os dados da Tabela 3 mostram que entre as mulheres, as médias dos dentes cariados foram menores que as médias dos dentes restaurados em todas as faixas 
etárias. Na população feminina, em média, de 11,62 dentes presentes, 2,55 encontravamse cariados e 3,97 encontravam-se restaurados. O número de dentes presentes diminuiu com o aumento da idade.

Tabela 4 - Média, desvio padrão, limite inferior e limite superior de dentes presentes, cariados e restaurados em homens. Município de São Paulo. SP. 2006 ( $n=117.600)$.

\begin{tabular}{|c|c|c|c|c|c|c|c|}
\hline Faixa etária & $\mathrm{n}$ & Dentes & Média & DP & LI & $\mathrm{LS}$ & Valor de $p$ \\
\hline \multirow[t]{3}{*}{$65|-| 69$} & \multirow{3}{*}{46.310} & Cariados & 2,36 & 3,76 & 2,33 & 2,39 & 0,00 \\
\hline & & Restaurados & 3,23 & 4,53 & 3,19 & 3,27 & 0,00 \\
\hline & & Presentes & 14,85 & 7,39 & 14,78 & 14,92 & 0,00 \\
\hline \multirow[t]{3}{*}{$70 \mid-174$} & \multirow{3}{*}{30.732} & Cariados & 2,74 & 3,79 & 2,70 & 2,78 & 0,00 \\
\hline & & Restaurados & 3,53 & 4,67 & 3,48 & 3,58 & 0,00 \\
\hline & & Presentes & 14,93 & 7,64 & 14,84 & 15,02 & 0,00 \\
\hline \multirow[t]{3}{*}{$75 \mid-179$} & \multirow{3}{*}{23.881} & Cariados & 3,75 & 3,45 & 3,71 & 3,79 & 0,00 \\
\hline & & Restaurados & 2,86 & 3,81 & 2,81 & 2,91 & 0,00 \\
\hline & & Presentes & 12,16 & 8,22 & 12,06 & 12,26 & 0,00 \\
\hline \multirow[t]{3}{*}{$801-$} & \multirow{3}{*}{16.667} & Cariados & 3,20 & 2,98 & 3,15 & 3,25 & 0,00 \\
\hline & & Restaurados & 2,88 & 3,95 & 2,82 & 2,94 & 0,00 \\
\hline & & Presentes & 11,65 & 6,86 & 11,55 & 11,75 & 0,00 \\
\hline \multirow[t]{3}{*}{ Total } & \multirow{3}{*}{117.600} & Cariados & 2,86 & 3,64 & 2,84 & 2,88 & 0,00 \\
\hline & & Restaurados & 3,18 & 4,36 & 2,82 & 2,94 & 0,00 \\
\hline & & Presentes & 13,87 & 7,69 & 13,83 & 13,91 & 0,00 \\
\hline
\end{tabular}

$\overline{\mathrm{DP}}=$ Desvio padrão; $\mathrm{LI}$ = Limite inferior; $\mathrm{LS}$ = Limite superior

Quanto aos homens, a Tabela 4 mostra que nas faixas etárias de 65I-I69 anos e 70|-174 anos as médias dos dentes cariados foram menores que as médias dos dentes restaurados. Nas faixas etárias de 75|-I79 anos e 80|- e mais anos as médias dos dentes cariados foram maiores que as médias dos dentes restaurados. Na população masculina, em média, de 13,87 dentes presentes, 2,86 encontravam-se cariados e 3,18 encontravam-se restaurados. O número de dentes presentes diminuiu com o aumento da idade.

A distribuição de frequiência de dentes hígidos variou de 0 a 25; de dentes cariados de 0 a 22; de dentes restaurados de 0 a 21 e de dentes presentes de 1 a 28 entre as mulheres. Entre os homens a distribuição de freqüência de dentes hígidos variou de 0 a 24; de dentes cariados de 0 a 18; de dentes restaurados de 0 a 22 e de dentes presentes de 1 a 31. 
Tabela 5 - Média da proporção, desvio padrão, limite inferior e limite superior de dentes cariados e restaurados segundo sexo. Município de São Paulo. SP. 2006 (n= 247.218).

\begin{tabular}{|c|c|c|c|c|c|c|c|c|c|c|c|}
\hline & & Mulhere & & & & & & Hom & & & \\
\hline & $\mathrm{n}$ & Média & DP & LI & LS & $\mathrm{n}$ & Média & DP & LI & LS & $\begin{array}{l}\text { Valor } \\
\text { de p }\end{array}$ \\
\hline $\begin{array}{l}\text { Proporção } \\
\text { de dentes }\end{array}$ & & & & & & & & & & & \\
\hline $\begin{array}{l}\text { cariados } \\
\text { Proporção }\end{array}$ & & 23,31 & 30,19 & 23,15 & 23,47 & & 23,34 & 27,87 & 23,18 & 23,50 & 0,84 \\
\hline de dentes & 129.618 & 2891 & 2790 & 2876 & 2906 & 117.600 & 1941 & 2152 & 1929 & 1953 & 000 \\
\hline $\begin{array}{l}\text { Proporção } \\
\text { de dentes }\end{array}$ & & & & & & & & & & & \\
\hline hígidos & & 47,76 & 32,83 & 47,58 & 47,94 & & 57,24 & 30,33 & 57,07 & 57,41 & 0,00 \\
\hline
\end{tabular}

A média da proporção de dentes cariados em relação aos dentes presentes foi igual entre os sexos: $23 \%(\mathrm{p}=0,84)$. Quanto à média da proporção de dentes restaurados em relação ao dentes presentes, em mulheres foi de 28,91\% (p=0,00) e entre os homens de 19,41\% ( $\mathrm{p}=0,00)$. A proporção de dentes hígidos em relação aos dentes presentes foi de 47,76\% ( $\mathrm{p}=0,00)$ entre as mulheres e de 57,24 ( $\mathrm{p}=0,00)$ entre os homens.

Figura 3 - Porcentagem de dentes em mulheres segundo o tipo de tratamento e faixa etária. São Paulo, SP. 2006.

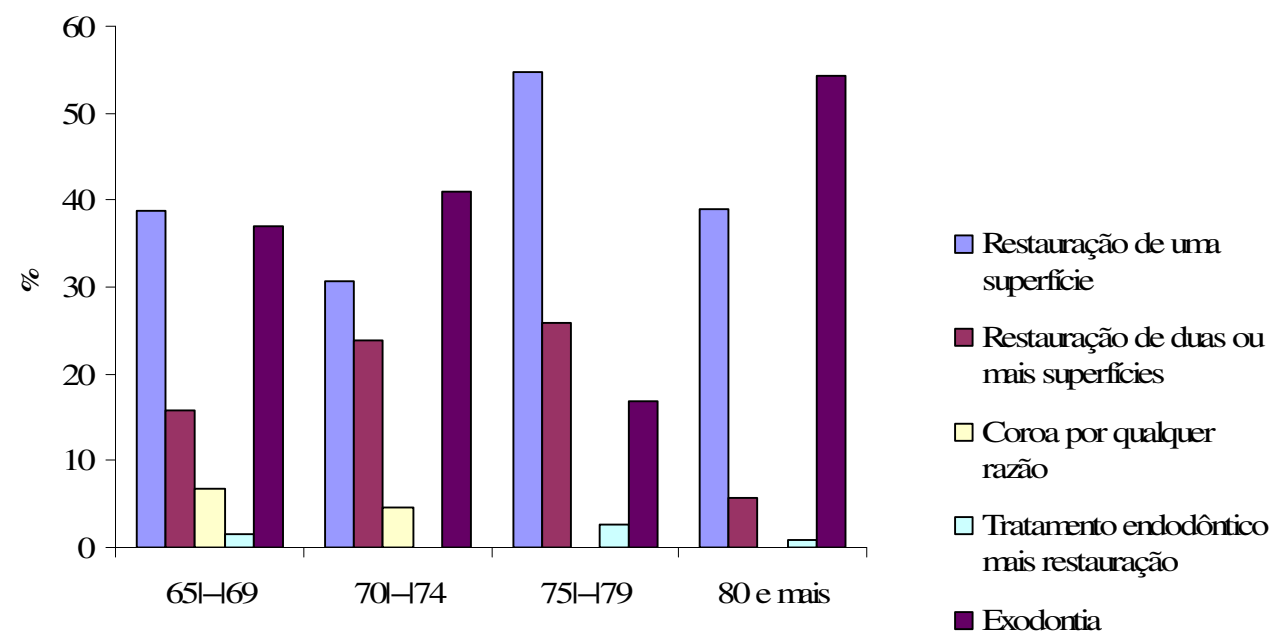

Faixa etária 
Em mulheres as necessidades de exodontia e restaurações de uma superfície foram semelhantes: 37,11\% e 38,65\%, respectivamente (Figura 3).

Figura 4 - Porcentagem de dentes em homens segundo o tipo de tratamento e faixa etária. São Paulo, SP. 2006.

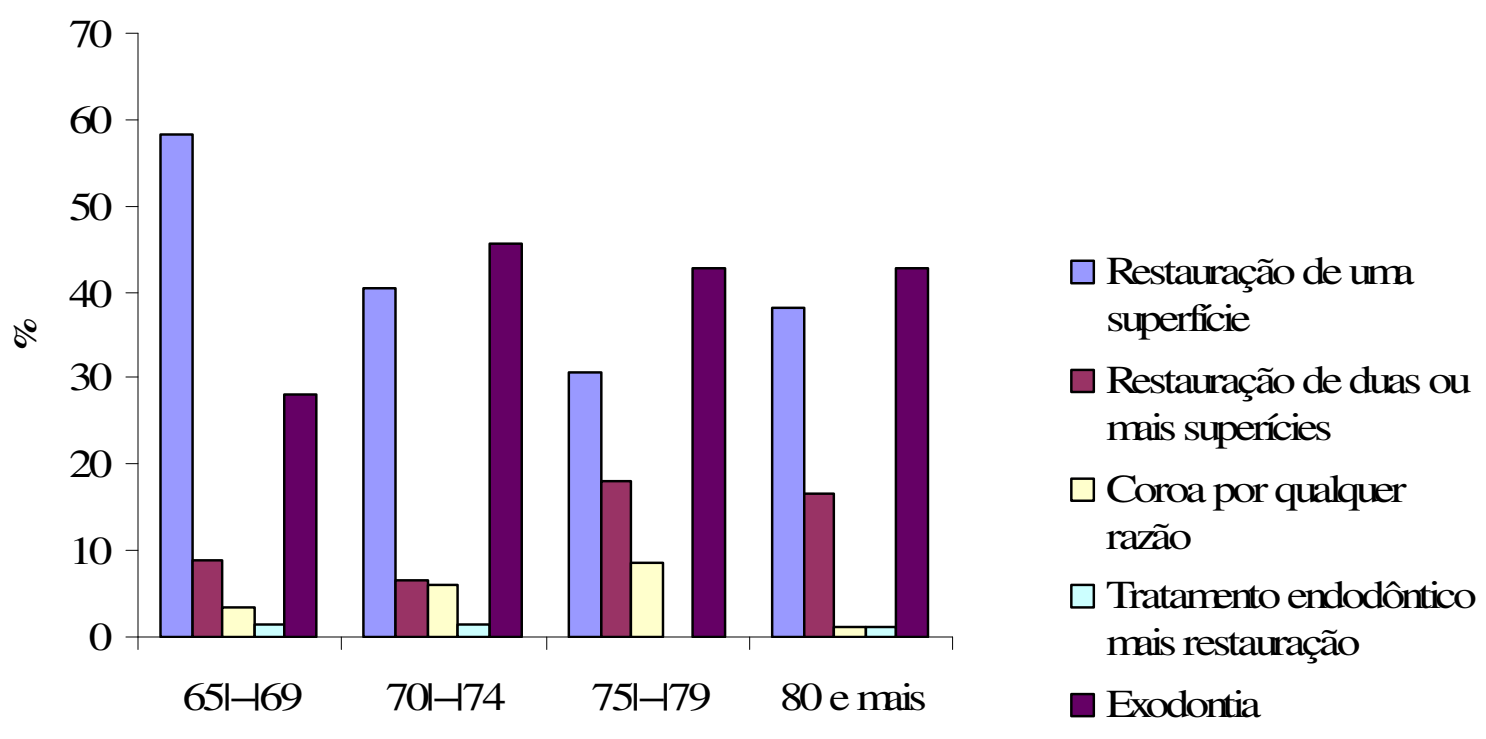

Faixa etária

Em homens a maior necessidade de tratamento foi por restaurações de uma superfície $(58,17 \%)$. A necessidade de exodontia foi de 27,99\% (Figura 4). 


\section{DISCUSSÃO}

O fenômeno da transição demográfica e suas implicações têm levado os países de todo o mundo a voltar sua atenção para a saúde bucal e suas conseqüências na saúde geral e qualidade de vida dos idosos (SHEIHAM e WATT, 2000)

Os índices de cárie na população adulta e idosa variam amplamente entre os países e dentro dos países conforme mostram as pesquisas realizadas a fim de avaliar as condições de saúde bucal dessa faixa etária.

Alguns pesquisadores relatam melhora da saúde bucal com diminuição da prevalência de cárie e do edentulismo; outros referem precárias condições de saúde bucal com alta prevalência de cárie, inclusive cáries radiculares (O’MULANE e WELTON, 1994; FURE e ZICKERT, 1997; KALSBEEK e col, 1998; LYNCH e col, 2000).

ETTINGER (1993), numa revisão sobre a saúde oral dos idosos no mundo, concluiu que a cárie é o principal problema de saúde bucal dos idosos, levando a perdas dentárias e conseqüente edentulismo.

PETERSEN e YAMAMOTO (2005) relatam que a média de dentes cariados e restaurados entre idosos nos países em desenvolvimento está entre 2,2 e 5,3\%. Na China, um inquérito de saúde bucal mostrou que a média de dentes cariados e restaurados foi de 2,5 entre os idosos.

Sabe-se que não são boas as condições de saúde bucal dos idosos brasileiros. Vários estudos têm sido levados a efeito para conhecer a situação de saúde bucal dessa população. Apesar desse interesse a maior parte das investigações sobre idosos refere-se a populações institucionalizadas (SILVA, 1999; CARNEIRO, 2001; MENEGHIN, 2002). São ainda poucos os estudos epidemiológicos de base populacional voltados às condições de saúde bucal no Brasil (NARVAI e ANTUNES, 2003).

No Levantamento Epidemiológico em Saúde Bucal: Estado de São Paulo, 1998 (SES-FSP, 1999), foram examinados 4.894 idosos (3.035 mulheres e 1.859 homens) de 65 a 74 anos, usuários de serviços de saúde e associados de grêmios variados. Houve, em média, 0,67 dentes cariados, 1,27 dentes restaurados e 27,06 dentes perdidos.. 
Em 2004 foram publicados os resultados do mais abrangente levantamento epidemiológico realizado na área de saúde bucal no Brasil. O projeto SB Brasil 2003 Condições de Saúde Bucal da População Brasileira (BRASIL, 2004) obteve dados para a população brasileira entre 65 e 74 anos. Foram examinados 5.349 idosos; o componente cariado apresentou média de 0,65, o componente restaurado média de 0,91 e o componente perdido média de 26,24.

MESAS e col. (2006) encontraram em idosos de uma comunidade de Londrina, PR, em média 2,9 dentes cariados, 2,2 dentes restaurados e 20,4 dentes perdidos entre os homens e 1,0 dentes cariados, 2,2 dentes restaurados e 26,3 dentes perdidos entre as mulheres.

A média de dentes perdidos teve alta participação nos estudos acima que analisaram os dados da população como um todo sem dividir a amostra em pessoas edêntulas (ausência de todos os dentes) daquelas não edêntulas.

O Projeto SABE (LEBRÃO e LAURENTI, 2005) é um estudo de base populacional. Os dados obtidos podem ser inferidos para a população de 65 anos e mais de idade moradora no município de São Paulo em 2006 e representou 515.040 idosos. Desses, 48\% (246.517) possuíam à época do exame bucal pelo menos um elemento dentário remanescente. Os dados descritos neste artigo dizem respeito a essa população. Considerou-se importante separar da amostra as pessoas edêntulas dado que o número de dentes perdidos, devido ao seu alto valor entre idosos, tende a mascarar as necessidades daqueles que possuem dentes. Além disso, as análises efetuadas não consideraram o número de dentes perdidos da amostra aqui estudada para desta forma, procurar conhecer as reais condições dos dentes cariados, restaurados e hígidos da população.

O Levantamento Epidemiológico em Saúde Bucal: Brasil, zona urbana, 1986 (MINISTÉRIO DA SAÚDE, 1988) apresentou dados para a população de 50 a 59 do município de São Paulo. A média de dentes presentes encontrada foi de 7,92, a média de dentes cariados foi de 0,95 e a média de dentes obturados foi de 1,94. 
ROSA e col. (1989), num estudo com uma mostra representativa dos idosos moradores no município de São Paulo encontraram uma média de 2 dentes hígidos entre os idosos não institucionalizados.

Os estudos citados analisaram os dados da população como um todo sem dividir a amostra em pessoas edêntulas (ausência de dentes) daquelas não edêntulas.

No presente estudo, onde foi realizada esta divisão, a média de dentes presentes foi de 12,69 ( $\pm 3,60)$, a média de dentes cariados foi de 2,70 e a média de dentes restaurados foi de $3,59( \pm 4,56)$.

As mulheres apresentaram menor número de dentes presentes como já foi mostrado em outros estudos (SILVA, 1999; MESAS e col., 2006). Com exceção da faixa etária de 65I-169 anos, nenhuma outra apresentou porcentagens iguais ou maiores que $50 \%$ com relação à presença de mais de 9 dentes. Isto pode ser atribuído ao fato das mulheres procurarem os serviços de saúde com maior assiduidade e terem sido submetidas às práticas odontológicas mutiladoras das décadas passadas.

Entre os homens, a presença de mais de 9 dentes foi maior que $50 \%$ em todas as faixas etárias.

Pode-se sugerir que os homens encontraram maior dificuldade no acesso aos serviços odontológicos seja por características dos serviços ou pelo fato de apresentarem maior resistência em procurar os serviços de saúde. Tanto é assim que apresentaram maiores médias de dentes cariados que as mulheres, embora a média da proporção de dentes cariados em relação aos dentes presentes tenha sido igual para ambos os sexos $(23 \%$; $\mathrm{p}=0,84)$. Por outro lado, as mulheres apresentaram maiores médias de dentes restaurados; $3,97( \pm 4,70)$. Entre os homens a média foi de 3,18 $( \pm 4,36)$. Ainda assim, a média de dentes hígidos foi maior entre o sexo masculino $(7,83$; $\pm 5,75)$ do que no sexo feminino $(5,09 ; \pm 4,30)$.

Embora os homens tenham menor acesso aos serviços odontológicos e a média de dentes cariados tenha sido maior entre eles, podemos admitir que a saúde bucal masculina apresentou-se melhor que a feminina já que entre os homens houve maior número de dentes presentes, maior número de dentes hígidos, menor número de dentes restaurados e a média da proporção de dentes cariados foi igual a das mulheres. 
A média do componente cariado foi de 2,55 ( $\pm 3,56)$ nas mulheres e 2,86 $( \pm 3,64)$ nos homens. Foi baixa a média de dentes cariados não só pela pequena quantidade de dentes presentes, mas também porque a média de dentes hígidos foi de $5,09( \pm 4,30)$ dentre 11,62 $( \pm 7,49)$ presentes, nas mulheres. Nos homens, a média de dentes hígidos foi de 7,83 $( \pm 5,75)$ para 13,87 $( \pm 7,69)$ presentes. Poder-se-ia sugerir que entre os idosos a cárie não é tão prevalente, pois a maioria dos dentes presentes se encontrava hígido ou restaurado.

Pesquisas realizadas na Europa (O’MULLANE e WHELTON, 1994) mostram que é crescente o número de raízes cariadas entre os idosos. O mesmo não ocorreu na população estudada que apresentou uma média de raízes cariadas de 0,16 nas mulheres $( \pm 0,61)$ e de 0,27 nos homens $( \pm 0,84)$. A prevalência de cárie de raiz foi baixa; a grande maioria das raízes mesmo expostas encontrava-se hígidas. Os resultados são semelhantes aos encontrados para o Brasil segundo dados do Projeto SB Brasil 2003 (BRASIL, 2003).

A perda total de dentes é tida como algo normal pela sociedade, algo que fatalmente acontecerá com o avançar da idade, e não como o reflexo da falta de políticas preventivas e de saúde voltadas à população adulta, para que mantenha seus dentes até idades mais avançadas (PUCCA JR, 1998).

A proporção de dentes cariados foi de $23 \%$. Cerca de 1 a cada 4 dentes encontra-se cariado em ambos os sexos.

Em ambos os sexos as maiores necessidades de tratamento foram por restaurações de uma superfície e exodontias. Em mulheres as necessidades de restaurações e exodontias foram semelhantes, prova de que ainda continuam sujeitas a mutilação dentária.

É de se esperar que cada vez mais a população idosa permaneça com maior número de dentes, o que demandará dos serviços uma nova abordagem de cuidado em saúde bucal. Na população estudada, 21,90\% das mulheres e 27,92\% dos homens possuíam 20 ou mais dentes presentes.

Boas condições de saúde bucal são essenciais para uma boa qualidade de vida. Muito embora 44,4\% das mulheres e 32,9\% dos homens façam uso de prótese total 
superior e inferior, há idosos que não as usam e dentre estes há aqueles que possuem dentes e demandam serviços.

Assim, faz-se necessário estabelecer novas abordagens no tratamento preventivo e curativo, procurando manter boas condições de saúde bucal, essenciais para uma boa qualidade de vida. 


\section{REFERÊNCIAS}

Brasil, Ministério da Saúde, Secretaria de Atenção à Saúde, Departamento de Atenção Básica. Projeto SB Brasil 2003 - condições de saúde bucal da população brasileira 2002-2003: resultados principais. Brasília:2004.

Carneiro, RMV. Saúde bucal em idosos institucionalizados na Cidade de São Paulo: Estudo epidemiológico e de auto-percepção. São Paulo, 2001. [Dissertação de Mestrado em Saúde Pública - Faculdade de saúde Pública da Universidade de São Paulo].

DeStefano F, Anda RF, Kahn HS, Williamson DF, Russell CM. Dental disease and risk of coronary heart disease and mortality. BMJ 1993; 306:688-691.

Ettinger RL. Oral health needs of the elderly - an international review. Int. Dental Journal 1993; 43(4): 348-54.

Fure S, Zickert I. Incidence of tooth loss and dental caries in 60, 70 and 80-year-old Swedshi individuals. Community Dent Oral Epidemiol 1997;25:137-142.

Holm-Pedersen P, Avlund K, Morse DE, Stoltze K, Katz RV, Viitanen M, Winblad B. Dental Caries, Periodontal Disease, and Cardiac Arrhythmias in Community-Dwelling Older Persons Aged 80 and Older: Is There a Link? Journal of the American Geriatrics Society. 2005;53(3):430-437.

Kalsbeek H, Truin GJ, Van Rossum GM, Van Rukom HM, Poorterman JH, Verrips GH. Trends in caries prevalence in Dutch adults between 1983 and 1995. Caries Res 1998; 32(3):160-165.

Lebrão, ML Laurenti, R. - Saúde, Bem-estar e Envelhecimento: O estudo Sabe no município de São Paulo. Rev Bras Epidemiol. 2005;8(2):127-41.

Lynch E, Baysan A, Ellwood R, Davies R, Petersson L, Borsboon P. Effectiveness of two fluoride dentifrices to arrest rooth carious lesions. Am J Dent. 2000;13(14):218-220. 
Marcene W, Steele JG, Sheiham A. A relação entre estado dentário, seleção alimentar, ingestão de nutrientes, estado nutricional e índice de massa corporal em idosos. Cad Saúde Pública 2003;19(3):809-16.

Meneghim MC, Pereira AC, Silva FRB. Prevalência de cárie radicular e condição periodontal em uma população idosa institucionalizada de Piracicaba - SP. Pesqui Odontol Brás 2002;(16):50-6.

Mesas AE, Andrade SM, Cabrera MAS. Oral health status of community-dwelling elderly in Londrina, Paraná, Brazil. Rev Bras Epidemiol 2006;9(4):471-480.

Ministério da Saúde. Levantamento epidemiológico em saúde bucal, zona urbana 1986. Brasília, Divisão Nacional de Saúde Bucal, 1988.

Narvai PC, Antunes JLF. Saúde bucal: a autopercepção da mutilação e das incapacidades. In: Lebrão ML, Oliveira YA (org). SABE - Saúde, Bem-estar e Envelhecimento - O Projeto Sabe no município de São Paulo: uma abordagem inicial. Brasília: OPAS; 2003.119-40.

O'Mullane DM, Whelton H. Caries prevalence in the Republic of Ireland. Int Dent J 1994;44(4- Supl. 1):387-391.

Petersen PE, Yamamoto T. Improving the oral health of older people: the approach of the WHO Global Oral Health Programme. Community Dent Oral Epidemiol 2005;33:81-92.

Pucca Jr GA. Perfil do edentulismo e do uso de prótese dentária em idosos residentes no município de São Paulo. São Paulo, 1998. [Dissertação - Escola Paulista de Medicina Universidade Federal de São Paulo]. 
Rosa AGF, Castellanos FRA, Pinto VG, Ramos LR. Condições de saúde bucal em pessoas de 60 anos ou mais no Município de São Paulo (Brasil). Rev Saúde Pública [periódico na Internet]. 1992 Jun [citado 2007 Jul 29]; 26(3): 155-160. Disponível em: http://www.scielo.br/scielo.php?script=sci_arttext\&pid=S0034-89101992000300005\&

SES-FSP - Secretaria de Estado da Saúde de São Paulo. Faculdade de Saúde Pública da Universidade de São Paulo. Levantamento Epidemiológico em Saúde Bucal - Estado de São Paulo, 1998. São Paulo, 1999.

Sheiham A, Watt RG. The Common Risk Factor Approach: a rational basis for promoting oral health. Community Dentistry and Oral Epidemiology 2000;28(6): 399_ 406.

Silva, SRC. Autopercepção das condições bucais em pessoas com 60 anos e mais de idade. São Paulo, 1999. [Tese de Doutorado - Faculdade de Saúde Pública da USP].

Silva SRC, Fernandes RAC. Autopercepção das condições de saúde bucal por idosos. Rev. Saúde Pública 2001;35(4):349-55.

World Health Organization. Oral health surveys: basic methods. $4^{\text {th }}$. ed. Geneva: WHO; 1997. 
ARTIGO 2

USO E NECESSIDADE DE PRÓTESE DENTÁRIA EM IDOSOS MORADORES DO MUNICÍPIO DE SÃO PAULO EM 2006 


\section{RESUMO}

Introdução - A alta prevalência do edentulismo é fato comum entre os idosos do mundo todo, variando de acordo com o nível de desenvolvimento dos países. No Brasil, a prevalência do edentulismo é alta entre os idosos. Objetivo - Verificar uso e necessidade de prótese dentária em idosos residentes no Município de São Paulo no ano de 2006. Método - Estudo transversal, de base populacional, com exame clínico da cavidade bucal dos idosos de 65 anos e mais em domicílio. Utilizou-se uma amostra ponderada composta por dois segmentos: o primeiro resultante de sorteio, correspondendo à amostra probabilística e o segundo por composição livre da amostra para grupos ampliados. Foram examinados 1.212 idosos residentes na área urbana do município de São Paulo. Os exames foram realizados por 15 cirurgiões-dentistas calibrados segundo os critérios metodológicos recomendados pela Organização Mundial da Saúde. Resultados - A prevalência do edentulismo foi de $69,40 \%$ nas mulheres e $30,60 \%$ nos homens; $74,48 \%$ das mulheres e $53,43 \%$ dos homens faziam uso de prótese dentária total superior e $45,51 \%$ das mulheres e $33,77 \%$ dos homens faziam uso de prótese dentária total inferior. Uso de prótese dentária total superior e inferior teve prevalência de $44,40 \%$ em mulheres e $32,90 \%$ em homens. O uso de prótese dentária parcial removível foi mais comum na arcada inferior em mulheres (16,38\%). A média da população de necessitava de prótese dentária total, mas não a usava foi de 5,70 sendo que a porcentagem foi maior na população masculina $(14,78 \%)$. A necessidade de prótese dentária total teve maior prevalência seguida da necessidade de prótese dentária parcial removível. Dentre os idosos que usavam outros tipos de prótese dentária a média de dentes presentes foi de 11,62 nas mulheres e 13,84 nos homens. Conclusão - A prevalência do edentulismo é alta entre a população idosa paulistana sendo maior nas mulheres. A julgar pela pequena porcentagem de pessoas que não usam, mas necessitam de prótese dentária, pode-se concluir que não há dificuldade de acesso para este tipo de necessidade. A prevalência do uso de prótese dentária total superior e inferior foi maior nas mulheres enquanto que a necessidade foi maior entre os homens. Houve diminuição de 13\% do edentulismo entre os anos de 1989 e 2006.

Descritores: Saúde bucal. Idoso. Edentulismo. CPOD. Estudos populacionais em saúde pública. 


\section{SUMMARY}

Introduction - The high prevalence of edentulism is a common event among the worldwide elderly population, varying according to the development level of the countries. In Brazil, the prevalence of edentulism is high among the elderly. Purpose To verify the use and necessity of prosthesis implanted in the elderly population living in the municipality of São Paulo during 2006. Methodology - Transversal study based on take-home clinical exams in the oral cavity of the population with 65 yeas of age or more. It was used a weighted sample composed by two segments: the first one was selected randomly, which corresponds to the probabilistic sample, and the second was selected by a sample free composition for enlarged groups. 15 dental surgeons examined 1212 elderly residents in the metropolitan area of São Paulo according to methodological criteria established by the World Wealth Organization. Results - The prevalence of edentulism was $69.4 \%$ for the female population and $30.6 \%$ for the male population; $74.48 \%$ of women and $53.43 \%$ of men have total superior prosthesis implanted and $45.51 \%$ of women and $33.77 \%$ of men have total inferior prosthesis implanted. The use of total superior and inferior prosthesis prevailed in $44.40 \%$ of the female population and $32.90 \%$ of the male population. The use of removable partial prosthesis was more common in the inferior arcade among women $(16.38 \%)$. The average of population in the need but which has no total prosthesis was $5.70 \%$, and the largest percentage was found among the male population (14.78\%). The necessity of total prosthesis was more prevailing, followed by removable partial prosthesis. Among the elderly population that has other prosthesis types implanted, the average of present teeth was 11.62 for the female population and 13.84 for the male population. Conclusion - The prevalence of edentulism is high among the elderly population in the city of São Paulo, with a higher concentration in the female population. Due to the small percentage of people that do not use prosthesis, but are in the need of one, it can be concluded that there are no access difficulties for this type of service. The prevalence of total dental superior and inferior prostheses is higher among the female population, but their necessity was higher among the male population. There was a 13\% reduction from 1989 to 2006 .

Descriptors: Oral health; elderly population; edentulism; population studies in Public Health 


\section{INTRODUÇÃO}

Os problemas bucais têm um impacto negativo na vida das pessoas, em particular entre pessoas idosas. Perdas dentárias extensas reduzem a efetividade da mastigação, provocam mudanças na alimentação sendo um fator de risco para perda de peso entre idosos. Além disso, as pessoas edêntulas tendem a adquirir uma dieta pobre em fibras.

Os problemas com a mastigação em idosos, podem ter efeitos negativos nas relações sociais devido a problemas de comunicação. Sendo assim, a saúde bucal está intimamente relacionada com a saúde geral do indivíduo devido aos fatores de risco comum para doenças (DeSTEFANO e col. 1993; SHEIHAM e WATT, 2000).

O edentulismo é prevalente entre os idosos do mundo todo. Entretanto, nos países desenvolvidos, há uma tendência de declínio de perda dentária entre adultos, inclusive em idosos (PETERSEN e YAMAMOTO, 2205; O'MULLANE e WHELTON, 1994; FURE e ZICKERT, 1997; KALSBEEK e col., 1998).

Segundo PETERSEN e YAMAMOTO (2005) a prevalência do edentulismo entre os idosos de Madagascar é de 25\%; no Canadá é de 58\%, na Arábia Saudita em torno de $31 \%$ a 46\%; na Finlândia é de 41\%; na Índia de $19 \%$ e na Malásia de $57 \% \%$.

No Brasil, estereótipos da velhice comprometem a possibilidade de uma qualidade de vida melhor. Em nosso meio, velhice está associada à perda, incapacidade e dependência (PASCHOAL, 2004). Assim, segundo PUCCA Jr (1998), o edentulismo é aceito pela sociedade e pelos profissionais de odontologia como algo normal e natural com o avanço da idade. Vários estudos mostram o edentulismo como um dos principais problemas que acometem a saúde bucal dos idosos (SES-FSP, 1998; SILVA e FERNANDES, 2001; COLUSSI e col., 2004).

Não obstante o interesse pela saúde bucal desse segmento da população, ações curativas, preventivas e de promoção de saúde são escassas e invariavelmente relegadas ao segundo plano. Em 2007 foi lançado pelo Ministério da Saúde o Caderno de Atenção Básica $n^{\circ}$ 19, cujo tema é Envelhecimento e Saúde da Pessoa Idosa (BRASIL, 2006). Não há orientações sobre como avaliar a saúde bucal do idoso. Foram 
descritas apenas as atribuições da equipe de saúde bucal no atendimento odontológico. Pode-se concluir que persiste a prática de se colocar a saúde bucal em segundo plano. Este é um dos principais motivos pelos quais a porcentagem de edêntulos entre os idosos no Brasil gira em torno de $40 \%$.

Ainda que as prioridades do programa de atenção à pessoa idosa continuem recaindo sobre outras doenças que não as bucais, são crescentes as preocupações com a atenção à saúde bucal dos idosos. Em vários municípios brasileiros os idosos dispõem de ações específicas desenvolvidas no âmbito do Sistema Único de Saúde (SUS), com a finalidade de promover a saúde bucal e prevenir doenças bucais.

Os estudos realizados no Brasil não apontam para a diminuição do edentulismo na população idosa.

ROSA e col, num estudo realizado em 1989 numa amostra representativa dos idosos moradores no Município de São Paulo observaram que a prevalência do edentulismo era de $65 \%$ entre idosos não institucionalizados.

O Levantamento Epidemiológico em Saúde Bucal - Estado de São Paulo, 1998 (SES-FSP, 1999), quanto ao uso de prótese dentária encontrou os seguintes resultados: $67 \%$ dos idosos utilizavam prótese na arcada superior sendo $62,6 \%$ prótese total e $48 \%$ utilizavam na arcada inferior sendo $38,3 \%$ prótese total.

SILVA (2001) em estudo com idosos que freqüentavam um Centro de Saúde em Araraquara, SP, encontrou índice CPOD de 26,66; média de dentes cariados de 1,10 , dentes restaurados 4,43 e perdidos 20,58 ; os edêntulos perfaziam $40,4 \%$ da amostra.

COLUSSI (2004) em seu estudo sobre o perfil epidemiológico da cárie e do uso e necessidade de prótese na população idosa de Biguaçu, SC, encontrou uma prevalência de edentulismo de $48,4 \%$.

Em 2005 foram publicados os resultados do mais abrangente levantamento epidemiológico realizado na área de saúde bucal no Brasil. O projeto SB Brasil 2003 - Condições de Saúde Bucal da População Brasileira (MINISTÉRIO DA SAÚDE, 2004), obteve dados para a população brasileira entre 65 e 74 anos (recomendada pela Organização Mundial da Saúde para avaliar a situação de saúde 
bucal de idosos). Foram examinados 5.349 idosos e o CPOD médio para o Brasil foi de 27,8 sendo que o componente perdido foi responsável por $93 \%$ do índice.

MESAS e col (2006) encontraram em idosos de uma comunidade de Londrina, PR, os seguintes resultados: média do índice CPOD de 29,5, médias de dentes cariados de 1,0, perdidos 26,3 e restaurados 2,2 em mulheres e média do índice CPOD de 25,5, média de dentes cariados de 3,4, perdidos 20,4 e restaurados 3,6 em homens e $43,1 \%$ de edêntulos.

Pelo exposto a população idosa brasileira não apresenta bons índices de saúde bucal. O principal desafio que se coloca diante deste quadro, é impedir a perda dos dentes daqueles que fazem uso de outros tipos de prótese que não prótese total e, além disso, envidar esforços no sentido de desfazer a crença de que a perda dos dentes na velhice seja um processo natural e inevitável.

O estudo SABE - Saúde Bem Estar e Envelhecimento (LEBRÃO E LAURENTI, 2005), uma pesquisa de base populacional realizada em 7 capitais da América Latina e Caribe, uma delas São Paulo teve início em 2000, e à época os idosos participantes responderam a algumas questões sobre a percepção de sua saúde bucal. Em 2006, a investigação teve continuidade no município de São Paulo, transformando-se em um estudo longitudinal que buscou as pessoas entrevistadas em 2000 para exame da cavidade bucal. O presente artigo que faz parte do projeto SABE, teve como objetivo avaliar as condições de uso e necessidade de prótese dos idosos examinados. 


\section{METODOLOGIA}

A pesquisa SABE - Saúde Bem Estar e Envelhecimento (LEBRÃO e LAURENTI, 2005) foi planejada e organizada pela Organização Pan-Americana de Saúde (OPAS), entre os anos de 1997 e 2003, em sete grandes cidades: Bridgetown (Barbados); Buenos Aires (Argentina); Havana (Cuba); México (México); Montevidéu (Uruguai); Santiago (Chile) e São Paulo (Brasil). O estudo caracterizado por ser multicêntrico, transversal, simultâneo e rigorosamente comparável foi o primeiro dessa natureza na região da América Latina e Caribe.

O questionário do estudo foi aplicado em 2.143 pessoas de 60 anos e mais, residentes no Município de São Paulo (Brasil) no ano 2000. Essa amostra foi composta por dois segmentos: o primeiro, resultante de sorteio, correspondente à amostra probabilística formada por 1.568 entrevistas. O segundo, formado por 575 residentes nos distritos em que foram realizadas as entrevistas anteriores, correspondeu ao acréscimo efetuado para compensar a mortalidade na população de maiores de 75 anos e completar o número desejado de entrevistas nesta faixa etária. Para sorteio de domicílios usou-se o método de amostragem por conglomerados em dois estágios sob o critério de partilha proporcional ao tamanho. Um cadastro permanente de 72 setores censitários, existente no Departamento de Epidemiologia da Faculdade de Saúde Pública, foi considerado a amostra de primeiro estágio. Essa amostra foi tomada do cadastro da Pesquisa Nacional por Amostra de Domicílios (PNAD), 1995, composto por 263 setores censitários sorteados sob o critério de probabilidade proporcional ao número de domicílios. O número mínimo de domicílios sorteados no segundo estágio foi aproximado para 90. A complementação da amostra de pessoas de 75 anos e mais foi realizada através da localização de moradias próximas aos setores selecionados ou, no máximo, dentro dos limites dos distritos aos quais pertenciam os setores sorteados. Cada questionário teve um peso calculado de acordo com o setor censitário de que fazia parte (peso $=1 / \mathrm{f})$ e, para os questionários realizados com indivíduos em domicílios que foram selecionados, porém não sorteados (faixa etária 75 anos e mais), o cálculo do peso foi realizado de acordo com a relação da população de idosos (de ambos os sexos) nessas 
faixas etárias, residentes no Município de São Paulo em 1998, e o número de idosos nessas mesmas faixas encontradas na amostra final do estudo.

Em 2006, o estudo teve continuidade no Município de São Paulo, transformando-se em um estudo longitudinal que buscou as pessoas entrevistadas em 2000 para aplicação do questionário para coleta de informações sobre as atuais condições de vida e saúde, exame bucal e tomada de medidas antropométricas.

A coleta de dados foi realizada de março de 2006 a maio de 2007.

O exame da cavidade bucal dos idosos foi realizado utilizando-se os índices, critérios e recomendações contidos no manual sobre levantamento epidemiológico das condições de saúde bucal da Organização Mundial da Saúde (WHO, 1997).

Foram treinados 15 cirurgiões-dentistas, sendo que a parte teórica do treinamento foi realizada em 4 horas e a parte prática em 16 horas.

Os exames bucais e as medidas antropométricas foram realizados nos domicílios dos idosos. Procurou-se realizar os exames em local iluminado, amplo, com o idoso sentado e com a cabeça posicionada para trás e o examinador em frente a este.

Para a verificação da concordância inter-examinadores para diagnóstico de cárie foi utilizado o coeficiente Kappa sendo utilizada a concordância a cada elemento dentário entre os examinadores. $\mathrm{O}$ valor obtido para a estatística Kappa foi de 0,90 para observação de cárie, considerado de ótima concordância.

Para os exames foram utilizadas sondas CPI, espelhos bucais planos número 5 e espátulas de madeira.

As análises estatísticas foram efetuadas usando-se três pacotes estatísticos: Epi Info 6.0, Stata versão 7 e SPSS versão 13.0 e aplicando-se os testes de Kruscal-Wallis e Mann-Whitney. Para todos os testes estatísticos adotou-se um nível de significância de $5 \%$. 


\section{RESULTADOS}

O tamanho da amostra examinada foi de 1.212 idosos e representaram 515.040 pessoas de 65 anos de idade e mais. A expansão dos dados obtidos para a população foi permitida devido à metodologia empregada para o cálculo da amostra. Cada idoso participante representou um número de idosos com as mesmas características de idade, sexo, condição socioeconômica e setor censitário onde era domiciliado.

As fichas dos exames foram digitadas no programa Epi Data versão 3.0., num total de 153.924 toques, sendo 117 incorretos, perfazendo $0,08 \%$ de erros de digitação.

Todas as tabelas foram apresentadas com os dados expandidos para a população de idosos de 65 anos de idade e mais moradores no Município de São Paulo em 2006.

A Tabela 1 mostra que dentre a população estudada, 61,40\% eram mulheres e 38,60\% homens. Assim, como tem sido visto nos últimos censos e contagens populacionais, a estrutura etária das mulheres é mais envelhecida que a dos homens: uma em cada quatro tem 75 anos ou mais e no caso dos homens essa proporção é de um para cada cinco (LEBRÃO e LAURENTI, 2005).

A média de idade foi de 74,37 anos entre as mulheres $( \pm 6,89)$ e 73,45 anos entre os homens $( \pm 6,17)$.

Tabela 1. Número de idosos, média de idade, desvio padrão e percentual na população segundo sexo. Município de São Paulo, 2006.

\begin{tabular}{ccccc} 
Sexo & $\mathrm{n}$ & $\begin{array}{c}\text { Média de } \\
\text { idade }\end{array}$ & DP & $\%$ \\
\hline Feminino & 316.168 & 74,37 & 6,89 & 61,40 \\
Masculino & 198.872 & 73,45 & 6,17 & 38,60 \\
\hline Total & 515.040 & 74,02 & 6,63 & 100,00 \\
\hline
\end{tabular}


Dentre os participantes, $69,40 \%$ das mulheres e $30,60 \%$ dos homens eram edêntulos.

Figura 1 - Porcentagem de uso de prótese dentária total superior e inferior em idosos segundo faixa etária. São Paulo, SP, 2006.

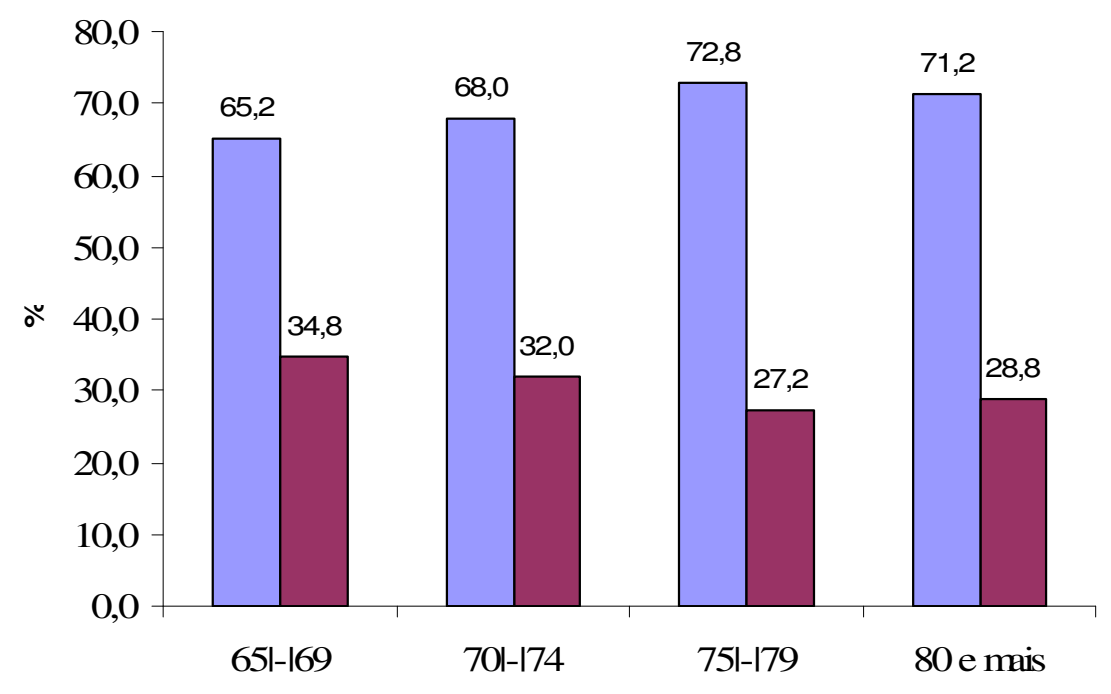

$\square$ Mulher

$\square$ Homem

\section{Faixa etária}

O uso de prótese dentária total superior e inferior é mais prevalente entre as mulheres. O número de homens que fazem uso de prótese dentária total superior e inferior diminuiu com o aumento da idade.

Figura 2 - Porcentagem de uso de prótese dentária superior em mulheres segundo faixa etária. São Paulo, SP, 2006.
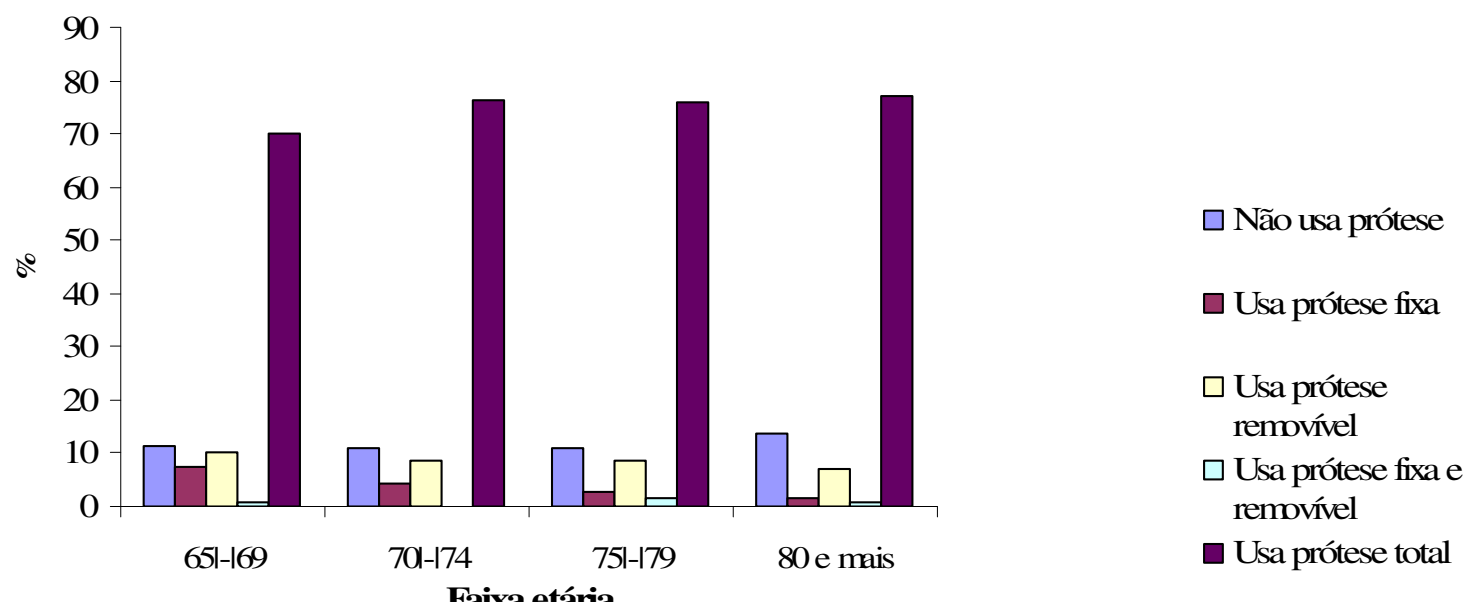

Faixa etária 
Figura 3 - Porcentagem de uso de prótese dentária superior em homens segundo faixa etária. São Paulo, SP, 2006.

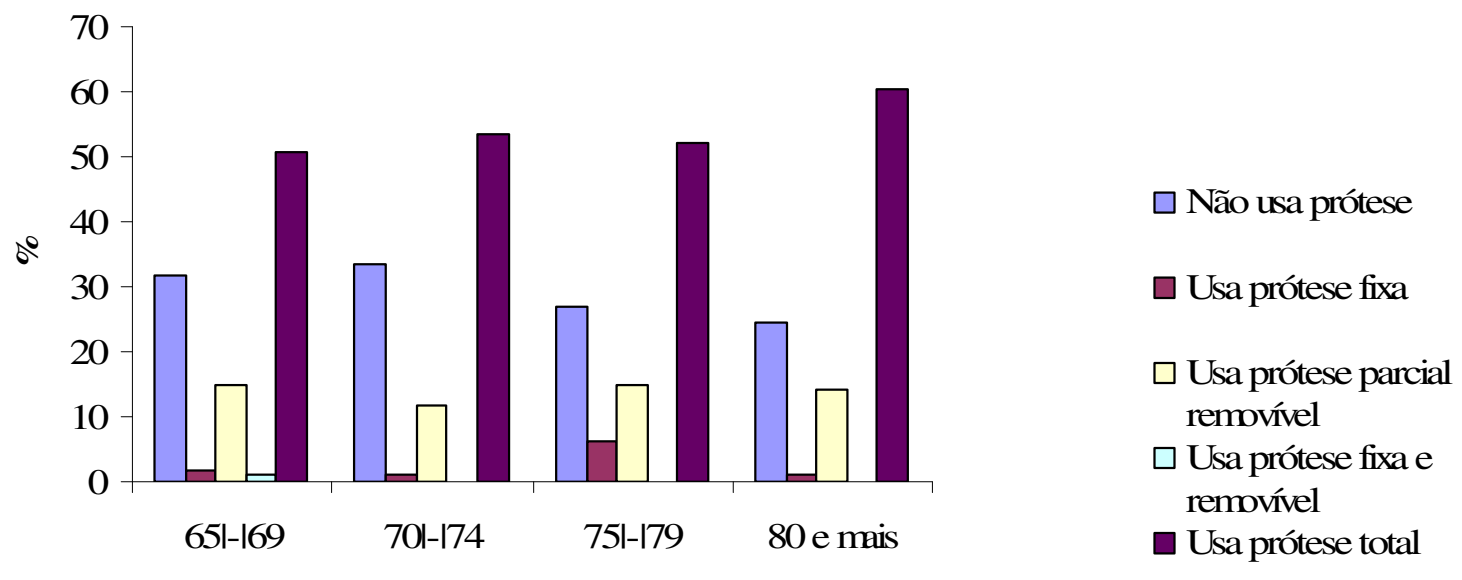

Faixa etária

As figuras 2 e 3 mostram a porcentagem do uso ou não de prótese dentária superior por mulheres e homens. Na população feminina $11,77 \%$ não usavam prótese dentária, 4,21\% usavam prótese dentária fixa, 8,80\% prótese dentária parcial removível, 0,74\% prótese dentária fixa e removível e 74,48\% prótese dentária total.

Entre os homens, 29,89\% não usavam prótese dentária, 2,43\% usavam prótese dentária fixa, 13,88\% prótese dentária removível, 0,37\% prótese dentária fixa e removível e 53,43\% prótese dentária total. 
Figura 4 - Porcentagem de uso de prótese dentária inferior em mulheres segundo faixa etária. São Paulo, SP, 2006.

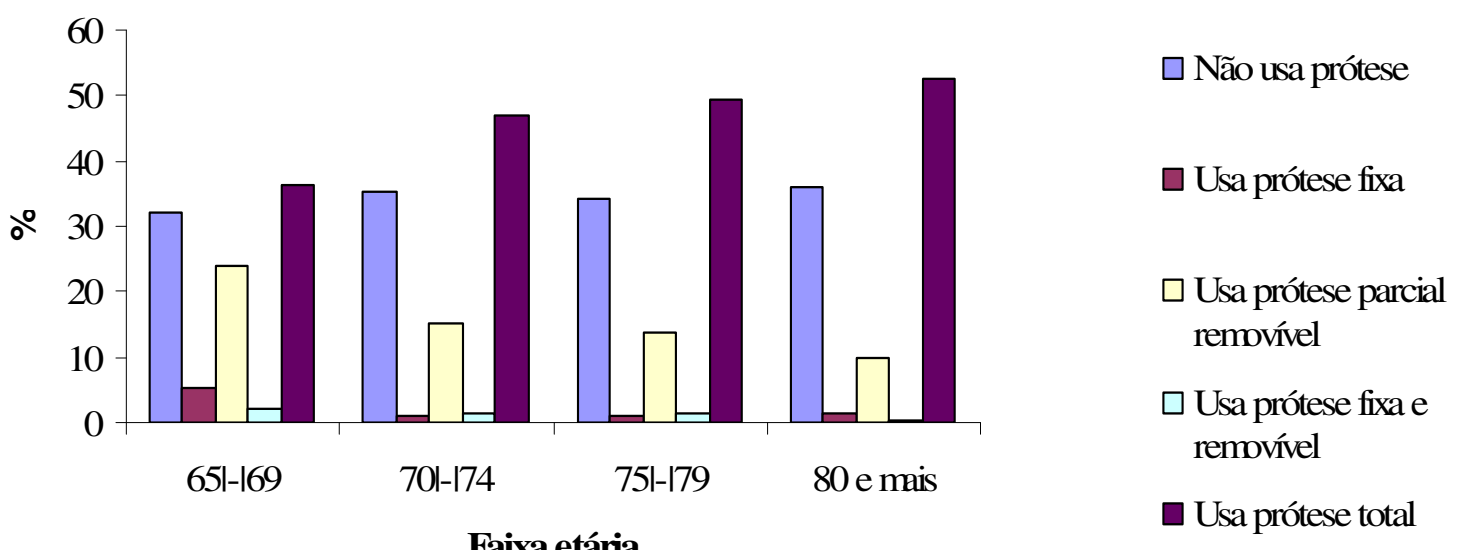

Figura 5 - Porcentagem de uso de prótese dentária inferior em homens segundo faixa etária. São Paulo, SP, 2006.

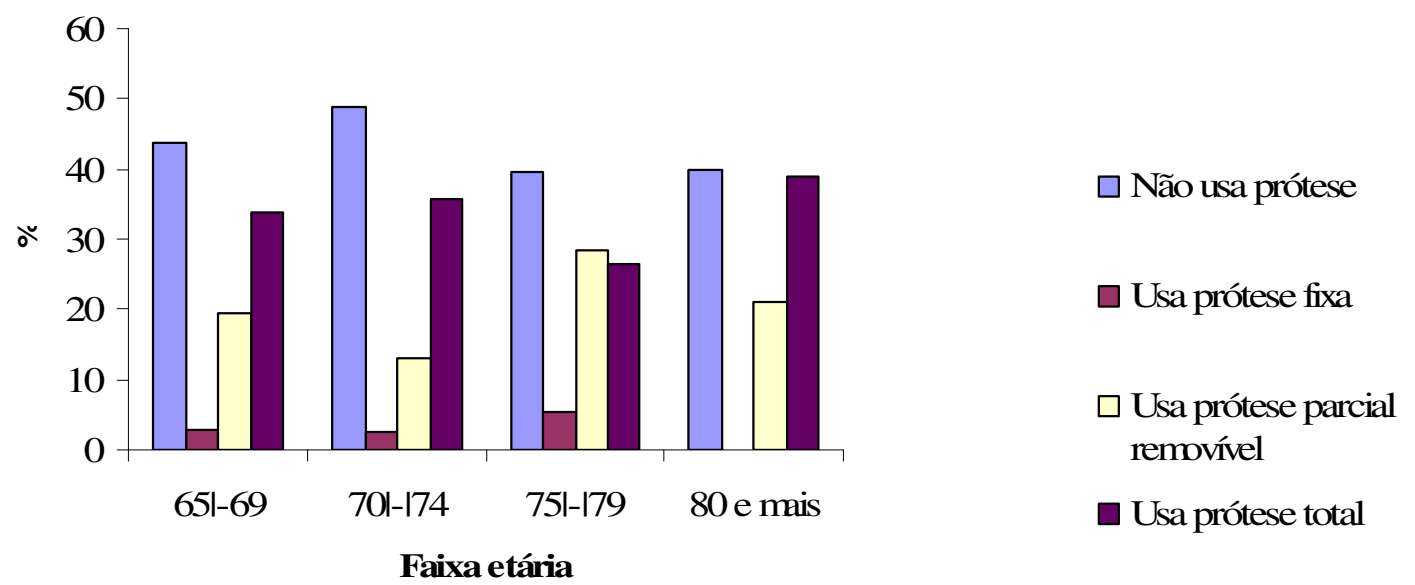

As figuras 4 e 5 mostram em porcentagem, o uso ou não de prótese dentária inferior por mulheres e homens de acordo com a faixa etária. Na população feminina 34,34\% não usavam prótese dentária, 2,47\% usavam prótese dentária fixa, 
16,38\% prótese dentária parcial removível, 1,30\% prótese dentária fixa e removível e $45,51 \%$ prótese dentária total.

Entre os homens 43,59\% não usavam prótese dentária, 2,80\% usavam prótese dentária fixa, 19,84\% prótese dentária removível, e 33,77\% prótese dentária total.

Figura 6 - Porcentagem de necessidade de prótese dentária superior em mulheres segundo faixa etária. São Paulo, SP, 2006.

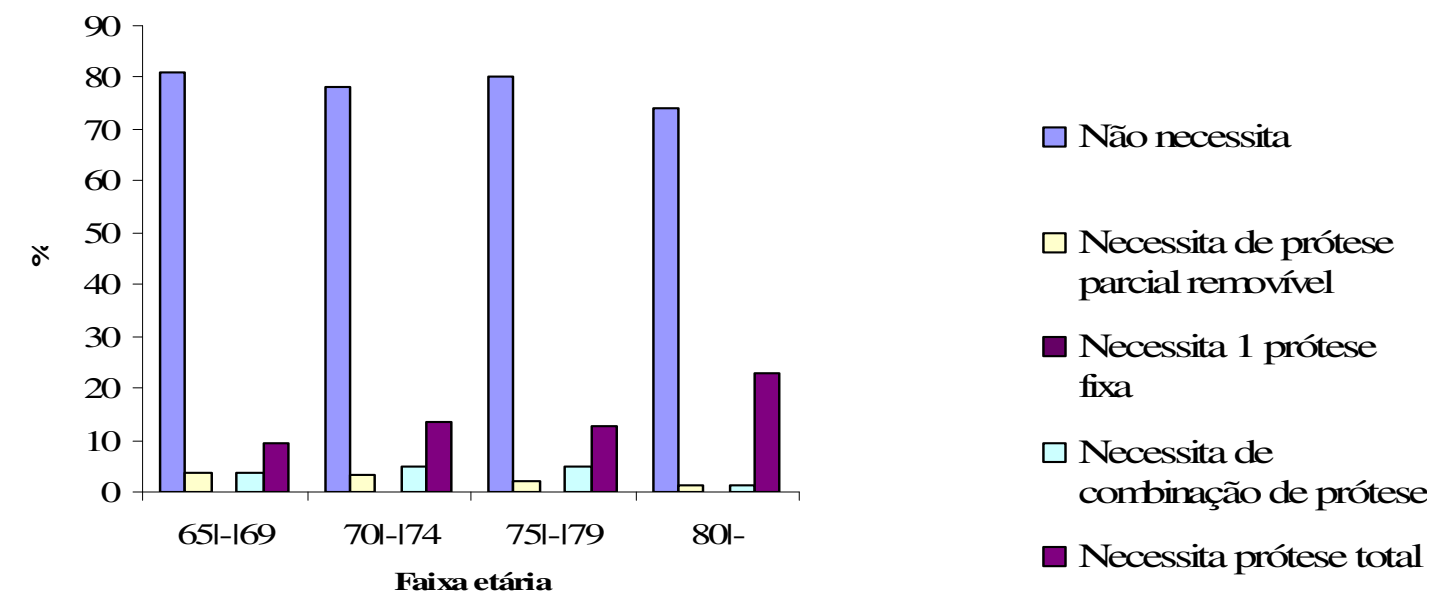

Figura 7 - Porcentagem de necessidade de prótese dentária superior em homens segundo faixa etária. São Paulo, SP, 2006.

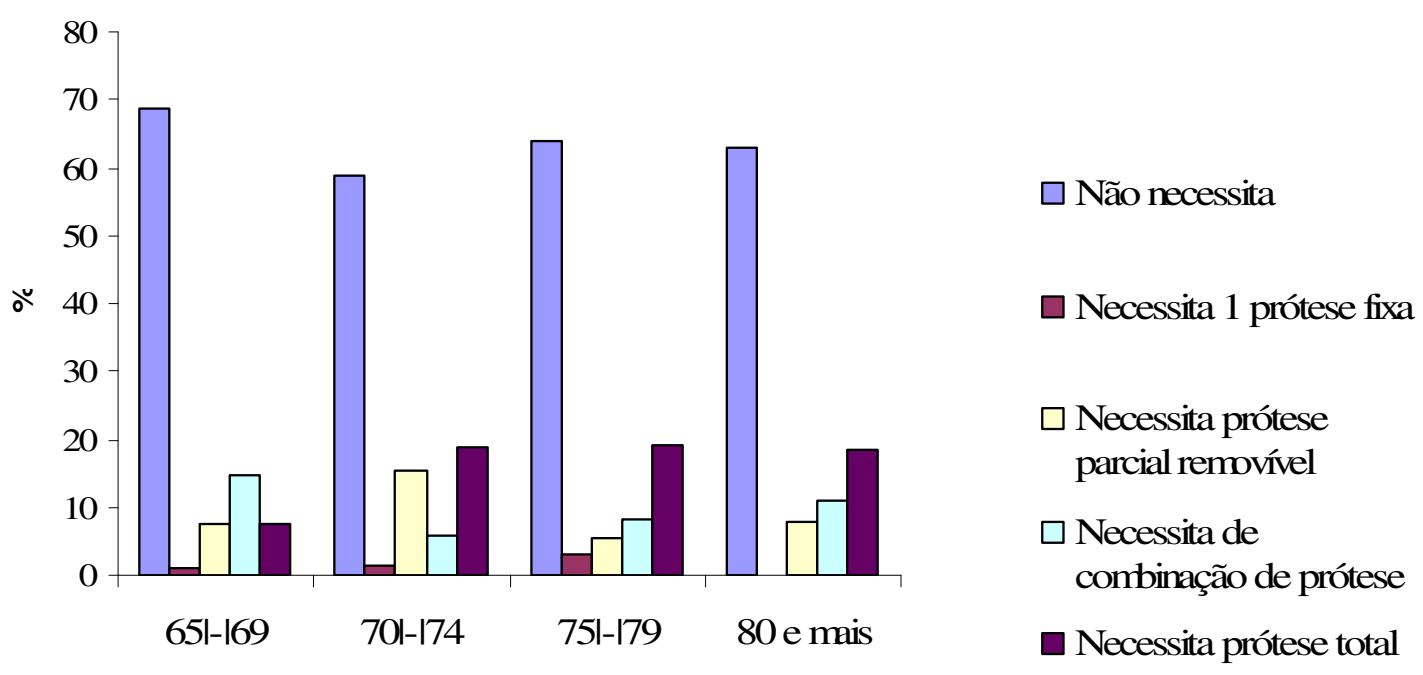

Faixa etánia 
As figuras 6 e 7 mostram, em porcentagem, a necessidade de prótese dentária superior em mulheres e homens de acordo com a faixa etária. Na população feminina 78,61\% não necessitava de prótese dentária, 0,847\% necessitava de prótese dentária fixa, 2,67\% de prótese dentária parcial removível, 3,71\% prótese dentária fixa e removível e 14,06\% de prótese dentária total.

Entre os homens 64,12\% não necessitavam de prótese dentária, 1,43 necessitavam de prótese dentária fixa, 9,27\% de prótese dentária parcial removível, 10,31\% de combinação de próteses dentárias e 14,87\% de prótese dentária total.

Figura 8 - Porcentagem de necessidade de prótese dentária inferior em mulheres segundo faixa etária. São Paulo, SP, 2006.

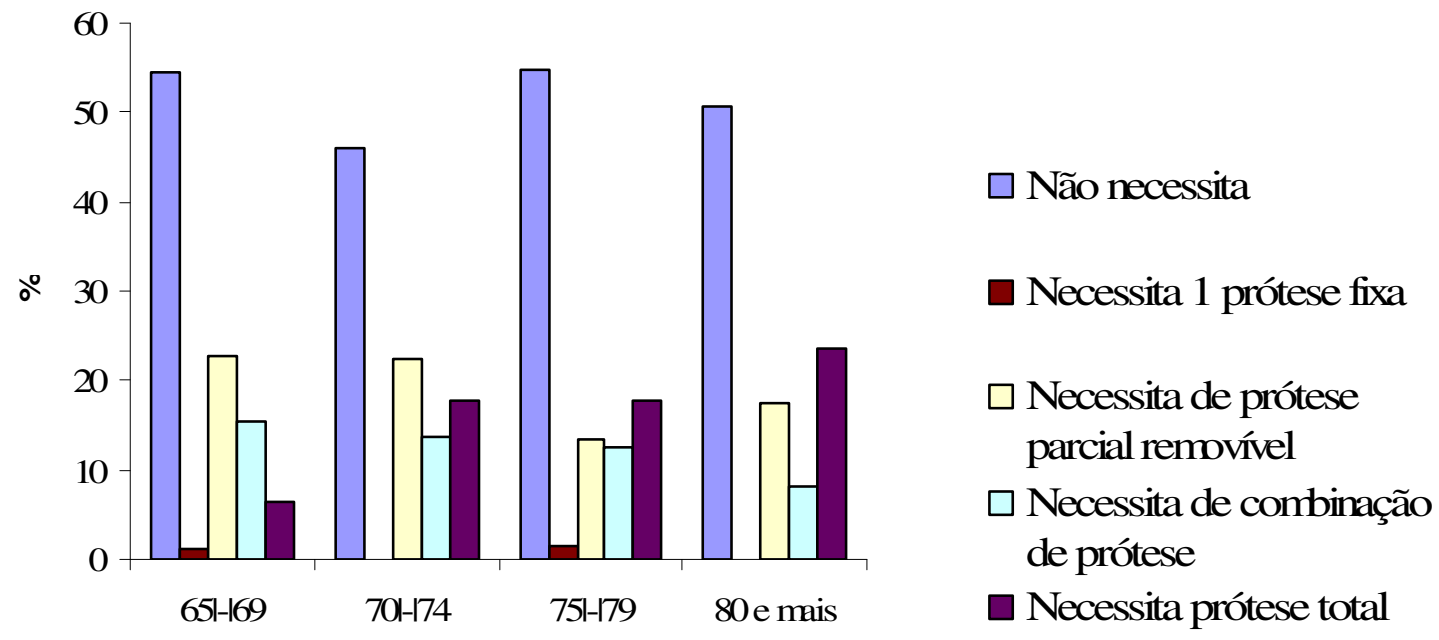

Faixa etária 
Figura 9 - Porcentagem de necessidade de prótese inferior em homens segundo faixa etária. São Paulo, SP. 2006.

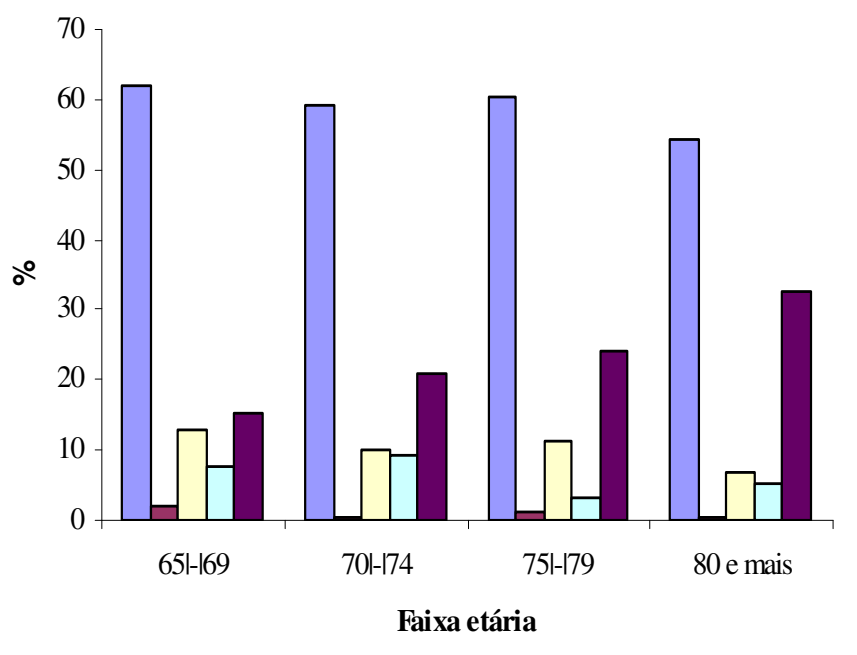

As figuras 8 e 9 mostram em porcentagem, a necessidade de prótese dentária inferior em mulheres e homens de acordo com a faixa etária. Na população feminina 59,28\% não necessitava de prótese dentária, 1,20\% necessitava de prótese dentária fixa, 10,49\% de prótese dentária parcial removível, 6,50\% de prótese dentária fixa e removível e $22,43 \%$ de prótese dentária total.

Entre os homens, 51,72\% não necessitavam de prótese dentária, 0,66\% necessitavam de prótese dentária fixa, 19,79\% de prótese dentária parcial removível, 13,08\% de combinação de próteses dentárias e 14,75\% de prótese dentária total. 


\section{DISCUSSÃO}

Segundo PUCCA Jr. (1998), o edentulismo é a prova cabal de que as medidas de atenção em saúde bucal fracassaram integralmente ou sequer existiram.

Estudos epidemiológicos têm mostrado que pessoas com baixo nível socioeconômico e baixos níveis educacionais e de renda possuem maior probabilidade de serem edêntulas do que pessoas com nível socioeconômico e educacional ou de renda maiores. Uma dentição funcional é medida pela presença de 20 ou mais dentes naturais. (ELIAS E SHEIHAM, 1998)

Os estudos levados a efeito no Brasil, invariavelmente encontram alta prevalência de edentulismo entre idosos. A alta prevalência é também fato comum em outros países variando de acordo com o seu nível de desenvolvimento. Num estudo realizado na China em idosos de 65 a 74 anos a prevalência do edentulismo foi de $11 \%$ e na Malásia de 57\% (PETERSEN e YAMAMOTO, 2005).

Neste estudo a prevalência de edentulismo foi de 69,40\% nas mulheres e $30,60 \%$ entre os homens. Na população total a prevalência do edentulismo foi de $52 \%$, abaixo do valor encontrado por ROSA e col.(1989) em estudo realizado com uma amostra representativa dos idosos do Município de São Paulo que foi de $65 \%$ e acima do encontrado por COLUSSI e col. (2004), 48,40\%, em estudo realizado em Biguaçu, SC e por MESAS e col (2006) em estudo realizado em Londrina, Paraná que foi de 43,10\%.

A prevalência de edentulismo foi maior entre as mulheres que entre os homens, achados estes que concordam com outros estudos (SILVA e FERNANDES, 2001).

Não foram observados idosos com todos os dentes presentes. A porcentagem de idosos com mais de 20 dentes presentes foi de 11,8\%; com 10 até 19 dentes presentes de $14,8 \%$ e com 1 a 9 dentes presentes de 21,5\%; pessoas edêntulas perfizeram um total de 52,0\%.

Tal medida de mutilação dentária tem sido motivo de vários estudos, porém, devido às várias metodologias utilizadas, tornou-se difícil estabelecer comparações. 
MESAS e col.(2006) encontraram $71,9 \%$ de mulheres que usavam prótese total superior e 41,9 \% que usavam prótese total inferior. No presente estudo, $74,48 \%$ das mulheres usam prótese total superior e 45,51\% usam prótese total inferior. Na população masculina 53,43\% faziam uso de prótese total superior e 33,7\% faziam uso de prótese total inferior.

O inquérito de saúde bucal realizado pelo Ministério da Saúde em 2003 (MINISTÉRIO DA SAÚDE, 2004) encontrou na região Sudeste 64,3\% de idosos que faziam uso de prótese total superior e 39,26\% que faziam uso de prótese total inferior. Os valores são muito próximos, o que denota a medida da mutilação dentária do idoso brasileiro.

A frequiência do uso de prótese total superior e inferior em mulheres foi de $44,4 \%$ e nos homens de $32,9 \%$. Poder-se-ia sugerir que estes valores se relacionam com o fato das mulheres procurarem muito mais os serviços de saúde que os homens e terem sido submetidas a tratamentos mutiladores e iatrogênicos.

A porcentagem de pessoas que não usavam prótese foi de $38,0 \%$ entre as mulheres e de 62,0 entre os homens.

A freqüência do uso de prótese parcial removível foi maior no arco inferior em homens. O uso de prótese removível superior nos homens foi de 13,88\% e nas mulheres $8,80 \%$. No arco inferior os homens apresentaram frequiência de uso de $19,84 \%$ e as mulheres de $16,38 \%$.

Estas frequiências já eram esperadas devido os homens possuírem maior número de dentes presentes e por isso, fazerem maior uso de prótese dentária parcial removível que as mulheres onde a prevalência do edentulismo é maior exigindo uso de próteses dentárias totais.

O uso de próteses fixas e combinação de próteses (próteses fixas e removíveis) apresentaram freqüências muito baixas entre a população estudada, conseqüência da abordagem de atenção em saúde bucal dispensada ao idoso onde predominam ações mutiladoras em detrimento de ações conservadoras e preventivas, e do alto custo de tratamentos dentários mais elaborados. 
No que diz respeito à necessidade de prótese total, 4,65\% das mulheres e $14,78 \%$ dos homens as necessitavam, mas não as usavam. No total da população a porcentagem foi de 5,7\% o que sugere facilidade de acesso aos serviços odontológicos. Quanto aos homens, cuja necessidade é mais de duas vezes maior que a das mulheres, poder-se-ia sugerir que a necessidade sentida não é tão premente como nas mulheres ou que muitos homens desta faixa etária são trabalhadores que muito frequentemente tornam-se impossibilitados de freqüentar os serviços de saúde devido ao horário de trabalho, procurando-os somente quando são acometidos pela dor.

NARVAI e ANTUNES (2003) chamam a atenção para o fato dos estudos apresentarem elevadas porcentagens de uso de prótese e de extrações o que nos leva a concluir que a população de idosos possui um razoável grau de acesso aos serviços odontológicos básicos.

Esta situação sugere urgência na mudança do tipo de serviços oferecidos a esta parcela da população, tendo em vista que outras necessidades de tratamento foram observadas como restaurações, tratamento endodôntico e próteses fixas. Dentre as necessidades de tratamento encontradas nas mulheres $36 \%$ foram para tratamento conservador e entre os homens a porcentagem foi de $60 \%$. A necessidade de exodontia em mulheres foi de 37,2\% e os homens de 39,5\%. A necessidade de exodontia foi menor do que a necessidade por outros tipo de tratamento indicando a necessidade de adoção de medidas para que as pessoas idosas possam conservar seus dentes até o final da vida.

Dentre as pessoas que usam outros tipos de prótese que não as próteses totais, a média de dentes presentes foi de 11,62 em mulheres e 13,84 nos homens.

ROSA e col. (1989) encontraram 65\% de edêntulos na população. O valor encontrado por este estudo foi de $52 \%$ de pessoas edêntulas.

Tomando-se por base estes dois estudos verificamos que o edentulismo teve uma redução de $13 \%$ na população idosa paulistana. Ainda não se atingiu a meta da OMS-FDI para o ano de 2000 de redução de $25 \%$ do edentulismo em pessoas idosas.

Há na cidade de São Paulo um grande número de idosos que demandam outros tipos de prótese dentárias que não as próteses totais. O principal desafio, quanto à saúde bucal, colocado aos profissionais de saúde que trabalham com a atenção à saúde 
do idoso é impedir a perda dos dentes e, em sua ocorrência, assegurar a pronta reabilitação protética. Ações de educação em saúde, tratamento periodontal, prótese parciais removíveis são demandas desta faixa etária da população bem como a ampliação do acesso por idosos que trabalham e não possuem disponibilidade de tempo no horário de funcionamento dos serviços.

Existem muitos mitos em se tratando de saúde bucal e envelhecimento tais como: edentulismo é conseqüência do envelhecimento; quem usa prótese total não necessita visitar o dentista com regularidade e ainda, prevenção em saúde bucal não se aplica aos idosos.

Observa-se que, quanto aos idosos paulistano, os problemas de saúde bucal têm sido relegados ao descaso, transformando-se em fator de aceleração dos problemas naturais da velhice, tornando-a ainda mais incômoda do que deveria ser. 


\section{REFERÊNCIAS}

Brasil. Ministério da Saúde. Secretaria de Atenção à Saúde. Departamento de Atenção Básica. Envelhecimento e saúde da pessoa idosa / Ministério da Saúde, Secretaria de Atenção à Saúde. Departamento de Atenção Básica - Brasília: Ministério da Saúde, 2006. - Série A. Normas e Manuais Técnicos - Cadernos de Atenção Básica n. 19.

Colussi CF, Freitas SFT. Perfil epidemiológico da cárie e do uso e necessidade de prótese na população idosa de Biguaçu, Santa Catarina. Rev Bras Epidemiol 2004; 7(1): $88-97$

DeStefano F, Anda RF, Kahn HS, Williamson DF, Russell CM. Dental disease and risk of coronary heart disease and mortality. BMJ 1993; 306:688-691.

Elias AC, Sheiham A. The relationship between satisfaction with mouth and number and position of teeth. Journal of Oral Rehabilitation 1998; 25; 649-61.

FDI - Fédèration Dentaire Internationale. Global goals for oral health in the year 2000. Int Dent J 1982; 32(1):74-7.

Fure S, Zickert I. Incidence of tooth loss and dental caries in 60, 70 and 80-year-old Swedshi individuals. Community Dent Oral Epidemiol 1997; 25:137-142.

Kalsbeek H, Truin GJ, Van Rossum GM, Van Rukom HM, Poorterman JH, Verrips GH. Trends in caries prevalence in Dutch adults between 1983 and 1995. Caries Res 1998; 32(3):160-165.

Lebrão, ML Laurenti, R. - Saúde, Bem-estar e Envelhecimento: O estudo Sabe no município de São Paulo. Rev Bras Epidemiol 2005;8(2):127-41.

Mesas AE, Andrade SM, Cabrera MAS. Oral health status of community-dwelling elderly in Londrina, Paraná, Brazil. Rev Bras Epidemiol 2006; 9(4):471-480. 
Ministério da Saúde, Secretaria de Atenção à Saúde, Departamento de Atenção Básica. Projeto SB Brasil 2003 - condições de saúde bucal da população brasileira 2002-2003: resultados principais. Brasília: 2004.

Narvai PC, Antunes JLF. Saúde bucal: a autopercepção da mutilação e das incapacidades. In: Lebrão ML, Oliveira YA (org). SABE - Saúde, Bem-estar e Envelhecimento - O Projeto Sabe no município de São Paulo: uma abordagem inicial. Brasília: OPAS; 2003.119-40.

O’Mullane DM, Whelton H. Caries prevalence in the Republic of Ireland. Int Dent J 1994; 44(4- Supl. 1):387-391.

Paschoal SMP. Qualidade de vida do idoso: construção de um instrumento de avaliação através do método do impacto clínico. São Paulo; 2004. [Tese - Faculdade de Medicina - Universidade de São Paulo].

Petersen PE, Yamamoto T. Improving the oral health of older people: the approach of the WHO Global Oral Health Programme. Community Dent Oral Epidemiol 2005; 33: 81-92.

Pucca Jr GA. Perfil do edentulismo e do uso de prótese dentária em idosos residentes no município de São Paulo. São Paulo; 1998. [Dissertação - Escola Paulista de Medicina Universidade Federal de São Paulo].

Rosa AGF, Castellanos Fernandez RA, Pinto VG . Condições de saúde bucal em pessoas de 60 anos ou mais no Município de São Paulo (Brasil). Rev Saúde Pública 1992; 26(3).

SES-FSP - Secretaria de Estado da Saúde de São Paulo. Faculdade de Saúde Pública da Universidade de São Paulo. Levantamento Epidemiológico em Saúde Bucal - Estado de São Paulo, 1988. São Paulo, 1999. 
Sheiham A, Watt RG. The Common Risk Factor Approach: a rational basis for promoting oral health. Community Dentistry and Oral Epidemiology 2000; 28(6): 399_ 406.

Silva SRC, Fernandes RAC. Autopercepção das condições de saúde bucal por idosos. Rev Saúde Pública 2001; 35(4):349-55.

World Health Organization. Oral health surveys: basic methods. $4^{\text {th }}$. ed. Geneva: WHO; 1997. 
PARTE III

REFERÊNCIAS E ANEXOS 


\section{5 - REFERÊNCIAS}

Albala C, Lebrão ML, Díaz EML, Ham-Chande R, Hennis AJ, Palloni A, Pratts O. Encuesta Salud, Bienestar y Envejecimiento (SABE): metodología de la encuesta y perfil de la población estudiada. Rev Panam Salud Publica 2005;17(5/6):307-22.

Bercht SMB. O preventivismo e o câncer de boca: o imobilismo que mata. Saúde em Debate 1992;37:48-50.

Biazevic MGH. Tendências e diferenciais socioeconômicos da mortalidade por câncer bucal e de glândulas salivares no município de São Paulo, de 1980 a 2000. São Paulo, 2003. [Tese - Faculdade de Saúde Pública da USP].

Brasil. Lei $\mathrm{n}^{\circ} 10.741$, de $1^{\circ}$ de outubro de 2003. Dispões sobre o estatuto do idoso e dá outras providências. Brasília: Ministério da Saúde; 2003.

Brasil. Ministério da Saúde. Secretaria de Atenção à Saúde. Departamento de Atenção Básica. Envelhecimento e saúde da pessoa idosa / Ministério da Saúde, Secretaria de Atenção à Saúde, Departamento de Atenção Básica - Brasília: Ministério da Saúde, 2006. - (Série A. Normas e Manuais Técnicos) (Cadernos de Atenção Básica, n. 19).

Camarano AA. Texto para discussão ${ }^{\circ} 1179$ - Mecanismos de proteção social para a população idosa brasileira. Rio de Janeiro: IPEA;2006.

Carneiro, RMV. Saúde bucal em idosos institucionalizados na Cidade de São Paulo: Estudo epidemiológico e de auto-percepção. São Paulo, 2001. [Dissertação de Mestrado em Saúde Pública - Faculdade de saúde Pública da Universidade de São Paulo].

Carvalho RL, Wong, L. Algumas evidências sobre a evolução da saúde em diversas coortes de idosos (1998-2003). Trabalho submetido ao XV Encontro Nacional de Estudos Populacionais, ABEP; 18 a 22 de setembro. Caxambu, BR. Minas Gerais; 2006 
[acesso em 06/05/2007]. Disponível em: http://abep.nepo.unicamp.br/encontro2006/docspdf/ABEP2006_606.pdf.

Chaimowicz F. A saúde dos idosos brasileiros. Rev Saúde Pública 1997;1(2): 184-200.

Colussi CF, Freitas SFT. Perfil epidemiológico da cárie e do uso e necessidade de prótese na população idosa de Biguaçu, Santa Catarina. Rev Bras Epidemiol 2004;7(1): $88-97$.

FDI -Fédération Dentaire Internationale. Global goals for oral health in the year 2000. Int Dent J 1982;32 (1): 74-77.

IBGE - Instituto Brasileiro de Geografia e Estatística [homepage na internet]. Censo Demográfico 2000. [acesso em 27/07/2007]. Disponível em: http://ibge.gov.br/ home/estatística/população/censo2000/defaulttab_brasil.shtm.

IBGE - Instituto Brasileiro de Geografia e Estatística [homepage na internet]. Pesquisa Nacional por Amostra de Domicílios - 2004. Rio de Janeiro; 2005 [acesso em 05/12/2006]. Disponível em: http://www.ibge.gov.br/home/estatistica/populacao/trabalhoerendimento/pnad2004/.

IBGE - Instituto Brasileiro de Geografia e Estatística [homepage na internet]. Censo Demográfico 2000. [acesso em 27/07/2007]. Disponível em: http://ibge.gov.br/home/

INCA - Instituto Nacional de Câncer. Coordenação de Prevenção e Vigilância. Estimativa 2006: Incidência de câncer no Brasil. Rio de Janeiro: INCA, 2005.[acesso em 22/07/2007].Disponível em http://www.inca.go.br/estimativa/2006/.

Kalache A, Veras RP, Ramos LR. O Envelhecimento da população mundial. Um desafio novo. Rev Saúde Publ 1987;21(3) 200-10.

Lebrão, ML Laurenti, R. - Saúde, Bem-estar e Envelhecimento: O estudo Sabe no município de São Paulo. Rev Bras Epidemiol 2005;8(2):127-41. 
Lima-Costa MF, Barreto SM, Giatti L. Condições de saúde, capacidade funcional, uso de serviços de saúde e gastos com medicamentos da população idosa brasileira: um estudo descritivo baseado na Pesquisa Nacional por Amostra de Domicílios. Cad Saúde Pública. 2003;19(3): 735-743.

Marchioni DML. Fatores Dietéticos e câncer oral: um estudo caso-controle na região metropolitana de São Paulo. São Paulo, 2003. [Tese - Faculdade de Saúde Pública da USP].

Meneghim MC, Pereira AC, Silva FRB. Prevalência de cárie radicular e condição periodontal em uma população idosa institucionalizada de Piracicaba - SP. Pesqui Odontol Bras 2002;(16): 50-6.

Mesas AE, Andrade SM, Cabrera MAS. Oral health status of community-dwelling elderly in Londrina, Paraná, Brazil. Rev Bras Epidemiol 2006;9(4):471-480.

Ministério da Saúde - Indicadores e dados Básicos - Brasil 2005 [homepage na internet]. Brasília: Rede Interagencial de Informações para a Saúde; [acesso em 05/05/2007].

Disponível em: http://tabnet.datasus.gov.br/idb/

Brasil - Ministério da Saúde. Secretaria de Atenção à Saúde, Departamento de Atenção Básica. Projeto SB Brasil 2003 - condições de saúde bucal da população brasileira 2002-2003: resultados principais. Brasília:2004.

Narvai PC, Antunes JLF. Saúde bucal: a autopercepção da mutilação e das incapacidades. In: Lebrão ML, Oliveira YA (org). SABE - Saúde, Bem-estar e Envelhecimento - O Projeto Sabe no município de São Paulo: uma abordagem inicial. Brasília: OPAS; 2003.119-40.

Netto, MP. Gerontologia. São Paulo: Ateneu; 1997.

OPAS - Organização Pan-Americana de Saúde. Saúde dos Idosos. In: 25ª Conferência Sanitária Pan-Americana; 1988; Washington (DC). 
PAHO - Pan American Health Organization - Research in Public Health - Technical Papers - SABE Project: Protocol of the Multicenter study: Health, Well-Being and Aging in Latin America and the Caribbean. Washington, DC; April 1999.

Palloni A, Peláez M., Histórico e natureza do estudo. In: Lebrão ML, Oliveira YA (org.). SABE - Saúde, Bem-estar e Envelhevimento - O projeto Sabe no município de São Paulo: uma abordagem inicial. Brasília: OPAS; 2003.

Petersen PE. The World Health Oral Helath Report 2003: continuous improvement of oral health in the $21^{\text {st }}$ century - the approach of the WHO Oral Health Programme. Community Dentistry and Oral Epidemiology. 2003;31(1): 3-24.

Ramos LR, Rosa TEC, Oliveira ZM, Medina MCG, Santos FRG. Perfil do idoso na área metropolitana na região sudeste do Brasil: resultados de inquérito domiciliar. Rev Saúde Públ 1993;27(2): 87-94.

Rosa AGF, Castellanos FRA, Pinto VG, Ramos LR. Condições de saúde bucal em pessoas de 60 anos ou mais no Município de São Paulo (Brasil). Rev Saúde Pública [periódico na Internet]. 1992 Jun [citado 2007 Jul 29]; 26(3): 155-160. Disponível em: http://www.scielo.br/scielo.php?script=sci_arttext\&pid=S0034-89101992000300005\&

SES-FSP - Secretaria de Estado da Saúde de São Paulo. Faculdade de Saúde Pública da Universidade de São Paulo. Levantamento Epidemiológico em Saúde Bucal - Estado de São Paulo, 1988. São Paulo, 1999.

Silva NN. Aspectos metodológicos: processo de amostragem. In: Lebrão ML, Duarte YAO. SABE - Saúde Bem Estar e Evelhecimento. O Projeto SABE no município de São Paulo: uma aborgadem inicial. Brasília: OPAS; 2003. p 47-57.

Silva SRC, Fernandes RAC. Autopercepção das condições de saúde bucal por idosos. Rev. Saúde Pública. 2001;35(4): 349-55. 
Silva, SRC. Autopercepção das condições bucais em pessoas com 60 anos e mais de idade. São Paulo, 1999. [Tese de Doutorado - Faculdade de Saúde Pública da USP].

Universidade de Michigan. The Health and Retirement Study - AHEAD - Asset and health dynamics amonh the oldest old [homepage na internet]. Michigan; 1993 [acesso em 13/12/2206]. Disponível em http://hrsonline.isr.umich.edu/meta/sho_meta.php?hfyle=qnaires.

Veras, R.P. País jovem com cabelos brancos: a saúde doidoso no Brasil. $2^{\mathrm{a}}$ ed. Rio de Janeiro, Relume Dumará, 1994.

WHO - World Health Organization - The World Oral Health Report 2003: Continuous improvement of oral health in the 21st century - the approach of the WHO Global Oral Health Programme. Geneva; 2003.

WHO - World Health Organization. Oral health surveys: basic methods. $4^{\text {th }}$. ed. Geneva: WHO; 1997. 
ANEXO A 
ANEXO B 


\section{ANEXO C}




\section{CADERNO DE INSTRUÇÕES}




\section{São Paulo}

2006

\subsection{INFORMAÇÕES GERAIS}

\section{NOME}

Nome completo do indivíduo.

IDADE EM ANOS

Deve ser preenchida com os anos completos do indivíduo, na ocasião do exame. Preencher sempre as duas caselas

\section{SEXo}

Serão utilizados os códigos 1, para o sexo feminino e 2, para o sexo masculino.

\subsection{Prótese Dentária}

A situação quanto às próteses dentárias será avaliada a partir de informações sobre seu uso e necessidade, os quais têm como base a presença de espaços protéticos. Um mesmo indivíduo pode estar usando e, ao mesmo tempo, necessitar prótese(s). Deve ser assinalado o uso e a necessidade para os arcos superior e inferior.

As observações ao exame levarão em conta os códigos e critérios ilustrados nos quadros a seguir. Vale lembrar que os exemplos citados são apenas os mais comuns. É importante que, durante o treinamento, a equipe considere outras ocorrências e crie um mesmo padrão de análise. 
Códigos, critérios e exemplos de uso de prótese

\section{Uso de Prótese}

\begin{tabular}{cl}
\hline Código & Critério \\
\hline $\mathbf{0}$ & $\begin{array}{l}\text { Não usa prótese } \\
\text { dentária }\end{array}$
\end{tabular}

1 Usa uma ponte fixa

Uma ponte fixa posterior

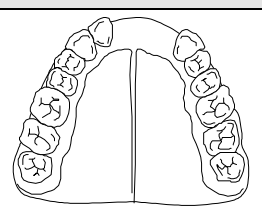

Desdentado parcial, mas sem prótese presente

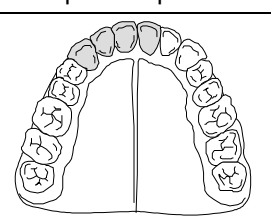

Uma ponte fixa anterior

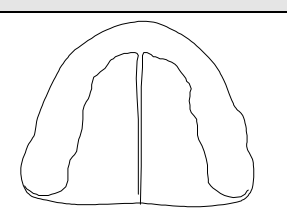

Desdentado total e sem prótese presente

2 Usa mais do que uma ponte fixa

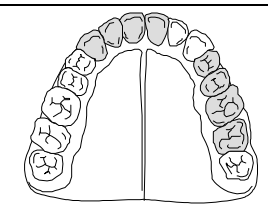

Duas pontes fixas em pontos diferentes (anterior e posterior)

3 Usa prótese parcial removível

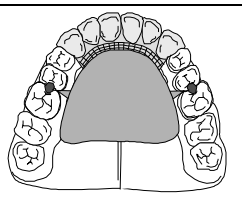

Prótese Parcial

Removível anterior

\section{Código Critério}

Usa uma ou mais

4 pontes fixas e uma ou mais próteses parciais removiveis

\section{Exemplos}

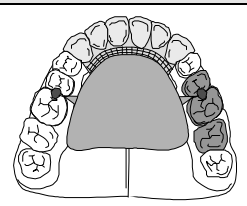

Prótese removível anterior e ponte fixa posterior

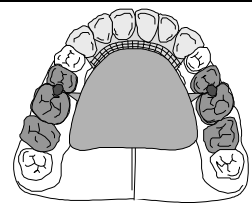

Prótese removível anterior e duas pontes fixas posteriores

5

Usa prótese dentária

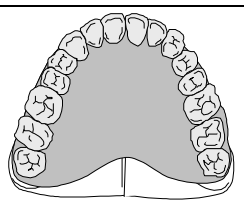

Prótese total

9 Sem informação 
Códigos, critérios e exemplos de necessidade de prótese.

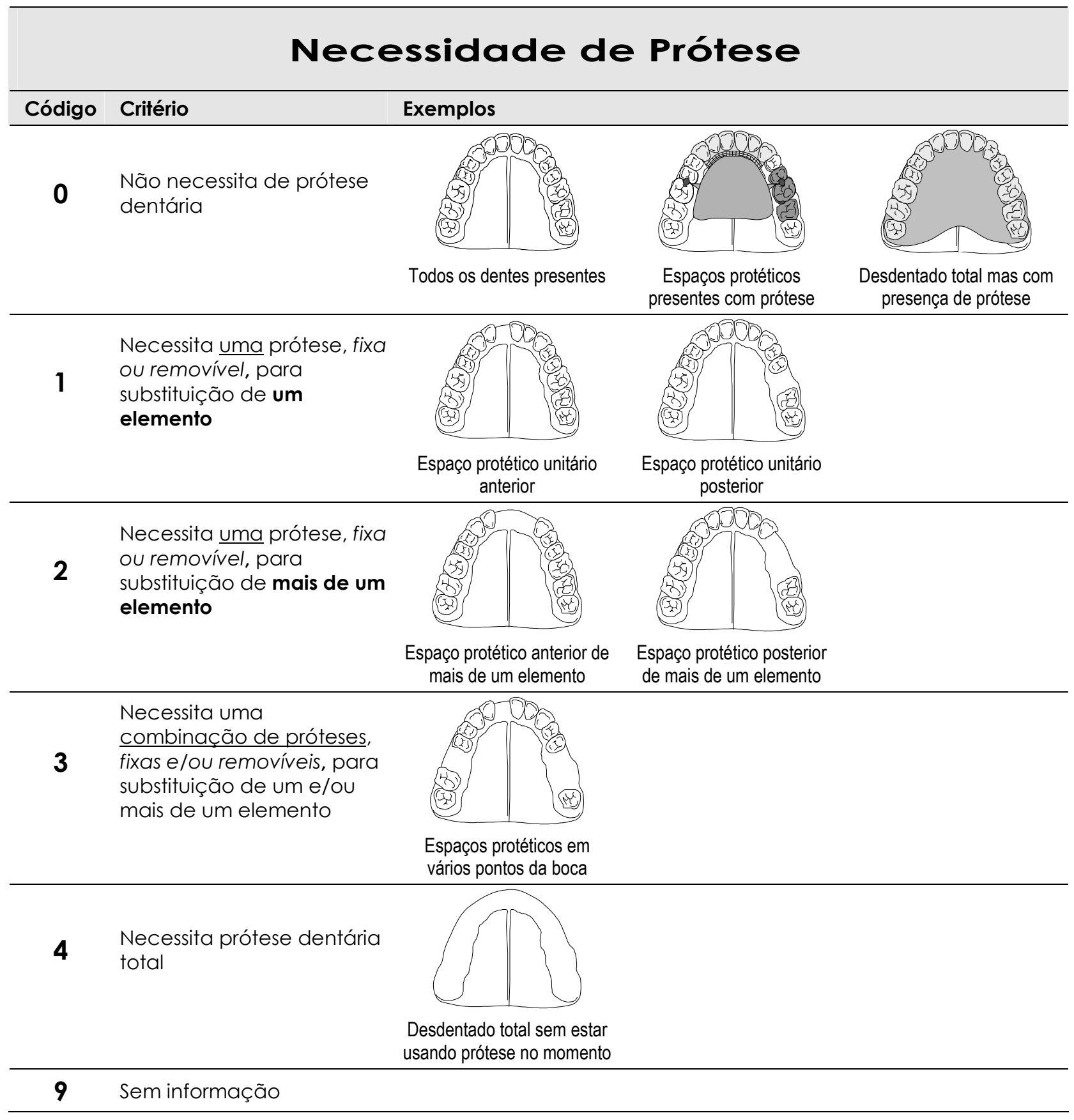




\subsection{Cárie Dentária e Necessidade de Tratamento}

Serão avaliados três aspectos em cada espaço dentário: as condições da coroa e da raiz e a necessidade de tratamento. Após o exame de cada espaço, o examinador dirá os três respectivos códigos para serem anotados e passará ao espaço dentário seguinte.

\section{Cárie Dentária}

Os códigos e critérios são os seguintes (para decíduos entre parênteses):

\section{0 - Coroa Hígida.}

Não há evidência de cárie. Estágios iniciais da doença não são levados em consideração. Os seguintes sinais devem ser codificados como hígidos:

- manchas esbranquiçadas;

- descolorações ou manchas rugosas resistentes à pressão da sonda CPI;

- sulcos e fissuras do esmalte manchados, mas que não apresentam sinais visuais de base amolecida, esmalte socavado, ou amolecimento das paredes, detectáveis com a sonda CPI;

- áreas escuras, brilhantes, duras e fissuradas do esmalte de um dente com fluorose moderada ou severa;

- lesões que, com base na sua distribuição ou história, ou exame táctil/visual, resultem de abrasão.

Raiz Hígida. A raiz está exposta e não há evidência de cárie ou de restauração (raízes não expostas são codificadas como "8").

Nota: Todas as lesões questionáveis devem ser codificadas como dente hígido.

\section{1 - Coroa Cariada.}

Sulco, fissura ou superfície lisa apresenta cavidade evidente, ou tecido amolecido na base ou descoloração do esmalte ou de parede ou há uma restauração temporária (exceto ionômero de vidro). A sonda CPI deve ser empregada para confirmar evidências visuais de cárie nas superfícies oclusal, vestibular e lingual. Na dúvida, considerar o dente hígido.

Nota: Na presença de cavidade originada por cárie, mesmo sem doença no momento do exame, a FSP-USP adota como regra de decisão considerar o dente atacado por cárie, registrando-se cariado. Entretanto, este enfoque epidemiológico não implica admitir que há necessidade de uma restauração.

\section{Raiz Cariada.}

A lesão pode ser detectada com a sonda CPI. Se há comprometimento radicular discreto, produzido por lesão proveniente da coroa, a raiz só é considerada cariada se há necessidade de tratamento radicular em separado.

Nota: Quando a coroa está completamente destruída pela cárie, restando apenas a raiz, a OMS recomenda que o código "1" seja registrado apenas na casela correspondente à coroa. A FSP-USP indica registrar o código "9"na casela da raiz.

\section{2 - Coroa Restaurada mas Cariada.}


Há uma ou mais restaurações e ao mesmo tempo uma ou mais áreas estão cariadas. Não há distinção entre cáries primárias e secundárias, ou seja, se as lesões estão ou não em associação física com a(s) restauração(ões).

Raiz Restaurada, mas Cariada.

Idem coroa restaurada mas cariada. Em situações nas quais coroa e raiz estão envolvidas, a localização mais provável da lesão primária é registrada como restaurada mas cariada. Quando não é possível avaliar essa probabilidade, tanto a coroa quanto a raiz são registradas como restauradas mas com cárie. 3 - Coroa Restaurada e Sem Cárie.

Há uma ou mais restaurações definitivas e inexiste cárie primária ou recorrente. Um dente com coroa colocada devido à cárie inclui-se nesta categoria. Se a coroa resulta de outras causas, como suporte de prótese, é codificada como 7 .

Raiz Restaurada e Sem Cárie.

Idem coroa restaurada e sem cárie. Em situações onde coroa e raiz estão envolvidas, a localização mais provável da lesão primária é registrada como restaurada. Quando não é possível avaliar essa probabilidade, tanto a coroa quanto a raiz são registradas como restauradas.

4 - Dente Perdido Devido à Cárie.

Um dente permanente foi extraído por causa de cárie e não por outras razões. Essa condição é registrada na casela correspondente à coroa. Nota: Nesses casos o código registrado na casela correspondente à raiz é 9 ou 7 (quando tiver um implante no lugar).

5 - Dente Perdido por Outra Razão.

Ausência se deve a razões ortodônticas, periodontais, traumáticas ou congênitas.

Nota: Nesses casos o código registrado na casela correspondente à raiz é "7" ou "9".

\section{7 - Apoio de Ponte ou Coroa.}

Indica um dente que é parte de uma prótese fixa. Este código é também utilizado para coroas instaladas por outras razões que não a cárie ou para dentes com facetas estéticas. Dentes extraídos e substituídos por um elemento de ponte fixa são codificados, na casela da condição da coroa, como $\mathbf{4}$ ou $\mathbf{5}$, enquanto o código 9 deve ser lançado na casela da raiz.

Implante: Registrar este código (7) na casela da raiz.

\section{8 - Coroa Não Erupcionada.}

Quando o dente permanente ou decíduo ainda não foi erupcionado, atendendo à cronologia da erupção. Não inclui dentes perdidos por problemas congênitos, trauma etc.

\section{Raiz Não Exposta}

Não há exposição da superfície radicular, isto é, não há retração gengival para além da junção cemento-esmalte.

\section{T - Trauma (Fratura).}


Parte da superfície coronária foi perdida em conseqüência de trauma e não há evidência de cárie.

9 - Dente Excluído.

Aplicado a qualquer dente permanente que não possa ser examinado (bandas ortodônticas, hipoplasias severas etc.).

\section{Necessidade de Tratamento}

Imediatamente após registrar as condições da coroa e da raiz, e antes de passar ao espaço dentário seguinte, deve-se registrar o tratamento indicado. Quando não houver necessidade de tratamento, um "0" deve ser registrado no espaço correspondente. Isso precisa ser feito sempre, para evitar dificuldades no posterior processamento dos dados, uma vez que, não havendo registro, não será possível ao digitador saber o que aconteceu (se não há necessidade ou se o anotador esqueceu-se de preencher a casela).

Os códigos e critérios para as necessidades de tratamento são:

0 - Nenhum Tratamento.

A coroa e a raiz estão hígidas, ou o dente não pode ou não deve ser extraído ou receber qualquer outro tratamento.

1 - Restauração de uma superfície dentária

2 - Restauração de duas ou mais superfícies dentárias

3 - Coroa por qualquer razão

4 - Faceta Estética

5 - Tratamento Pulpar e Restauração.

O dente necessita tratamento endodôntico previamente à colocação da restauração ou coroa, devido à cárie profunda e extensa, ou mutilação ou trauma.

Nota: Nunca se deve inserir a sonda no fundo de uma cavidade para confirmar a presença de uma provável exposição pulpar.

6 - Extração

Um dente é registrado como indicado para extração, dependendo das possibilidades de tratamento disponíveis, quando:

- a cárie destruiu o dente de tal modo que não é possível restaurá-lo;

- a doença periodontal progrediu tanto que o dente está com mobilidade, há dor ou o dente está sem função e, no julgamento clínico do examinador, não pode ser recuperado por tratamento periodontal;

- um dente precisa ser extraído para confecção de uma prótese; ou

- a extração é necessária por razões ortodônticas ou estéticas, ou devido à impactação.

Nota a respeito das necessidades de tratamento: 
Os códigos 1 (restauração de uma superfície), 2 (restauração de 2 ou mais superfícies), 7 (remineralização de mancha branca) ou 8 (selante) serão usados para indicar o tratamento necessário para:

- tratar as cáries iniciais, primárias ou secundárias;

- tratar a descoloração de um dente ou um defeito de desenvolvimento;

- reparar o dano causado por trauma, abrasão, erosão ou atrição; ou

- substituir restaurações insatisfatórias se existirem uma ou mais das seguintes condições:

- margem deficiente, permitindo ou em vias de permitir infiltração na dentina. A decisão deve ser tomada com base no senso clínico do examinador, após ter inserido a sonda CPI na margem entre a restauração e o tecido duro ou após observar uma significativa descoloração do esmalte adjacente;

- excesso marginal, causando irritação local do tecido gengival e não podendo ser removido por meio de um ajuste da restauração;

- fratura, que possa causar a perda da restauração ou infiltração marginal;

9 - Sem Informação

Quando, por alguma razão, não for possível definir a necessidade de tratamento do dente. Via de regra, quando a condição da coroa for 9 (dente excluído), assinala-se 9 também na necessidade de tratamento. Na condição em que a coroa foi considerada não-erupcionada (8) ou dente perdido (4 ou 5), também deve ser assinalado 9 na casela referente à necessidade de tratamento. 
Resumo dos códigos para cárie dentária e necessidade de tratamento.

\begin{tabular}{|c|c|c|}
\hline \multirow{2}{*}{\multicolumn{2}{|c|}{$\begin{array}{c}\text { CÓDIGO } \\
\text { DENTES } \\
\text { PERMANENTES }\end{array}$}} & \multirow{3}{*}{ CONDIÇÃO/ESTADO } \\
\hline & & \\
\hline Coroa & Raiz & \\
\hline 0 & 0 & HÍGIDO \\
\hline 1 & 1 & CARIADO \\
\hline 2 & 2 & RESTAURADO MAS COM CÁRIE \\
\hline 3 & 3 & RESTAURADO E SEM CÁRIE \\
\hline 4 & $\begin{array}{l}\text { Não se } \\
\text { aplica }\end{array}$ & PERDIDO DEVIDO À CÁRIE \\
\hline 5 & $\begin{array}{l}\text { Não se } \\
\text { aplica }\end{array}$ & PERDIDO POR OUTRAS RAZÕES \\
\hline 7 & 7 & APOIO DE PONTE OU COROA \\
\hline 8 & 8 & NÃO ERUPCIONADO - RAIZ NÃO EXPOSTA \\
\hline $\mathbf{T}$ & $\begin{array}{l}\text { Não se } \\
\text { aplica }\end{array}$ & TRAUMA (FRATURA) \\
\hline 9 & 9 & DENTE EXCLUÍDO \\
\hline
\end{tabular}

\begin{tabular}{||c|l||}
\hline CÓDIGO & \multicolumn{1}{|c||}{ TRATAMENTO } \\
\hline 0 & NENHUM \\
1 & RESTAURAÇÃO DE 1 SUPERFÍCIE \\
2 & RESTAURAÇÃO DE 2 OU MAIS SUPERFÍCIES \\
3 & COROA POR QUALQUER RAZÃO \\
4 & FACETA ESTÉTICA \\
5 & PULPAR + RESTAURAÇÃO \\
6 & EXTRAÇÃO \\
9 & SEM INFORMAÇÃO \\
\hline
\end{tabular}




\section{Doença Periodontal}

A condição periodontal será avaliada com a utilização de dois indicadores: os índices CPI e PIP.

\section{Índice Periodontal Comunitário - CPI}

O Índice Periodontal Comunitário (emprega-se a sigla CPI, das iniciais do índice em inglês, pela facilidade fonética e pela sonoridade próxima ao consagrado $\mathrm{CPO})$ permite avaliar a condição periodontal quanto à higidez, sangramento e presença de cálculo ou bolsa.

Sonda CPI - Para realizar o exame utiliza-se sonda específica, denominada sonda $\mathrm{CPI}$, com esfera de $0,5 \mathrm{~mm}$ na ponta e área anelada em preto situada entre $3,5 \mathrm{~mm}$ e $5,5 \mathrm{~mm}$ da ponta. Outras duas marcas na sonda permitem identificar distâncias de $8,5 \mathrm{~mm}$ e $11,5 \mathrm{~mm}$ da ponta do instrumento (Figura 6).

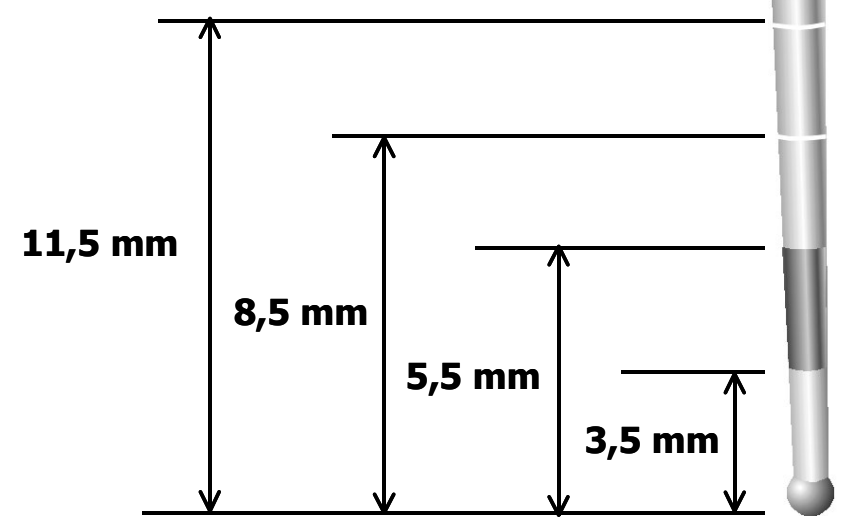

Figura 1. Sonda CPI, com as marcações das distâncias, em milímetros, da ponta da sonda.

Sextantes - A boca é dividida em sextantes definidos pelos dentes: 18-14, 1323, 24-28, 38-34, 33-43 e 44-48 (Figura 7). A presença de dois ou mais dentes sem indicação de exodontia (p. ex., comprometimento de furca, mobilidade etc.), é pré-requisito ao exame do sextante. Sem isso, o sextante é cancelado (quando há, p.ex., um único dente presente).

Dentes-Índices - São os seguintes os dentes-índices para cada sextante (se nenhum deles estiver presente, examinam-se todos os dentes remanescentes do sextante, não se levando em conta a superfície distal dos terceiros molares): - $17,16,11,26,27,37,36,31,46$ e 47. 


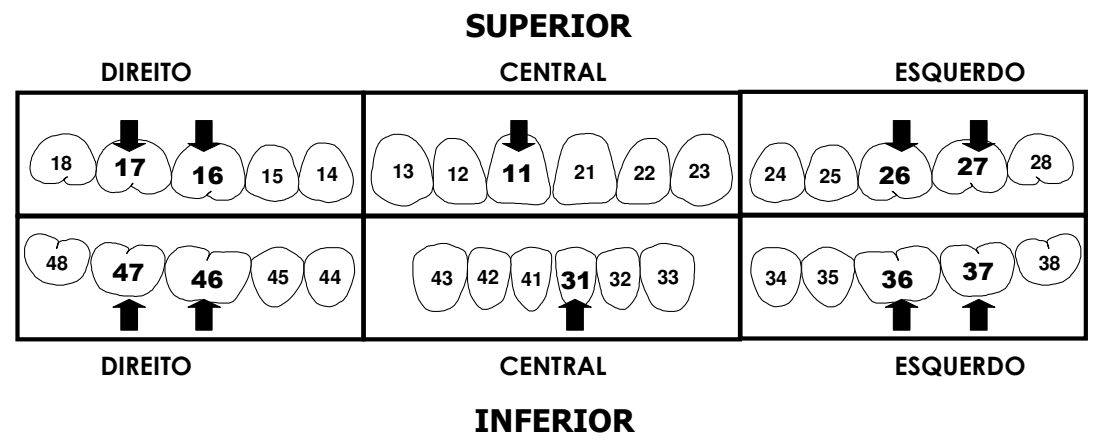

Figura 2. Divisão da arcada em sextantes e destaque dos dentes-índices para CPI e PIP.

Exame - Pelo menos 6 pontos são examinados em cada um dos 10 dentesíndices, nas superfícies vestibular e lingual, abrangendo as regiões mesial, média e distal. Os procedimentos de exame devem ser iniciados pela área disto-vestibular, passando-se para a área média e daí para a área mésiovestibular. Após, inspecionam-se as áreas linguais, indo de distal para mesial. A sonda deve ser introduzida levemente no sulco gengival ou na bolsa periodontal, ligeiramente inclinada em relação ao longo eixo do dente, seguindo a configuração anatômica da superfície radicular. Movimentos de vai-e-vem vertical, de pequena amplitude, devem ser realizados. A força na sondagem deve ser inferior a 20 gramas (recomenda-se o seguinte teste prático: colocar a ponta da sonda sob a unha do polegar e pressionar até obter ligeira isquemia).

Registros - Considerar que:

a) embora 10 dentes sejam examinados, apenas 6 anotações são feitas: uma por sextante, relativa à pior situação encontrada;

b) quando não há no sextante pelo menos dois dentes remanescentes e não indicados para extração, cancelar o sextante registrando um "X".

Códigos - São os seguintes os códigos utilizados no CPI (Figura 8):

\section{0 - sextante hígido;}

1 - sextante com sangramento (observado diretamente ou com espelho, após sondagem);

2 - cálculo (qualquer quantidade, mas com toda a área preta da sonda visível);

3 - bolsa de $4 \mathrm{~mm}$ a $5 \mathrm{~mm}$ (margem gengival na área preta da sonda);

4 - bolsa de $6 \mathrm{~mm}$ ou mais (área preta da sonda não está visível);

$\mathrm{X}$ - sextante excluído (menos de 2 dentes presentes);

9 - sextante não examinado.

Nota: Sabe-se que o tempo de resposta à sondagem da gengiva inflamada é variado. A OMS não define um período de tempo para a observação do sangramento à sondagem. A FSP-USP recomenda um tempo de observação após a sondagem de 10 a 30 segundos, critério utilizado na maioria dos índices com essa categoria de medida e recomendado também pelos pesquisadores que desenvolveram o CPI. 


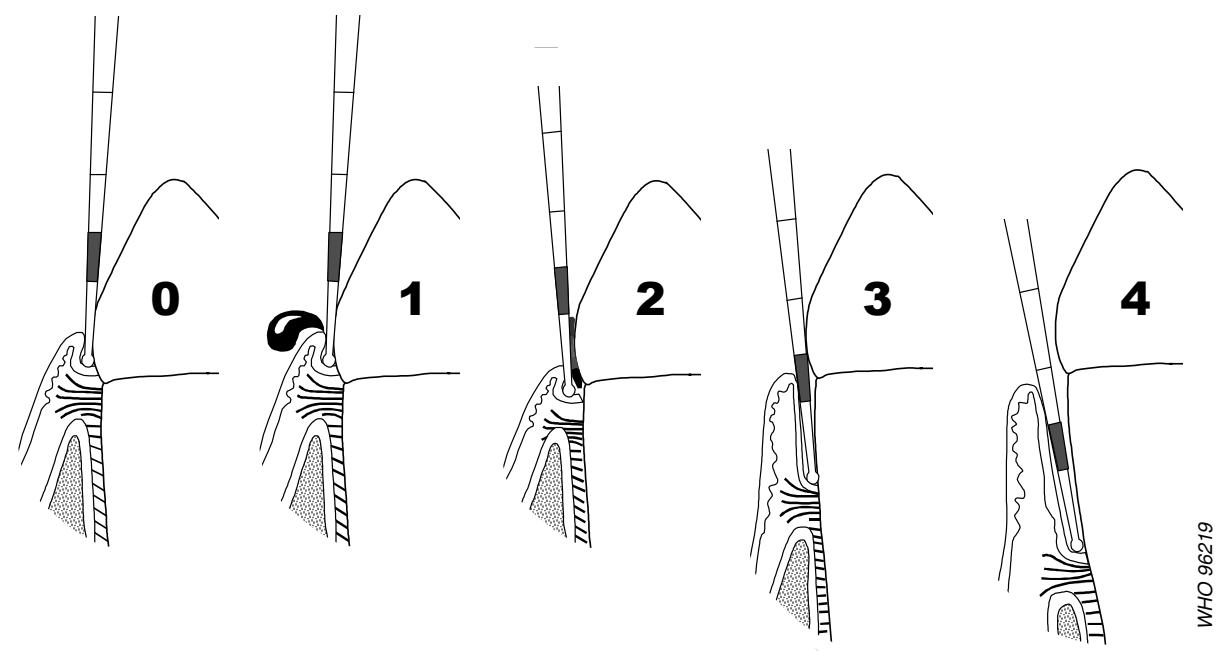

Figura 3. Posições da sonda ao exame e códigos do Índice Periodontal Comunitário (CPI).

\section{Índice de Perda de Inserção Periodontal - PIP}

O índice Perda de Inserção Periodontal (adotaremos a sigla "PIP", das iniciais em português) permite avaliar a condição da inserção periodontal, tomando como base a visibilidade da junção cemento-esmalte (JCE). Este índice permite comparações entre grupos populacionais e não há intenção de descrever a situação de indivíduos considerados isoladamente.

Relação com CPI - O PIP é basicamente um complemento do CPI. Os mesmos sextantes e dentes-índices são considerados, sob as mesmas condições. Entretanto, cabe alertar que o dente-índice onde foi encontrada a pior condição para o CPI pode não ser o mesmo com a pior situação para o PIP.

Exame - A visibilidade da JCE é a principal referência para o exame. Quando a JCE não está visível e a pior condição do CPI para o sextante é menor do que 4 (bolsa com menos de $6 \mathrm{~mm}$ ), qualquer perda de inserção para o sextante é estimada em menos de $4 \mathrm{~mm}(\mathrm{PIP}=0)$.

Códigos - São os seguintes os códigos utilizados no PIP (Figura 9):

0 - perda de inserção entre 0 e $\mathbf{3} \mathbf{~ m m}$ (JCE não visível e CPI entre 0 e 3).

Ou seja: se o CPI for igual a 4, não há possibilidade de o PIP ser 0 (zero).

Se a JCE não está visível e o CPI é 4, ou se a JCE está visível, então:

1 - perda de inserção entre $4 \mathrm{~mm}$ e $5 \mathrm{~mm}$ (JCE visível na área preta da sonda $\mathrm{CPI}$;

2 - perda de inserção entre $6 \mathbf{m m}$ e $8 \mathrm{~mm}$ (JCE visível entre limite superior da área preta da sonda CPI e a marca de $8,5 \mathrm{~mm}$ ); 
3 - perda de inserção entre $9 \mathbf{m m}$ e $11 \mathrm{~mm}$ (JCE visível entre as marcas de $8,5 \mathrm{~mm}$ e $11,5 \mathrm{~mm}$ );

4 - perda de inserção de 12 mm ou mais (JCE visível além da marca de 11,5 $\mathrm{mm}$ );

X - sextante excluído (menos de 2 dentes presentes);

9 - sem informação (JCE nem visível nem detectável). Utilizar este código também nas situações em que o exame não estiver indicado.
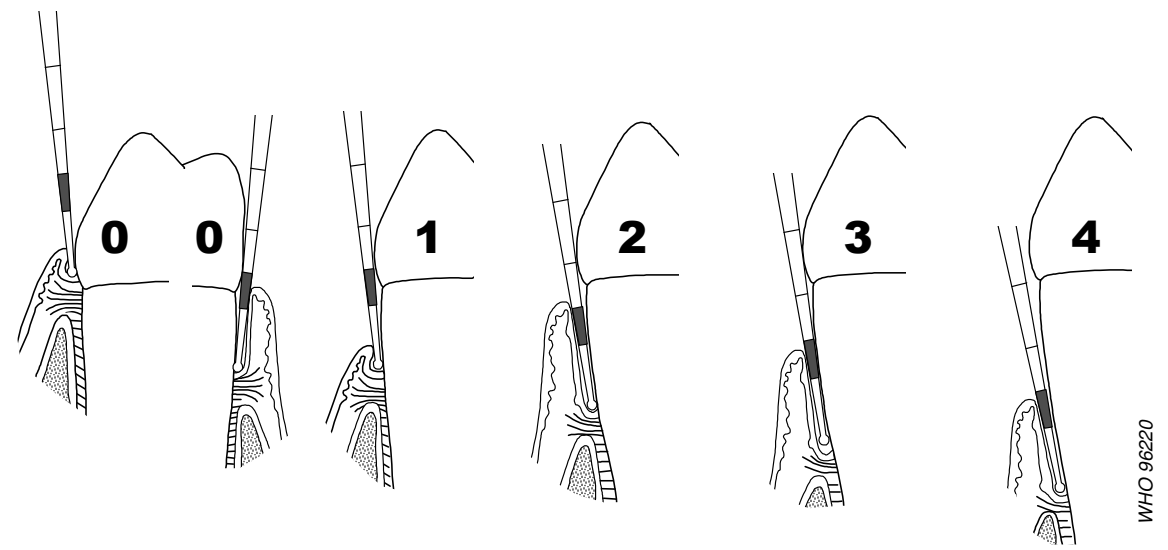

Figura 4. Posições da sonda ao exame e códigos do Índice de Perda de Inserção Periodontal (PIP).

\section{Alterações de tecido mole}

Assinala-se na casela a presença de qualquer alteração em tecido mole, a partir dos seguintes códigos:

0 - Ausência

1 - Presença

9 - Sem Informação 
ANEXO D 


\section{Estudo SABE - Saúde, bem estar e envelhecimento}

S A B E

\section{Exame bucal}

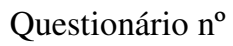
A06 Nome:

Idade em anos

(1) MULHER

(2) HOMEM
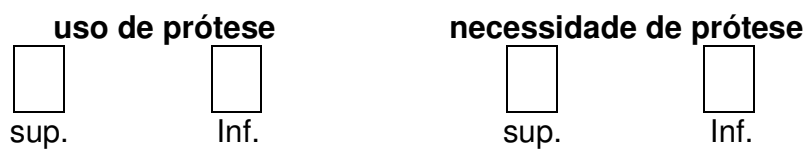

CÁRIE DENTÁRIA E NECESSIDADE DE TRATAMENTO
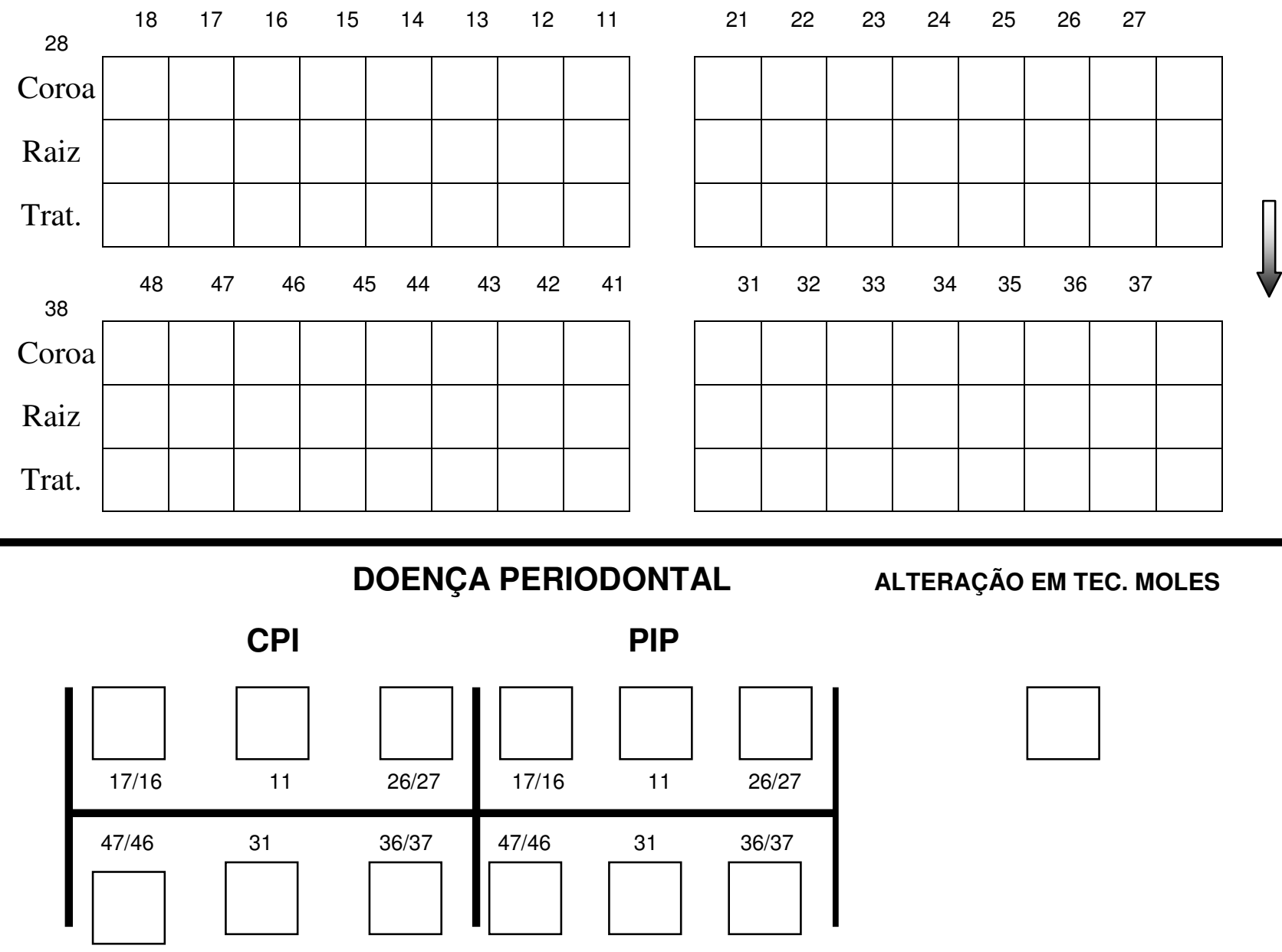

EXAMINADOR: 